\title{
ANÁLISE PARAMÉTRICA DA INFILTRAÇÃO E SUA INFLUÊNCIA NA ESTABILIDADE DE TALUDES EM SOLO NÃO SATURADO.
}

\section{CLÁUDIO RODRIGUES DOS SANTOS}

Engenheiro Civil

Orientador: Prof. Dr. ORENCIO MONJE VILAR

Dissertação apresentada à Escola De Engenharia de São Carlos, para obtenção do Título de Mestre em Geotecnia.

SÃO CARLOS

São Paulo - Brasil

Janeiro de 2004 
"Assim começou ele pela tentativa mais estranha, porque pode dar-se o caso de que, em semelhantes transes, as empresas mais extravagantes pareçam as mais realizáveis a semelhantes pessoas".

Fiodor M. Dostoiévski.

"Talvez tenham feito uma coisa errada, podemos admitir que cometeram um erro mas, seja como for, fizeram alguma coisa, realizaram algo, ousaram dar um salto e é preciso coragem para isso. Nós que fomos aplicados, pacientes e ajuizados, não fizemos nada, não demos salto nenhum".

Hermann Hesse. 


\section{AGRADECIMENTOS}

Ao Prof. Dr. Orencio Monje Vilar pela orientação e pelo apoio na realização deste trabalho.

À CAPES, agência financiadora pela concessão de bolsa de mestrado.

Ao Departamento de Geotecnia, pela oportunidade de realização do curso de mestrado.

Ao Eng $^{\circ}$ Herivelto Moreira pelo auxílio, atenção e presteza.

Ao Prof. Dr. Nelson Aoki por sua contribuição no desenvolvimento de meu senso crítico.

Aos meus colegas do Departamento de Geotecnia pelo convívio construtivo, em especial a Fernanda e Karla pela compreensão e companheirismo e a Kleber pela manutenção do ambiente "inquieto" e inspirador.

Aos meus pais, Élida e Ademir, pelo incentivo, apoio e carinho. Às minhas irmãs Roberta e Mônica pela paciência e por todas palavras acolhedoras.

Ao pessoal de "Entre Rios" pela força, em especial aos meus irmãos Glauco e Alan, por todas as questões pertinentes a esta empreita.

À Lia por todo o carinho, apoio, incentivo e pela presença imprescindível no decorrer deste trabalho, Obrigado.

A Deus por fazer com que todas estas graças operassem em minha vida. 


\section{RESUMO}

Apresenta-se um estudo paramétrico acerca da infiltração de água e sua repercussão no Fator de Segurança de talude em solos não saturados. Na análise adota-se um talude de referência com geometria fixada conforme a inclinação típica para taludes em areia argilo siltosa, característica do Centro-Oeste do estado de São Paulo. A análise paramétrica foi desenvolvida a partir de uma simulação de fluxo em regime transiente utilizando o programa SEEP/W, que utiliza o método de elementos finitos, e posteriormente uma análise de estabilidade do talude de referência utilizando o método de Bishop simplificado conforme apresentado no programa SLOPE/W. Foram analisados taludes homogêneos compostos por três diferentes tipos de solo, uma areia, um silte argiloso e uma areia argilo siltosa. Os parâmetros analisados compreendem a curva de retenção de água, a função condutividade hidráulica do solo e a intensidade de precipitação. Verificoutse que a função condutividade hidráulica e a pressão de entrada de ar são os principais determinantes do comportamento da infiltração e conseqüentemente da estabilidade do talude. As simulações de fluxo evidenciaram que os taludes em solos mais arenosos apresentam taxas de infiltração maiores que as apresentadas pelos taludes compostos por solos

siltosos. Consequentemente, os escorregamentos ocasionados pela perda da contribuição da sucção para a resistência ao cisalhamento ocorrem primeiramente nos taludes compostos por solos arenosos e posteriormente naqueles compostos por solos siltosos, fato este que pôde ser confirmado pelas análises de estabilidade do talude de referência.

PALAVRAS CHAVE: Solo não saturado, Estabilidade de Taludes, Análise Paramétrica, Infiltração, Sucção matricial. 


\section{ABSTRACT}

A parametric study is presented about water infiltration and its repercussion in the safety factor of unsaturated soil slopes. In the analysis it is adopted a reference slope with determined geometry according to the typical inclination for slopes in silty clayey sand, characteristic of the mid-western region of São Paulo State, in Brazil. The parametric analysis was developed from a flux simulation in transient regime using the SEEP/W software, which uses the finite elements method, and thereafter, a stability analysis of the reference slope using simplified Bishop method, as presented in the SLOPE/W software. Homogeneous slopes composed by three different types of soil (sand, clayey silt and silty clayey sand) were considered. The analyzed parameters include the water retention curve, the hydraulic conductivity function and the precipitation intensity. It was verified that the hydraulic conductivity function and the air entry value are the main determinants of the infiltration behavior and, subsequently, of the slope stability. The flux simulations have evidenced that coarser soils slopes show higher infiltration rates than the ones presented in finer soil slopes. Consequently, the slides caused by the loss of the suction's contribution to shear strength occur primarily in coarser soil slopes than in fine soil slopes, what could be verified in the stability analysis of the reference slope.

KEYWORDS: Unsaturated Soil, Slope Stability, Parametric Analysis, Infiltration, Matric Suction. 


\section{SUMÁRIO}

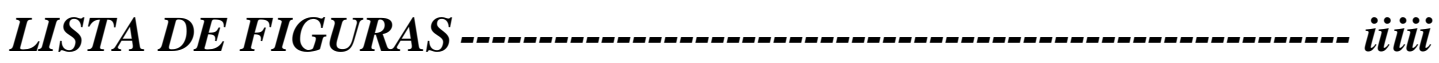

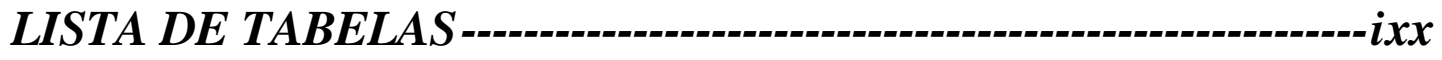

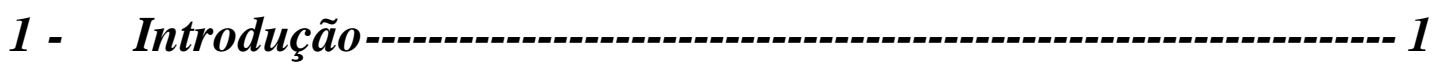

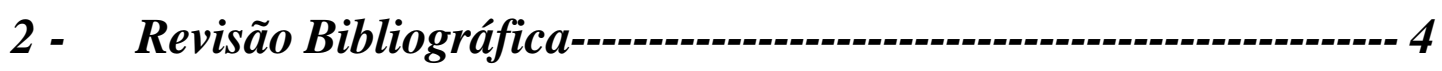

2.1 - Conceitos Gerais de Mecânica dos Solos Não saturados--------------------------4

2.2 - Curva de Retenção -

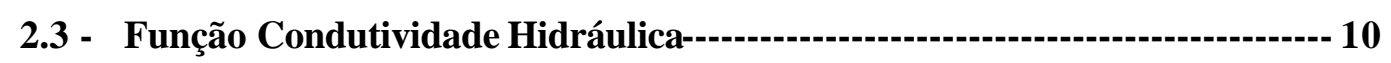

2.4 - Resistência ao cisalhamento de Solos não saturados ---a- 12

2.5 - Infiltração de água no solo --- 19

2.6 - Estabilidade de talude em solo não sat urado --- 25

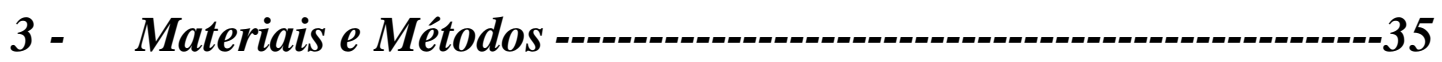

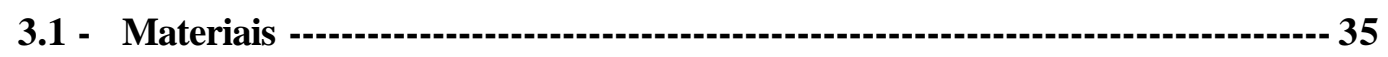

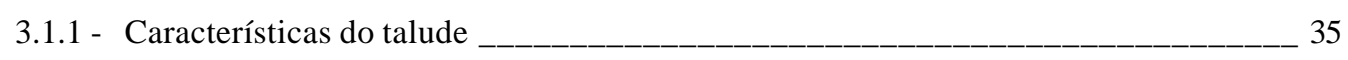

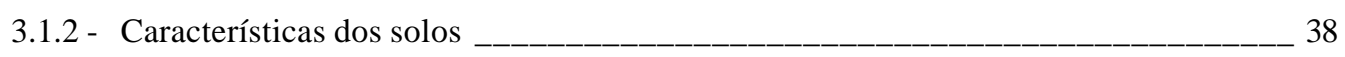

3.1.3 - Características da precipitação____-__-_-_ 40

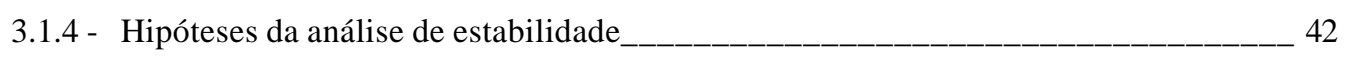

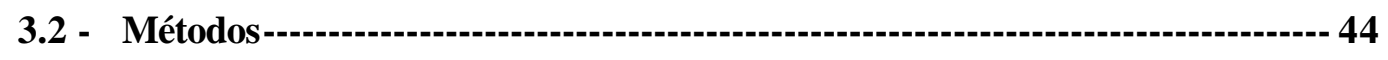

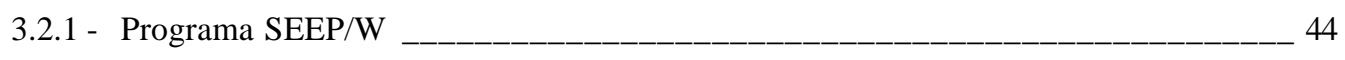

3.2.2 - Programa SLOPE/W _-_-_-_-_-_-_-_-_-_-_-_-_-_-_-_-_-_-_-_-_-_-_-_-_ 47

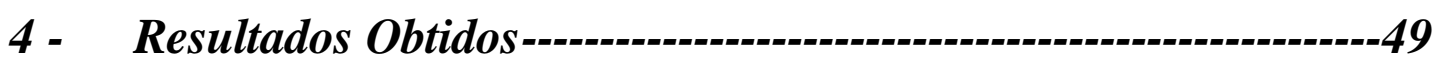

4.1 - Perfis de pressão de água durante a Infiltração --- 49

4.1.1 - Influência da Condutividade hidráulic a saturada __________________________________-_ 58

4.1.2 - Influência da Função condutividade hidráulica_________________________________ 59

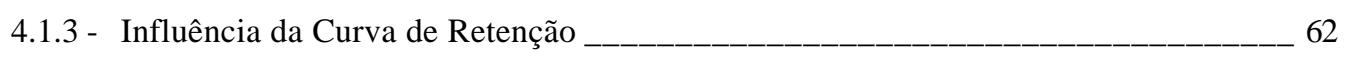

4.2 - Estabilidade do talude de referência - 71

4.2.1 - Fator de Segurança Inicial________________________________________________ 71

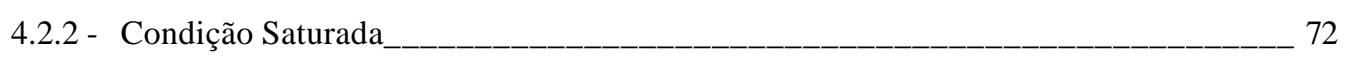


4.2.3 - Casos básicos (solos nas condições naturais) 73

4.2.4 - Influência da condutividade hidráulica saturada 77

4.2.5 - Influência da Função condutividade hidráulica 79

4.2.6 - Influência da Curva de Retenção (solos híbridos) 80

4.2.7 - Influência do parâmetro $\phi^{\mathrm{b}}$ da envoltória de Resistência ao Cisalhamento 84

4.3 - Evolução da superfície crítica 85

5 - Conclusões $-89$

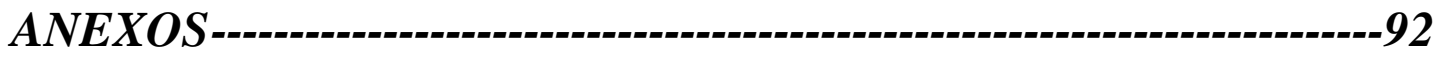

ANEXO A : ROTINA SIM PLIFICADA DE UTILIZAÇÃO DO PROGRAMA SEEP/W (DEFINE E SOLVE) 93

ANEXO B : PARÂMETROS DE CONVERGÊNCIA UTILIZADOS NO

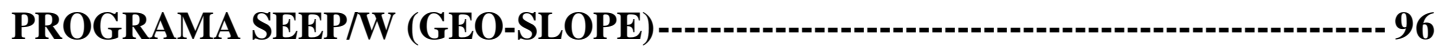

6 - Referências Bibliográficas ----------------------------------------98 


\section{LISTA DE FIGURAS}

Figura 1. Esquema ilustrativo da definição de sucção total: Corresponde a ua-uw de sorte a não haver fluxo através da membrana semi-permeável. (VILAR, 2001) 5

Figura 2. Elementos da Curva de Retenção 6

Figura 3. Curvas de retenção para diferentes tipos de solo (FREDLUND \& XING, 1994). 7

Figura 4. Representação gráfica da expressão de FREDLUND et al. (1978). 14

Figura 5. Variação da coesão e do ângulo de atrito para dois solos distintos (ESCARIO \& JUCÀ, 1989). 15

Figura 6. a) Resistência ao cisalhamento $x$ tensão normal para diferentes valores de sucção matricial b)Resistência ao cisalhamento x sucção para diferentes valores de tensão normal (ESCARIO \& SAEZ, 1986).

Figura 7. Variação da coesão e do ângulo de atrito interno em função da sucção matricial (DELAGE et al., 1987 apud RÖHM, 1997).

Figura 8. Representação esquemática da expressão de GREEN-AMPT (1906) 22

Figura 9. Representação gráfica do modelo de infiltração de LUMB (1975) 23

Figura 10. Evolução da frente de umedecimento. (a) Perfil de sucção inicial (b) Perfil após início da infiltração $\mathrm{t}=\mathrm{tb}(\mathrm{c})$ Perfil após início da infiltração $\mathrm{t}=\mathrm{tc}$, com tc>tb (d) Elevação do Nível freático devido ao armazenamento de água dentro do solo (SMITH, 2002). 24

Figura 11. a) Esquema da distribuição da sucção versus profundidade. b) Esquema de ajuste de perfil de sucção para Fator de Segurança igual a um (CAMPOS, 1985). 
Figura 12. a) Redução do fator de segurança de talude composto por solo arenoso sujeito a diferentes intensidades de precipitação. b) Redução do fator de segurança de talude composto por solos de diferente graduação (ALONSO et al., 1995). 27

Figura 13. Curva de Retenção e Função Condutividade Hidráulica dos Solos A (arenoso), B (siltoso) e C (fictício). (SHIMADA et al., 1995) 28

Figura 14. Influência da curva retenção e da função condutividade hidráulica na redução do fator de segurança de taludes devido à infiltração. (SHIMADA et al., 1995) 29

Figura 15. Resultados de Análise Transiente de Infiltração (GASMO et al., 2000).

Figura 16. a) Superfícies de Ruptura de Talude sujeito à infiltração, $k_{s}=5 E-5 m / s$, precipitação de $20 \mathrm{~mm} / \mathrm{h}$. b) Superfícies de Ruptura de Talude sujeito à infiltração , $\mathrm{k}_{\mathrm{s}}$ =5E-6m/s , precipitação de 20mm/h. (CHO \& LEE, 2001). 32

Figura 17. Influência da condutividade hidráulica saturada na redução do fator de segurança de taludes sujeitos a infiltração (CHO \& LEE, 2001). 33

Figura 18. Geometria do talude de referência, conforme inclinação típica para taludes em areia argilo siltosa característica do Centro-Oeste do estado de São Paulo.

Figura 19. Perfil de sucção inicial (antes da precipitação). 37

Figura 20. Precipitação diária e sucções de campo obtidas por CALLE (2000)._ 37

Figura 21. Curva de Retenção - Areia, silte e areia argilo siltosa. 39

Figura 22. Função condutividade hidráulica - Areia, silte e areia argilo siltosa. 39

Figura 23. a) Superfície de ruptura para o método das fatias b) Esforços em uma fatia. 
Figura 24. Malha de elementos finitos e sistema de coordenadas utilizado no programa SEEP/W 45

Figura 25. Pontos sem sentido físico em perfis de pressão de água durante a infiltração 47

Figura 26. Definição da malha de centros de rotação, raios e limites para busca da superfície crítica circular utilizada no programa SLOPE/W 48

Figura 27. Posição de estudo do perfil de pressão de água nas análises de infiltração

Figura 28. Condutividade hidráulica dos solos A, B e C, $\mathrm{k}_{\mathrm{s}}=1 \mathrm{E}-6 \mathrm{~m} / \mathrm{s}$ e precipitações aplicadas. 50

Figura 29. Perfil de pressão de água ao longo do tempo - Solos A e C (acima), e B (abaixo), $\mathrm{k}_{\mathrm{s}}=1 \mathrm{E}-6 \mathrm{~m} / \mathrm{s}$, precipitação $=1 \mathrm{~mm} / \mathrm{h}$. 51

Figura 30. Perfil de pressão de água ao longo do tempo - Solo A, $\mathrm{k}_{\mathrm{s}}=1 \mathrm{E}-6 \mathrm{~m} / \mathrm{s}$, precipitação $=1 \mathrm{~mm} / \mathrm{h}$, posicionada a $5 \mathrm{~m}$ do pé do talude. 53

Figura 31. Perfil de pressão de água ao longo do tempo - Solos A, B e C respectivamente, precipitação $=20 \mathrm{~mm} / \mathrm{h}$. 53

Figura 32. Padrões de Comportamento do perfil de pressão de água no decorrer da precipitação. 55

Figura 33. Distribuição de pressão de água ao longo de todo o talude, Perfil Tipo 1. (Solo C, precipitação igual a $70 \mathrm{~mm} / \mathrm{h}, \mathrm{k}_{\mathrm{s}}$ igual a $10^{-6} \mathrm{~m} / \mathrm{s}$ e t igual a 90 horas) 56

Figura 34. Distribuição de pressão de água ao longo de todo o talude, Perfil Tipo 2. (Solo B, precipitação igual a $20 \mathrm{~mm} / \mathrm{h}, \mathrm{k}_{\mathrm{s}}$ igual a $10^{-8} \mathrm{~m} / \mathrm{s}$ e t igual a 3000 horas) _ 56

Figura 35. Distribuição de pressão de água ao longo de todo o talude, Perfil Tipo 3. (Solo C, precipitação igual a $1 \mathrm{~mm} / \mathrm{h}, \mathrm{k}_{\mathrm{s}}$ igual a $10^{-5} \mathrm{~m} / \mathrm{s}$ e t igual a 140 horas) 56 
Figura 36. Distribuição de pressão de água ao longo de todo o talude, Perfil Tipo 4.

(Solo B, precipitação igual a $1 \mathrm{~mm} / \mathrm{h}, \mathrm{k}_{\mathrm{s}}$ igual a $10^{-6} \mathrm{~m} / \mathrm{s}$ e t igual a 780 horas) 57

Figura 37. Intensidade de precipitação $(1 \mathrm{~mm} / \mathrm{h})$ e curvas condutividade hidráulica Solo $\mathrm{C}, \mathrm{k}_{\mathrm{s}}=1 \mathrm{E}-5,1 \mathrm{E}-6$ e $1 \mathrm{E}-7 \mathrm{~m} / \mathrm{s}$. 58

Figura 38. Perfil de pressão de água ao longo do tempo - Solos C, $\mathrm{k}_{\mathrm{s}}=1 \mathrm{E}-5,1 \mathrm{E}-6 \mathrm{e}$ $1 \mathrm{E}-7 \mathrm{~m} / \mathrm{s}$ respectivamente, precipitação igual a $1 \mathrm{~mm} / \mathrm{h}$. 59

Figura 39. Perfil de pressão de água ao longo do tempo - "RetC-CondA", "RetCCondB" e Solo C respectivamente, precipitação $=20 \mathrm{~mm} / \mathrm{h}$. 60

Figura 40. Intensidade de precipitação $(20 \mathrm{~mm} / \mathrm{h})$ e curvas condutividade hidráulica ("C1", Solo C e "C2"). 61

Figura 41. Perfil de pressão de água ao longo do tempo - "C1", Solo C e "C2" respectivamente, precipitação $=20 \mathrm{~mm} / \mathrm{h}$. 61

Figura 42. Perfil de pressão de água ao longo do tempo - "RetA-CondB" e "RetCCondB", respectivamente, precipitação igual a $20 \mathrm{~mm} / \mathrm{h}$. 62

Figura 43. Perfil de pressão de água ao longo do tempo - Solo B, precipitação igual a $20 \mathrm{~mm} / \mathrm{h}$. 63

Figura 44. Curvas de Retenção ("B-10", Solo B e "B+20"). 64

Figura 45. Perfil de pressão de água ao longo do tempo - "B-10" e Solo B, respectivamente, precipitação igual a $20 \mathrm{~mm} / \mathrm{h}$. 64

Figura 46. Perfil de pressão de água ao longo do tempo - "B+20", respectivamente, precipitação igual a $20 \mathrm{~mm} / \mathrm{h}$. 65

Figura 47. Curvas de Retenção ("B a=15", Solo B,"B a=60") 66

Figura 48. Perfil de pressão de água ao longo do tempo - "B a=15", Solo B, respectivamente, precipitação igual a $20 \mathrm{~mm} / \mathrm{h}$. 67 
Figura 49. Perfil de pressão de água ao longo do tempo - "B a=60", precipitação igual a $20 \mathrm{~mm} / \mathrm{h}$.

Figura 50. Curvas de Retenção ("B m=0.1", Solo B, "B m=0.6"). 68

Figura 51. Perfil de pressão de água ao longo do tempo - "B m=0.6", Solo B, respectivamente, precipitação igual a $20 \mathrm{~mm} / \mathrm{h}$.

Figura 52. Perfil de pressão de água ao longo do tempo - "B m=0.1", precipitação igual a $20 \mathrm{~mm} / \mathrm{h}$. 69

Figura 53. Curvas de Retenção ("B n=2.5", Solo B, "B n=8"). 70

Figura 54. Perfil de pressão de água ao longo do tempo - "B n=2.5", Solo B, "B $\mathrm{n}=8$ ", respectivamente, precipitação igual a $20 \mathrm{~mm} / \mathrm{h}$. 71

Figura 55. Superfície crítica, Perfil de pressão inicial, válidos para todos os solos. 72

Figura 56. Superfície de Ruptura para condição saturada 73

Figura 57. Evolução do Fator de Segurança com o tempo - Solo $A, \phi^{b}=20^{\circ}, k_{s}=5 E-$ $6 \mathrm{~m} / \mathrm{s}$, precipitações de 1,20 e $70 \mathrm{~mm} / \mathrm{h}$ 74

Figura 58. Evolução do Fator de Segurança com o tempo - Solo $B, \phi^{\mathrm{b}}=20^{\circ}, \mathrm{k}_{\mathrm{s}}=1 \mathrm{E}-$ $8 \mathrm{~m} / \mathrm{s}$, precipitações de 1,20 e $70 \mathrm{~mm} / \mathrm{h}$ 75

Figura 59. Evolução do Fator de Segurança com o tempo - Solo C, $\phi^{\mathrm{b}}=20^{\circ}, \mathrm{k}_{\mathrm{s}}=1 \mathrm{E}-$ $6 \mathrm{~m} / \mathrm{s}$, precipitações de 1,20 e $70 \mathrm{~mm} / \mathrm{h}$ 75

Figura 60. Evolução do Fator de Segurança com o tempo - Solo C, $\phi^{\mathrm{b}}=20^{\circ}, \mathrm{k}_{\mathrm{s}}=1 \mathrm{E}-$ $5,1 \mathrm{E}-6$ e $1 \mathrm{E}-7 \mathrm{~m} / \mathrm{s}$, precipitação igual a $1 \mathrm{~mm} / \mathrm{h}$ 78

Figura 61. Evolução do Fator de Segurança com o tempo - "RetC-CondA", "RetCCondB" e Solo C, $\phi^{\mathrm{b}}=20^{\circ}, \mathrm{k}_{\mathrm{s}}=1 \mathrm{E}-6 \mathrm{~m} / \mathrm{s}$, precipitação igual a $20 \mathrm{~mm} / \mathrm{h}$. 79

Figura 62. Função condutividade hidráulica:"RetC-CondA", "RetC-CondB", Solo C. 79 
Figura 63. Evolução do Fator de Segurança com o tempo - "C1", "C2" e solo C, $\phi^{\mathrm{b}}=20^{\circ}, \mathrm{k}_{\mathrm{s}}=1 \mathrm{E}-6 \mathrm{~m} / \mathrm{s}$, precipitação igual a $20 \mathrm{~mm} / \mathrm{h}$. 80

Figura 64. Evolução do Fator de Segurança com o tempo - "RetA-CondB", "RetCCondB" e Solo B, $\phi^{\mathrm{b}}=20^{\circ}, \mathrm{k}_{\mathrm{s}}=1 \mathrm{E}-6 \mathrm{~m} / \mathrm{s}$, precipitação $=20 \mathrm{~mm} / \mathrm{h}$. 81

Figura 65. Evolução do Fator de Segurança com o tempo - "B -10", "B +20" e Solo $\mathrm{B}, \phi^{\mathrm{b}}=20^{\circ}, \mathrm{k}_{\mathrm{s}}=1 \mathrm{E}-6 \mathrm{~m} / \mathrm{s}$, precipitação $=20 \mathrm{~mm} / \mathrm{h}$. 81

Figura 66. Função condutividade hidráulica fictícia solo B e "B +20" 83

Figura 67. Evolução do Perfil de Segurança com o tempo - Solos B, "B+20" e "B+20 kf ", ks = 1E-6m/s e precipitação = $20 \mathrm{~mm} / \mathrm{h}$. 83

Figura 68. Evolução do Fator de Segurança com o tempo - Solo A, $\phi^{\mathrm{b}}=10^{\circ}$ e $30^{\circ}$, $\mathrm{k}_{\mathrm{s}}=5 \mathrm{E}-6 \mathrm{~m} / \mathrm{s}$, e precipitação $=1$ e $20 \mathrm{~mm} / \mathrm{h}$. 84

Figura 69. Evolução da Superfície Crítica com o tempo - Solo $B, \phi^{\mathrm{b}}=20^{\circ}, \mathrm{k}_{\mathrm{s}}=1 \mathrm{E}-6$ $\mathrm{m} / \mathrm{s}, 20 \mathrm{~mm} / \mathrm{h}$ 86

Figura 70. Diagrama de pressões de água atuantes na superfície crítica - Solo A, $\phi^{\mathrm{b}}=20^{\circ}, \mathrm{k}_{\mathrm{s}}=1 \mathrm{E}-6 \mathrm{~m} / \mathrm{s}, 20 \mathrm{~mm} / \mathrm{h}, \mathrm{t}=20 \mathrm{~h}$ 87

Figura 71. Diagrama de pressões de água atuantes na superfície crítica - Solo A, $\phi^{\mathrm{b}}=20^{\circ}, \mathrm{k}_{\mathrm{s}}=1 \mathrm{E}-6 \mathrm{~m} / \mathrm{s}, 20 \mathrm{~mm} / \mathrm{h}, \mathrm{t}=40 \mathrm{~h}$

Figura 72. Diagrama de pressões de água atuantes na superfície crítica - Solo A, $\phi^{\mathrm{b}}=20^{\circ}, \mathrm{k}_{\mathrm{s}}=1 \mathrm{E}-6 \mathrm{~m} / \mathrm{s}, 20 \mathrm{~mm} / \mathrm{h}, \mathrm{t}=70 \mathrm{~h}$ 87 


\section{LISTA DE TABELAS}

Tabela 1: Parâmetros dos solos analisados 38

Tabela 2: $\quad$ Duração da precipitação para alguns Tempos de Retorno a partir da Equação de chuva para a região de São Carlos 41 


\section{1 - INTRODUÇÃO}

A ruptura de um talude pode ser condicionada por diversos fatores, que agem isolada ou conjuntamente na deflagração do movimento de massa. Dentre estes, podem se citar os fatores geológicos, os geotécnicos, os hidrológicos, os climáticos e os antrópicos.

Em se tratando de taludes em solo não saturado, a dinâmica da água na atmosfera e no solo e todos os seus condicionantes ganham vital importância na medida em que a sucção, variável que descreve a interação entre a água e os sólidos do solo, interfere significativamente no comportamento do meio solo.

As interações entre a água no solo e na atmosfera são regidas pelos fenômenos de evapotranspiração das plantas, evaporação e infiltração, dentre os quais este último é o responsável pela deflagração de muitos escorregamentos em regiões de clima tropical.

Os principais efeitos da infiltração em um solo não saturado são: a diminuição da sucção atuante no meio e consequentemente de sua contribuição para a coesão (coesão aparente), o aumento da condutividade hidráulica do solo, e o aumento do peso específico do solo. Em determinados casos, a coesão aparente pode ser a responsável pela manutenção da estabilidade de taludes, como reportado por CAMPOS (1985) e WOLLE \& HACHICH (1989), em que a ruptura foi condicionada pela perda da contribuição da sucção para a coesão.

A importância da sucção na estabilidade de taludes em solo não saturado é clara, entretanto quantificar a variação da sucção em um talude sujeito a infiltração apresenta-se como uma tarefa complexa, em função da própria complexidade do processo de infiltração de água em um determinado solo. 
Dentre os diversos fatores que influem na infiltração podem-se citar a função condutividade hidráulica do solo, a curva de retenção do solo, a intensidade de precipitação e a duração da mesma. Além disso, o processo é condicionado por facetas peculiares, como a infiltração em "fingers", em ma croporos e fendas ou fluxo afunilado no contato entre solos siltosos e solos arenosos sotopostos, situações que em muito se afastam das condições ideais de solo homogêneo e isotrópico.

Vale a pena ressaltar que tanto a natureza da cobertura vegetal do solo quanto a geometria do talude interferem no regime de infiltração, como pode ser observado na alteração do escoamento superficial devido à presença ou não de cobertura vegetal ou ainda devido a uma maior ou menor declividade do talude.

Assim, o presente trabalho tem por finalidade avaliar a influência da redução da sucção, devido à infiltração, na estabilidade de taludes compostos por solos em condição não saturada.

Para tanto efetua-se uma análise paramétrica, em que as características do solo e da precipitação são analisadas e a estabilidade do talude representa a resposta do sistema sujeito à variação destas características.

Para a realização da análise paramétrica foi utilizado um único talude de referência com geometria fixada conforme a inclinação típica para taludes em areia argilo siltosa, característica do Centro-Oeste do estado de São Paulo.

Segundo o Manual de Orientação para diagnóstico e soluções de problemas de taludes em rodovias do DER (IPT,1991), nesta região os principais problemas de estabilidade estão associados a escorregamentos, geralmente superficiais e de pequena dimensão, devido à inclinação acentuada dos taludes de corte e deficiência no sistema de drenagem superficial.

A análise paramétrica foi desenvolvida a partir de uma simulação de fluxo em regime transiente utilizando o método de elementos finitos e posteriormente uma análise de estabilidade do talude de referência utilizando um programa baseado no método das fatias.

O Capítulo 2 apresenta revisão bibliográfica de conceitos pertinentes a solos não saturados e modelos de infiltração, além de apresentar os principais trabalhos de estabilidade de taludes em solos não saturados. 
O Capítulo 3 expõe os materiais e métodos utilizados para a realização das análises de fluxo e estabilidade, as hipóteses adotadas neste trabalho, além da descrição dos programas utilizados para análise de fluxo (SEEP/W) e para análise de estabilidade (SLOPE/W).

O Capítulo 4 apresenta análise paramétrica da influência das características do solo sobre a evolução do perfil de pressão de água e sobre a estabilidade do talude de referência. Na análise do perfil de pressão de água, são avaliadas as influências da condutividade hidráulica saturada, da função condutividade hidráulica e da curva de retenção. Na análise da estabilidade de talude, é avaliada a influência do parâmetro $\phi^{\mathrm{b}}$ (FREDLUND et al.,1978), além da influência dos parâmetros anteriormente mencionados.

O Capítulo 5 apresenta as principais conclusões deste trabalho, bem como algumas considerações finais. 


\section{2 - REVISÃO BIBLIOGRÁFICA}

\section{1 - Conceitos Gerais de Mecânica dos Solos Não saturados}

Um elemento de solo saturado pode ser entendido como um sistema bifásico, formado por água e partículas minerais (matriz). Por outro lado, um elemento de solo não saturado apresenta ar em seus vazios. A presença da matriz, de ar e de água faz com que ocorram diferentes interfaces e interações entre estes componentes.

A interação solo-água pode ser quantificada a partir da afinidade que um solo não saturado tem por água. Se colocado em contato com um reservatório de água, o solo absorve água, isto é, ele exerce uma sucção sobre a água. Se uma pressão de sucção é aplicada sobre o reservatório de água livre, de sorte a impedir o fluxo de água, essa pressão na água livre equivale à pressão de água no solo, o que constitui uma medida de sucção. (VILAR, 2001)

A sucção total do solo $\left(\mathrm{u}_{\mathrm{a}}-\mathrm{u}_{\mathrm{w}}\right)$ é definida como a pressão manométrica negativa, em relação à pressão externa de gás sobre a água do solo, que deve ser aplicada a um reservatório de água pura (à mesma cota e temperatura) de sorte que se mantenha o equilíbrio, através de uma membrana semi-permeável (permite o fluxo de água, mas não de solutos), entre a água do reservatório e a água do solo (VILAR, 2001). A Figura 1 esquematiza esta definição. 


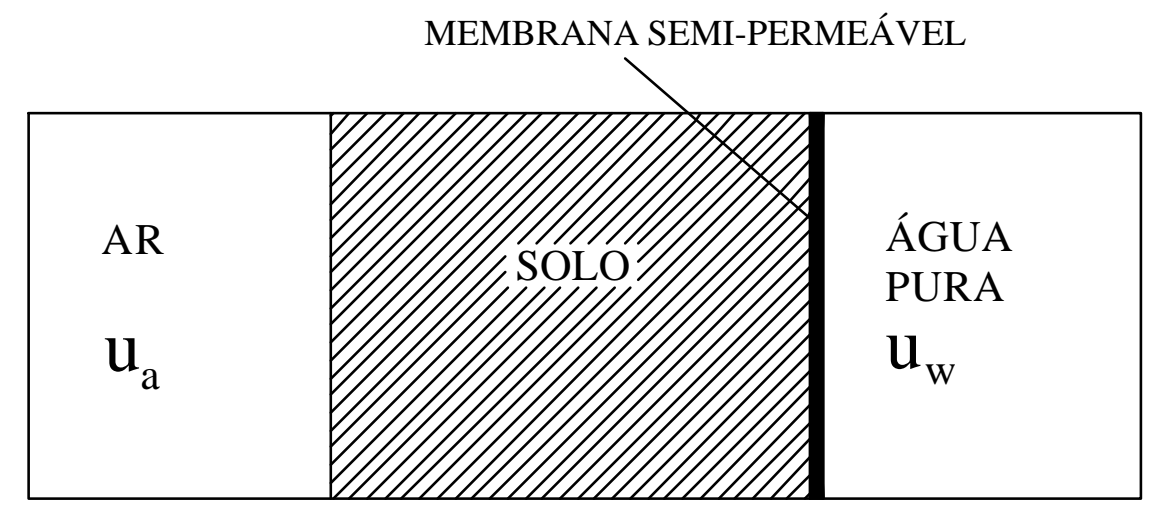

Figura 1. Esquema ilustrativo da definição de sucção total: Corresponde a ua-uw de sorte a não haver fluxo através da membrana semi-permeável. (VILAR, 2001)

A sucção total pode ser separada em suas componentes, a sucção osmótica e a sucção matricial.

A sucção osmótica equivale à sucção total quando o solo encontra-se saturado, restando apenas o efeito da concentração de solutos, ou seja, ocorre a tendência de fluxo de água do reservatório para o solo a fim de diminuir a diferença entre as concentrações da água do solo e do reservatório. (VILAR, 2001)

A sucção matricial eqüivale à sucção total quando a água do solo é idêntica à água padrão (água pura ou solução com mesma composição da água do solo), restando apenas o efeito da matriz do solo (capilaridade e adsorção) na atração por água. (VILAR, 2001)

O conteúdo inicial da água no solo parece ter uma relação direta com a componente da sucção matricial. Por outro lado, a sucção osmótica parece não ser sensitiva às variações do conteúdo de água no solo. Como resultado, em Mecânica dos Solos não saturados, tem-se atribuído uma mudança na sucção total a variações na sucção matricial, considerando desprezível a contribuição da sucção osmótica (FREDLUND \& RAHARDJO, 1993). Neste trabalho a notação $u_{\mathrm{a}}-\mathrm{u}_{\mathrm{w}}$ será utilizada para designar sucção matricial. 


\section{2 - Curva de Retenção}

A curva de retenção de água do solo representa a relação entre a sucção e o teor de umidade ou grau de saturação do solo. $\mathrm{O}$ teor de umidade pode ser o gravimétrico, relação entre a massa de água e a massa de solo seco ou o volumétrico, relação entre o volume de água e o volume total de solo.

A partir da curva de retenção de água alguns parâmetros podem ser definidos: a umidade volumétrica de saturação $\left(\theta_{s}\right)$, a umidade residual $\left(\theta_{r}\right)$ e a pressão de entrada de ar ou pressão de borbulhamento, conforme a Figura 2.

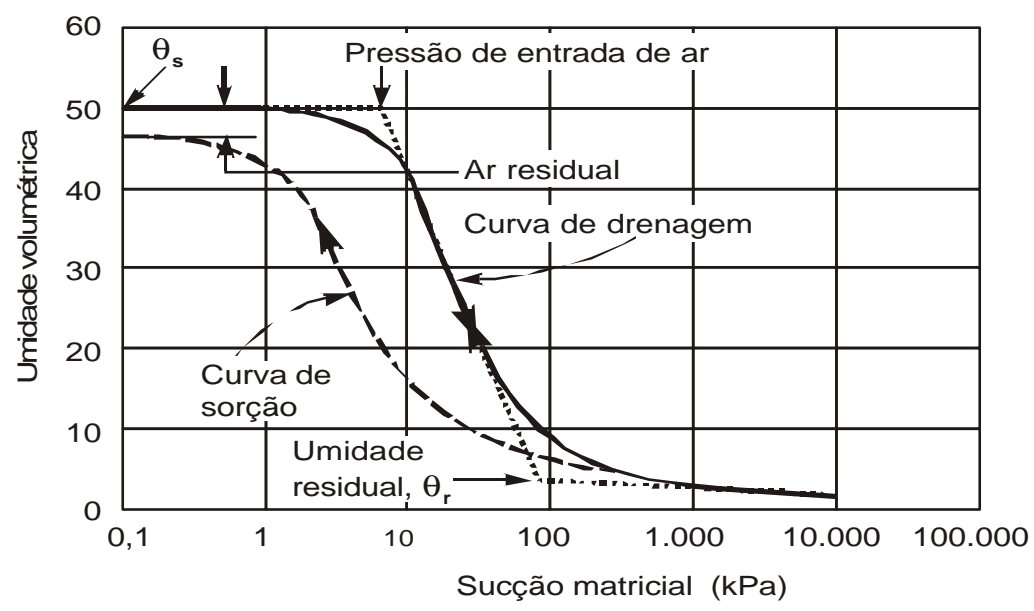

Figura 2. Elementos da Curva de Retenção

Em um solo saturado, todos os seus vazios estão totalmente preenchidos por água, independentemente do diâmetro dos vazios ou poros. Caso fossem aplicados valores progressivos de sucção no solo, a partir de um determinado valor, correspondente a tensão capilar dos poros de maior diâmetro, teria início o processo de drenagem do solo. Esta pressão é chamada pressão de entrada de ar.

De um modo geral a pressão de entrada de ar é menor para solos granulares do que para os siltosos. Além disso, como nos solos granulares existe maior possibilidade de uniformização granulométrica e porosimétrica, a pressão de entrada de ar mostra-se melhor caracterizada nestes que nos solos siltosos. (HILLEL, $1971 \mathrm{e}$ REICHARDT, 1985) 
Para valores inferiores à pressão de entrada de ar, o solo se mantém saturado, embora com pressões negativas na água, e o princípio das tensões efetivas é aplicável.

Com o avanço do processo de drenagem será atingido um valor de sucção em que qualquer acréscimo de pressão não poderá extrair mais água do solo. A umidade correspondente a esta sucção é denominada umidade residual $\left(\theta_{r}\right)$.

A forma da curva de retenção de um solo assim como os valores de sucção que são possíveis de atingir estão intimamente relacionados com a textura, composição mineralógica e estrutura do solo.

Nas curvas de retenção referentes a diferentes solos (Fig.3) pode se observar que os solos argilosos apresentam maior capacidade de retenção de água para uma mesma sucção. Além disso, pequenas variações de sucção respondem por praticamente toda a variação de umidade nos solos arenosos, diferentemente dos solos argilosos que necessitam de amplas variações de sucção para apresentar modificações sensíveis de umidade. (FREDLUND \& XING, 1994)

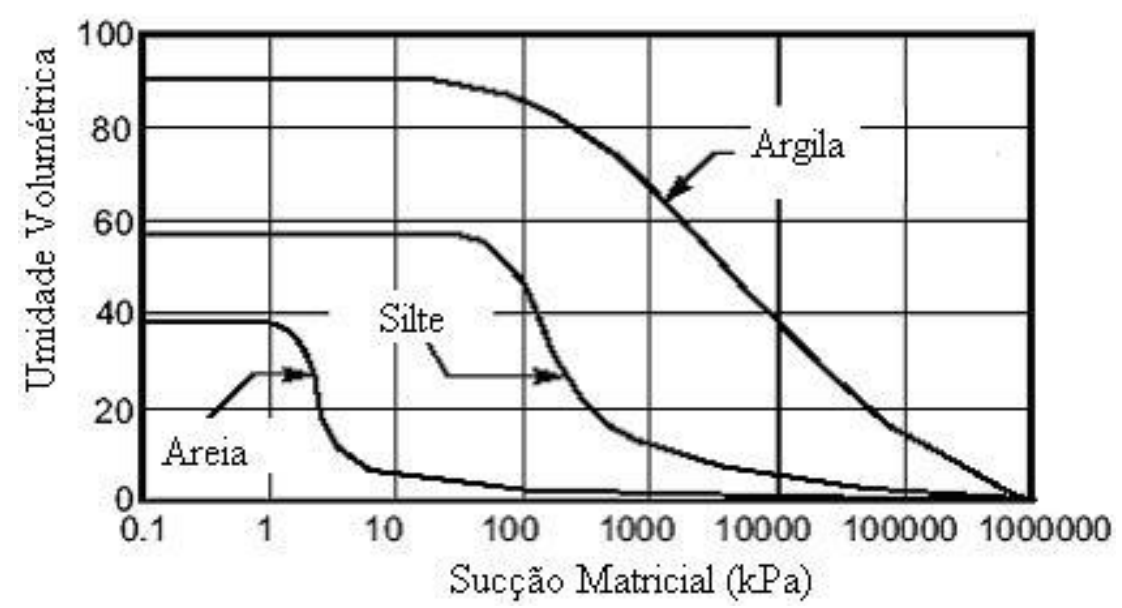

Figura 3. Curvas de retenção para diferentes tipos de solo (FREDLUND \& XING, 1994).

A curva de retenção depende ainda do histórico de variação do teor de umidade, ou seja, se o solo foi submetido à secagem ou umedecimento. Este fenômeno é denominado histerese e pode ser verificado na Figura 2, como sendo a diferença entre as curvas de umedecimento e secagem. Segundo RÖHM (1997), este fenômeno pode ser atribuído: 
- $\quad$ à desuniformidade geométrica de cada poro;

- $\quad$ ao efeito de ângulo de contato;

- às bolhas de ar capturadas nos vazios do solo durante o umedecimento;

- $\quad$ à alterações na estrutura do solo decorrentes da expansão ou contração associadas ao umedecimento ou secagem.

Comparando-se curvas de retenção de um mesmo solo em suas condições natural e compactada, pode-se observar que a compactação consegue diminuir as dimensões dos grandes poros entre as partículas do solo, entretanto os microporos parecem permanecer inalterados, evidenciando a influência da estrutura do solo na curva de retenção. (HILEL apud ROHM,1997)

VANAPALLI et al. (1999) apresentam estudo da influência da estrutura do solo e do histórico de tensões na curva de retenção de um silte argiloso compactado. As amostras compactadas no tramo seco da curva de compactação, com estrutura mais agregada, apresentam comportamentos de curva de retenção mais próximos de solos com granulação mais grosseira, que os compactados em outras condições. Entretanto em altos níveis de sucção (> $20000 \mathrm{kPa}$ ) o comportamento da curva de retenção de água de amostras compactadas sob diferentes condições parece não ser influenciado pela estrutura. Neste trabalho, os resultados levam a crer que a curva de retenção é pouco influenciada pelo histórico de pressões, pois o comportamento de amostras compactadas sob as mesmas condições, mas sujeitas a diferentes pressões de cedência (variando entre 0 - $200 \mathrm{kPa}$ ) foi muito similar.

NG \& PANG (2000) avaliam a influência do estado de tensões de um solo não perturbado na curva de retenção. As amostras de solo carregadas com tensões totais maiores exibiram menor umidade volumétrica inicial, apresentando uma menor tendência de alteração da umidade volumétrica com o aumento da sucção. Foi apresentada também uma tendência geral e consistente das amostras de solo que possuíam maiores valores de pressão de entrada de ar quanto maiores fossem as tensões a que estavam submetidas. Este comportamento foi atribuído à presença de menores poros interconectados na amostra sujeita a cargas superiores.

Dentre as aplicações para a curva de retenção, VANAPALLI et al.(1996) apresentam uma relação entre esta curva e parâmetros de resistência ao cisalhamento. 
Entretanto o uso mais consolidado é a derivação de funções condutividade hidráulica não saturada a partir desta curva. A curva de retenção de água também é necessária na determinação da mudança do volume de água armazenado no solo para cada alteração da sucção atuante. Para todas estas aplicações é interessante que a curva de retenção possa ser expressa como uma equação. Desta forma, ao longo dos anos diversas equações foram sugeridas para a curva de retenção.

LEONG \& RAHARDJO (1997a) discutem a aplicação e a origem de diversas equações propostas para a curva de retenção. Segundo estes autores, grande parte das equações propostas é empírica por natureza, baseadas apenas na forma sigmoidal da curva de retenção. Dentre as equações analisadas as que ajustam bem a forma mencionada são: van GENUCHTEN (1980), McKEE \& BUMB (1987) e FREDLUND \& XING (1994).

LEONG \& RAHARDJO (1997a) analisam o desempenho de diversas equações para ajuste da curva de retenção e concluem que a equação sugerida por FREDLUND \& XING (1994) apresenta os melhores ajustes, sendo assim recomendada para a representação da curva de retenção de água. Entretanto na obtenção dos parâmetros de ajuste, os dados utilizados devem incluir pontos depois de $\theta_{r}$.

A equação proposta por FREDLUND \& XING (1994) é apresentada abaixo:

$$
\Theta=\left\{\frac{1}{\ln \left[e+\left(\frac{\Psi}{a}\right)^{n}\right]}\right\}^{m}
$$

Onde:

$\Theta=\frac{\theta-\theta_{r}}{\theta_{s}-\theta_{r}}$

$\theta$ : umidade volumétrica;

$\theta_{r}$ : umidade volumétrica residual;

$\theta_{s}:$ umidade volumétrica de saturação;

$\Psi$ : Potencial de sucção;

$e: 2,71828$

$a$ : parâmetro de ajuste, relacionado à pressão de entrada de ar; 
$m, n$ : parâmetros de ajuste.

\section{3 - Função Condutividade Hidráulica}

Por definição, a condutividade hidráulica é uma medida da maior ou menor dificuldade que a água encontra para fluir através do solo.

$\mathrm{Na}$ condição não saturada, o solo tem parte de seus vazios preenchidos por ar o que gera uma perda da capacidade de transmitir água, ou seja, quanto maior a sucção menor a condutividade hidráulica do solo. A relação entre a sucção e a condutividade hidráulica do solo é denominada função condutividade hidráulica.

Durante o processo de perda de umidade, o ar progressivamente substitui a água dos poros. Segundo RICHARDS (1974), os fatores que geram esta perda de capacidade de transmitir água são:

A área total disponível para o fluxo da água decresce com a diminuição do número de poros saturados por água, pois o ar passa a obstruir a trajetória original da água.

- O esvaziamento dos poros avança dos maiores para os menores, acarretando uma diminuição da condutividade hidráulica porque o fluxo de água, segundo a equação de Poiseuille para fluxos laminares em tubos capilares é diretamente proporcional ao quadrado do raio do tubo;

Com o enchimento dos poros de ar, aumenta a quantidade de água que fica isolada e descontínua em diversos poros do solo, o que dificulta o fluxo da água como líquido.

MILLER \& LOW (1963) indicam que para sucções matriciais muito altas, além do aumento da tortuosidade e das diminuições da quantidade e das dimensões dos poros que conduzem água no solo, também ocorre uma alteração na viscosidade da água, que começa a se aproximar, cada vez mais, da camada adsorvida pelas partículas sólidas. 
A função condutividade hidráulica pode ser determinada através de ensaio específico para tanto. Contudo devido à dificuldade em medir valores muito baixos de condutividade, por vezes esta função é obtida através de modelos baseados na curva de retenção ou na distribuição porosimétrica do solo, ainda que tais modelos apresentem hipóteses simplificadoras de comportamento ou imprecisões em sua estimativas.

Segundo LEONG \& RAHARDJO (1997b), a função condutividade hidráulica, expressa por meio de equações, pode ser classificada segundo seu grau de sofisticação teórica:

Equações empíricas;

Modelos macroscópicos e;

Modelos estatísticos.

Ainda segundo estes autores, as equações empíricas, de aplicação mais consolidada que as demais, seguem uma relação generalizada do tipo:

$k_{r}=\Theta^{p}$

Onde:

$k_{r}$ : coeficiente relativo de condutividade hidráulica ou $k_{r}=k\left(u_{a}-u_{w}\right) / k_{s}$;

$\Theta=\frac{\theta-\theta_{r}}{\theta_{s}-\theta_{r}}$

$\theta$ : umidade volumétrica;

$\theta_{r}:$ umidade volumétrica residual;

$\theta_{s}:$ umidade volumétrica de saturação;

$p$ : parâmetro de ajuste.

Assim sendo, como $\Theta$ pode ser expressa como uma relação da sucção, assim também o pode a condutividade hidráulica não saturada, portanto a função condutividade hidráulica pode ser obtida a partir da curva de retenção. 


\section{4 - Resistência ao cisalhamento de Solos não saturados}

Em solos saturados, a variável tensão efetiva é utilizada pela teoria de MohrCoulomb para a previsão de sua resistência ao cisalhamento. A equação da resistência ao cisalhamento para solos saturados é expressa como uma função linear da tensão efetiva, da seguinte forma:

$$
\tau=c^{\prime}+\left(\sigma-u_{w}\right) \operatorname{tg} \phi^{\prime}
$$

Onde:

$\tau$ : resistência ao cisalhamento;

$c^{\prime}$ : coesão efetiva;

$\phi^{\prime}$ : ângulo de atrito interno efetivo;

$\sigma$ : tensão normal total no plano de ruptura;

$\left(\sigma-u_{w}\right)$ : tensão normal efetiva no plano de ruptura e;

$u_{w}$ : pressão neutra.

A influência da variação do teor de umidade (ou grau de saturação) é estudada de preferência através da sucção, pelas seguintes razões (JUCA, 1990 apud CALLE, 2000):

A sucção pode variar com o estado de tensões a que está submetido o solo, mesmo que o teor de umidade se mantenha constante;

Em solos compactados em um mesmo teor de umidade, a sucção matricial estará influenciada pela estrutura, e portanto também representa o tipo de energia de compactação que foi utilizada;

- $\quad$ Nas relações estabelecidas diretamente com a sucção matricial o efeito da histerese é menos pronunciado que nas relações entre os parâmetros do solo e o teor de umidade.

De forma geral, o efeito da sucção matricial na resistência pode ser considerado como um incremento na rigidez do solo, produzido pela ação intergranular que é gerada, tendendo a manter mais fortemente unidas às partículas do solo. 
Uma das primeiras e mais utilizadas expressões para relacionar a resistência ao cisalhamento com a sucção matricial se deve a BISHOP et al. (1960), a qual utiliza o critério da tensão efetiva atuando em um solo não saturado:

$$
\tau=c^{\prime}+\left(\sigma-u_{a}+\chi\left(\mathrm{u}_{\mathrm{a}}-u_{w}\right)\right) \operatorname{tg} \phi^{\prime}
$$

Onde:

$\chi$ : parâmetro que depende do grau de saturação, tipo de solo e de efeitos de histerese decorrentes da secagem ou umedecimento.

Entretanto JENNINGS \& BURLAND (1962) questionam a validade da expressão [6], pois tal equação define uma tensão intergranular e não efetiva, além de não conseguir expressar o comportamento de diversos solos com grau de saturação baixos, da ordem de $20 \%$ em areias, $50 \%$ em siltes e $85 \%$ em argilas. Além disto, esta expressão não consegue explicar o colapso. Com o umedecimento de um corpo de prova e a redução da sucção atuante e consequentemente da tensão efetiva, segundo a expressão [6], deveria ocorrer um aumento de volume, isto contraria a redução de volume que na realidade ocorre e que caracteriza o colapso.

FREDLUND \& MORGENSTERN (1977) mostram que pode-se tomar como variáveis de estado, para o estudo da resistência ao cisalhamento de solos nãosaturados, qualquer combinação de duas, das seguintes variáveis de estado: $\left(\sigma-u_{a}\right),\left(\sigma-u_{w}\right)$ e $\left(u_{a}-u_{w}\right)$, onde $u_{a}$ é a pressão de ar e $\left(u_{a}-u_{w}\right)$ é a sucção matricial.

FREDLUND et al. (1978) propõem uma equação linear para a resistência ao cisalhamento dos solos não-saturados, da seguinte forma:

$$
\tau=c^{\prime}+\left(\sigma-u_{a}\right) \operatorname{tg} \phi^{\prime}+\left(\mathrm{u}_{\mathrm{a}}-u_{w}\right) \operatorname{tg} \phi^{b}
$$

Onde:

$\phi^{b}$ : ângulo que indica a taxa de crescimento da resistência ao cisalhamento relativo a uma mudança na sucção.

A Figura 4 apresenta a representação gráfica da expressão de FREDLUND et al. (1978): 


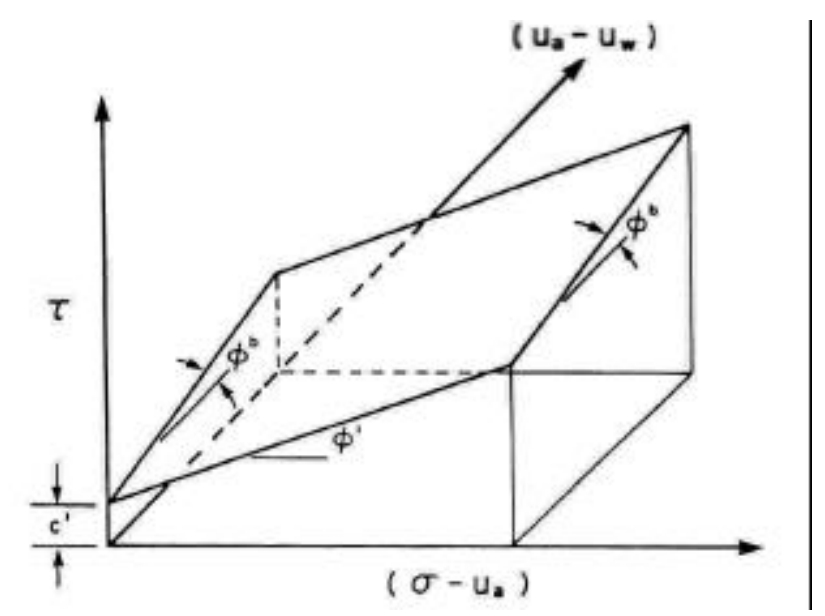

Figura 4. Representação gráfica da expressão de FREDLUND et al. (1978).

Algumas observações podem ser feitas a respeito da equação proposta por FREDLUND et al. (1978):

- $\quad$ o ângulo de atrito interno é suposto constante com a sucção matricial;

- a resistência ao cisalhamento cresce linearmente com a sucção matricial;

envoltória de ruptura plana (conforme apresentado na Figura 4); e como o ângulo de atrito interno é suposto constante com a sucção matricial, todo o ganho de resistência ao cisalhamento do solo se refletirá em um acréscimo de coesão, de modo que a coesão do solo não saturado pode ser quantificada por:

$c=c^{\prime}+\left(\mathrm{u}_{\mathrm{a}}-u_{w}\right) \operatorname{tg} \phi^{b}$

Um aspecto chama a atenção quando se compara as equações (6) e (7) pois nota-se que $\operatorname{tg} \phi^{b}=\chi \operatorname{tg} \phi^{\prime}$. Na medida em que $\chi$ não é linear, pois varia com o grau de saturação do solo, $\operatorname{tg} \phi^{b}$ também não pode ser constante em todo o intervalo de variação do grau de saturação.

ESCARIO \& SAEZ (1986) mostram ser inadequada a adoção de um valor de $\phi^{b}$ constante com a sucção matricial, principalmente para pequenos valores de sucção matricial, como mostra a Figura 6. A partir desta Figura pode-se ainda verificar que apesar da sucção matricial desempenhar função clara no incremento de coesão do solo, sua influência no ângulo de atrito interno é bastante controversa. 
Os resultados de VANAPALLI (1994) apud FREDLUND (1995) mostram que $\phi^{\prime}$ é independente da sucção para uma amostra de depósito glacial ensaiada com várias densidades e umidades iniciais para um intervalo de sucção de 0 a $500 \mathrm{kPa}$.

ESCARIO \& JUCA (1989) mostram que $\phi^{\prime}$ é independente da sucção para a areia argilosa de Madri $\left(\mathrm{W}_{\mathrm{L}}=32 \%, \mathrm{~W}_{\mathrm{P}}=15 \%, 17 \%\right.$ de argila, $31 \%$ de silte e $46 \%$ de areia) mas não para a argila vermelha de Guadalix $\left(\mathrm{W}_{\mathrm{L}}=33 \%, \mathrm{~W}_{\mathrm{P}}=13,6 \%, 86 \%\right.$ de argila, $11 \%$ de silte e $3 \%$ de areia) quando ensaiada para um grande intervalo de sucção (0 a $10000 \mathrm{kPa}$ ), como pode-se ver na Figura 5. Mais importante é a constatação de que a coesão não varia linearmente com a sucção para ambas amostras.
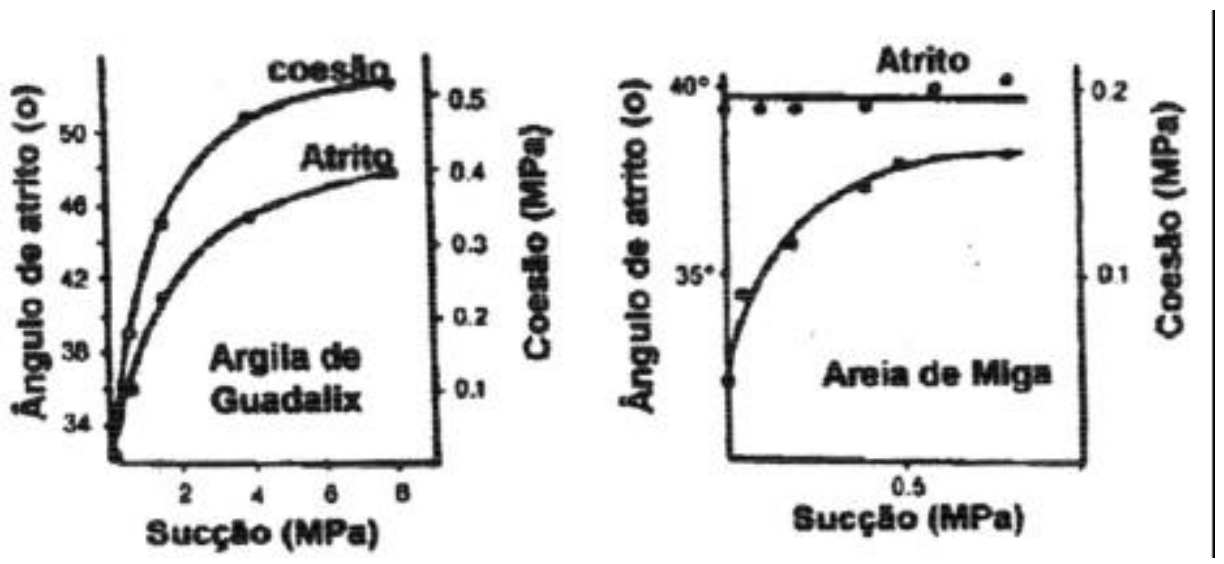

Figura 5. Variação da coesão e do ângulo de atrito para dois solos distintos (ESCARIO \& JUCÀ, 1989). 


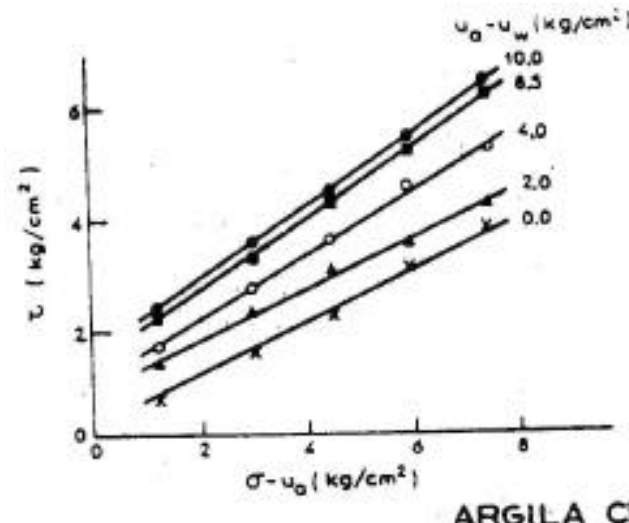

(a)

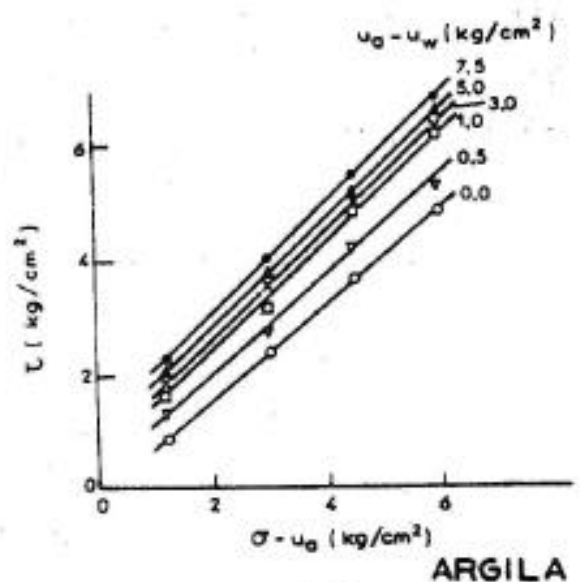

(a)

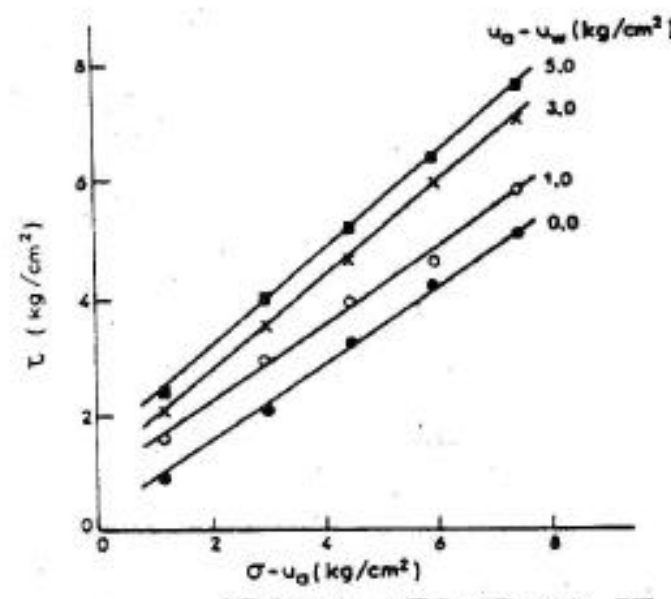

ARGILA VERMELHA DE

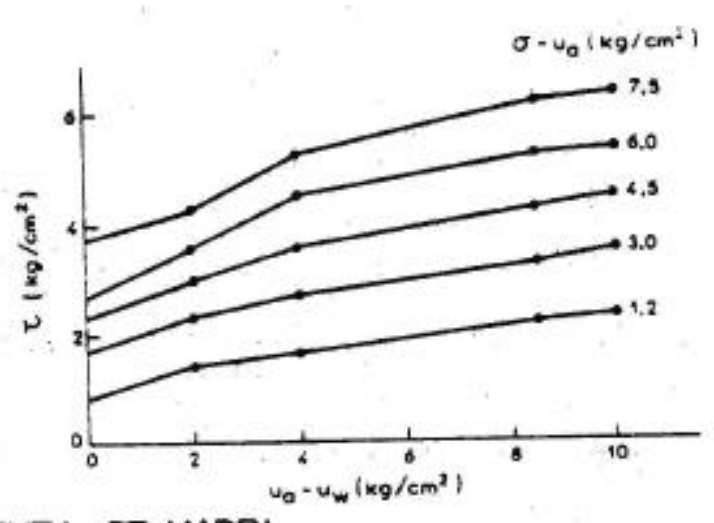

(b)

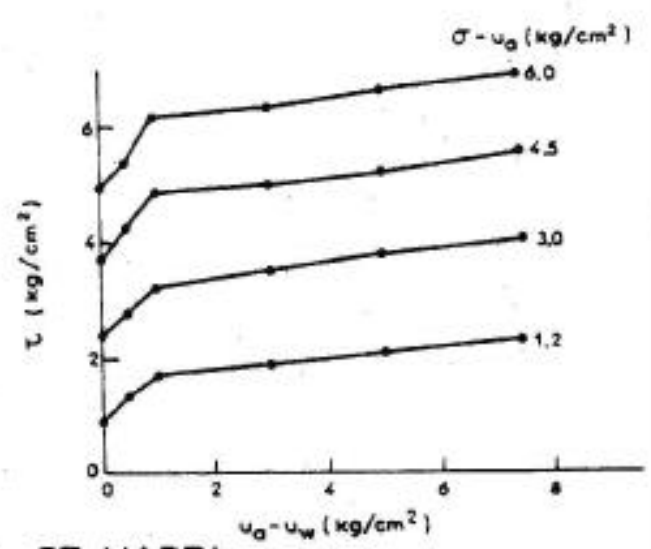

(b)

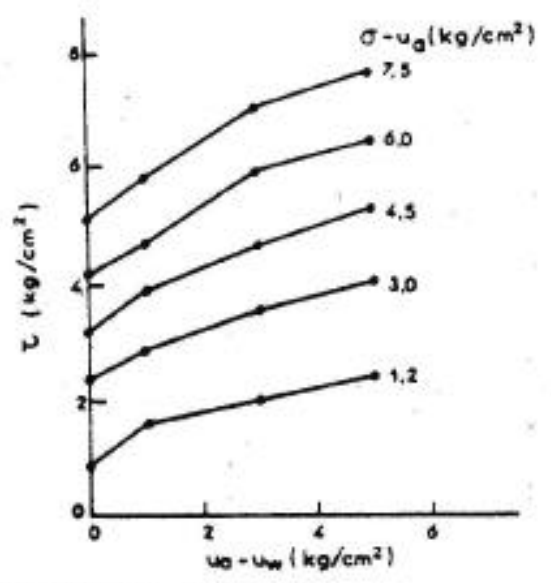

Figura 6. a) Resistência ao cisalhamento x tensão normal para diferentes valores de sucção matricial b)Resistência ao cisalhamento $x$ sucção para diferentes valores de tensão normal (ESCARIO \& SAEZ, 1986). 
DELAGE et al. (1987) apud RÖHM (1997) mostram resultados experimentais que permitem concluir que $\phi^{b}$ varia com a sucção, e que a coesão aparente $(c)$ e o ângulo de atrito interno $\left(\phi^{\prime}\right)$ também variam com a sucção, como apresentado na Figura 7:

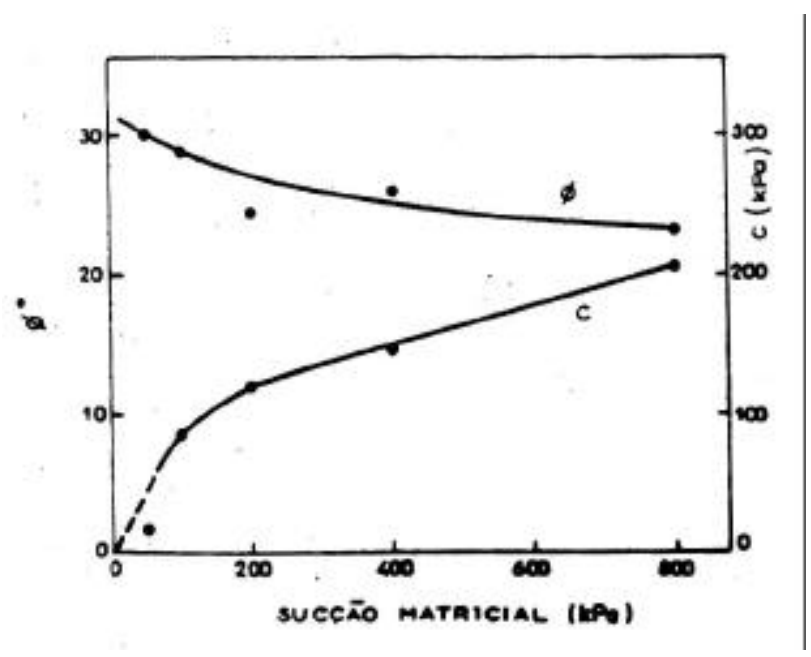

Figura 7. Variação da coesão e do ângulo de atrito interno em função da sucção matricial (DELAGE et al., 1987 apud RÖHM, 1997).

FREDLUND et al. (1987) admitem a não linearidade da resistência ao cisalhamento com a sucção matricial. Ainda segundo os autores para baixos valores de sucção matricial, tem-se aproximadamente $\phi^{b}$ igual a $\phi^{\prime}$.

ESCARIO (1988) analisa resultados experimentais de resistência ao cisalhamento obtida através de ensaios com a sucção matricial controlada correlacionando-os com a sucção matricial através de uma elipse de grau 2,5.

No ajuste da equação proposta por ESCARIO (1988) as seguintes observações devem ser asseguradas:

Sua tangente na origem, $\left(u_{a}-u_{w}\right)=0$, deve possuir inclinação igual a $\phi^{\prime} ; \mathrm{e}$

- Valor de resistência ao cisalhamento do solo deve alcançar um valor máximo para um valor finito de sucção matricial.

ABRAMENTO (1988) e ABRAMENTO \& CARVALHO (1989) admitem que a relação entre a coesão e a sucção matricial pode ser representada por uma função potencial com expoente, $\beta$, menor que a unidade, da seguinte forma: 
$c=c^{\prime}+\alpha\left(u_{A}-u_{W}\right)^{\beta}$

RÖHM (1992) apresenta resultados de ensaios triaxiais realizados em um colúvio arenoso indeformado nos quais obtém-se valores crescentes de $\phi^{\prime}$ com a sucção matricial. O intercepto de coesão do solo apresenta valores crescentes com a sucção matricial até valores de sucção de cerca de $200 \mathrm{kPa}$. A partir deste valor, acréscimos de sucção matricial pouco influenciaram os valores da coesão. Ainda segundo este autor, a relação entre a resistência ao cisalhamento e a sucção matricial segue uma lei hiperbólica.

TEIXEIRA (1996) apresenta resultados de ensaios triaxiais realizados no mesmo solo que RÖHM (1992), estando este em uma condição compactada. Os resultados obtidos indicam valores de $\phi^{\prime}$ praticamente constantes com a sucção matricial e valores de $c$ variando com a sucção conforme uma lei hiperbólica. Ainda segundo TEIXEIRA (1996) para baixos valores de sucção matricial é possível encontrar-se $\phi^{b}>\phi^{\prime}$.

Há evidências disponíveis na literatura que mostram um decréscimo da resistência ao cisalhamento o solo com o aumento da sucção matricial, como apresentado em DONALD (1956) apud FREDLUND (1995) e ESCARIO \& JUCA (1989). Este decréscimo na resistência ao cisalhamento é possível em baixos valores de sucção para solos como areias e pedregulhos, na medida em que estes dessaturam relativamente rápido (FREDLUND, 1995). Os resultados de DONALD (1956) mostram uma queda na resistência ao cisalhamento após valores de sucção de 10 a $15 \mathrm{kPa}$ para quatro diferentes areias ensaiadas. Para solos que apresentam uma maior porcentagem de finos, a resistência ao cisalhamento decresce apenas em altos valores de sucção. ESCARIO \& JUCA (1989) observam aumentos da resistência ao cisalhamento até valores de sucção de $1000 \mathrm{kPa}$ para uma areia argilosa. Entretanto para sucções de 1000 a $4000 \mathrm{kPa}$, uma queda na resistência ao cisalhamento foi observada. Para certos tipos de solo como argilas altamente plásticas, não há estágio de saturação residual, devido à alta capacidade de retenção de água destes tipos de solo. Tais solos apresentam aumentos da resistência ao cisalhamento mesmo para valores muito altos de sucção. ESCARIO \& JUCA (1989) relatam aumentos na resistência ao cisalhamento para uma argila vermelha de Guadalix em valores de sucção da ordem de $10000 \mathrm{kPa}$. 


\section{5 - Infiltração de água no solo}

A infiltração, definida com a penetração de água nos poros do solo, pode ocorrer em uma dada superfície do solo, a partir de uma precipitação, de irrigação ou de lâmina de água sobre a superfície ("poças”). Quando a intensidade da precipitação ou a taxa de irrigação são pequenas, a água infiltra sem a formação de poças na superfície do terreno.

O regime de infiltração não é determinado apenas pela disponibilidade de água na superfície do solo, mas também pela capacidade de infiltração desta superfície.

No solo há ainda a presença de facetas peculiares que fazem com que o comportamento real do solo distancie-se do comportamento do solo idealizado (homogêneo e isotrópico) pelas Leis de estudo de fluxo. Como exemplos destes tipos de singularidades pode-se citar a infiltração em "fingers", em macroporos e fendas ou o fluxo afunilado no contato entre solos siltosos e solos arenosos sotopostos.

A Lei de Darcy, que define o movimento de água nos solos, é válida tanto para solos saturados quanto para a condição não saturada. Assim, independente do grau de saturação do solo, a água percola na direção do gradiente hidráulico, partindo de onde há mais energia para onde há menos energia.

Como em um solo não saturado pode ocorrer variação no armazenamento de água dentro de uma dado volume de solo, o fluxo passa a ser descrito pela equação de Richards (Eq. 10), que representa uma equação geral de fluxo em um meio homogêneo (MIYAZAKI, 1993):

$$
\frac{\partial \theta}{\partial t}=\frac{\partial}{\partial x}\left(k_{x} \frac{\partial \psi}{\partial x}\right)+\frac{\partial}{\partial y}\left(k_{y} \frac{\partial \psi}{\partial y}\right)+\frac{\partial}{\partial z}\left(k_{z} \frac{\partial \psi}{\partial z}\right)+\frac{\partial k_{z}}{\partial z}
$$

Onde:

$\theta$ : umidade volumétrica;

$\psi$ : sucção total (carga hidráulica);

$x, y, z:$ direções no espaço;

$k_{x}, k_{y}, k_{z}$ : condutividade hidráulica na direção indicada;

$t:$ tempo. 
Existem várias equações empíricas que podem ser utilizadas para exprimir a capacidade de infiltração de um solo. Em geral, estas equações se aplicam a situações físicas nas quais a superfície do solo se mantém saturada durante todo o período de infiltração de água no solo. Entretanto nas simulações hidrológicas, há possibilidade da intensidade pluviométrica ser superior ou inferior a capacidade de infiltração do solo, além da possibilidade de ocorrência de precipitações intermitentes que permitem a recuperação da capacidade de infiltração (RIGHETTO, 1998). Assim a infiltração real em um instante $t, f r(t)$, é expressa por:

$$
f r(t)=\min [f(t) ; i(t)]
$$

Onde:

$f(t)$ : capacidade de infiltração do solo no instante $t$;

$i(t)$ : intensidade de precipitação no instante $t$.

Experimentos controlados demonstram que a infiltração tem decaimento aproximadamente exponencial com o tempo para a condição de superfície saturada. (RIGHETTO, 1998)

De maneira geral a condutividade hidráulica saturada representa o limite para a taxa de infiltração quando ocorre a estabilização do fluxo. No início da precipitação, a infiltração é influenciada pelo gradiente hidráulico, que pode ocasionar taxas de infiltração superiores à condutividade hidráulica saturada, como reportado por NG \& SHI (1998).

GREEN-AMPT (1906) apud RIGHETTO (1998) apresenta um modelo físico simplificado do avanço da frente de umedecimento que pode auxiliar na compreensão do fenômeno de infiltração em solos não saturados:

$$
f(t)=k \cdot\left(1+\frac{\psi_{f} \cdot \Delta \theta}{F(t)}\right)
$$

Onde:

$f$ : capacidade de infiltração do solo no tempo t [L/T]; 
$k$ : condutividade hidráulica do solo na superfície levando em conta o aprisionamento de ar nos poros do solo [L/T];

$\psi_{f}$ : potencial de sucção na frente de molhamento [L];

$\Delta \theta$ : diferença de umidade volumétrica do solo antes e depois da passagem da frente de molhamento $\left[\mathrm{L}^{3}\right.$ de água/ $\mathrm{L}^{3}$ de solo];

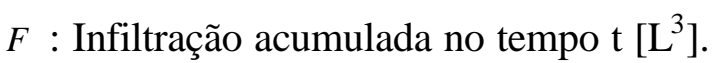

Vale a pena ressaltar que a equação de GREEN-AMPT (1906) é similar à equação de Darcy para fluxos em solos saturados:

$q=k . i$

Assim o gradiente hidráulico $(i$ ) pode ser expresso da seguinte forma:

$i=\left(1+\frac{\psi_{f} \cdot \Delta \theta}{F(t)}\right)$

No início da precipitação $(t=0)$ :

$$
F(0) \rightarrow 0 \quad \frac{\Psi_{f} \cdot \Delta \theta}{F(0)} \rightarrow \infty \quad \therefore i>1
$$

Quando o fluxo estabiliza $(t \rightarrow \infty)$ :

$$
F(\infty) \rightarrow \infty \quad \frac{\psi_{f} \cdot \Delta \theta}{F(\infty)} \rightarrow 0 \quad \therefore i=1
$$

A Figura 8 mostra uma representação esquemática para a expressão de GREEN-AMPT (1906) aplicada a um perfil de potencial de sucção homogêneo em superfície. Nota-se que a razão $F(t) / \Delta \theta$ expressa o avanço da frente de umedecimento no solo. 


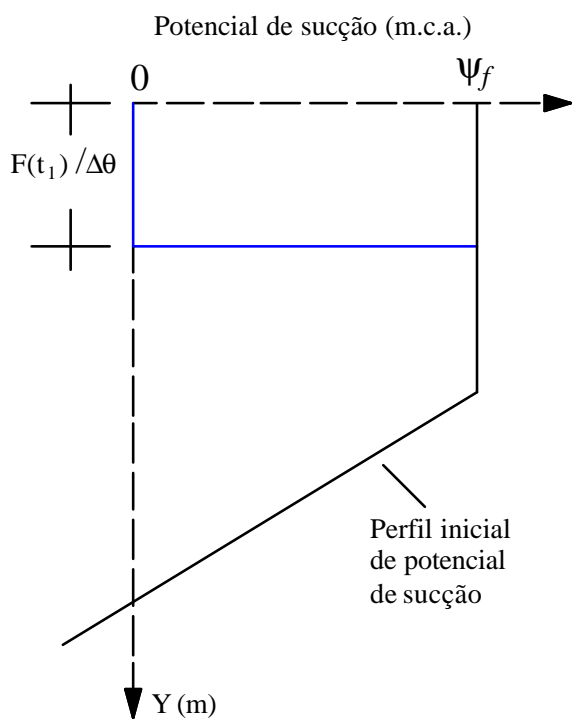

Figura 8. Representação esquemática da expressão de GREEN-AMPT (1906)

LUMB (1975) sugere que a taxa de infiltração da chuva em um solo homogêneo, na ausência de lâmina d'água, é numericamente igual à condutividade hidráulica saturada deste solo. Na Figura 9 pode-se observar que o avanço da água dentro do solo possui uma espessura de:

$$
h=\frac{k_{s} t}{n\left(S_{f}-S_{o}\right)}
$$

Onde:

$h$ : avanço da frente de saturação no solo;

$k_{s}:$ condutividade hidráulica saturada;

$t:$ tempo;

$n$ : porosidade;

$S_{f}$ : grau de saturação final;

$S_{o}$ : grau de saturação inicial.

Segundo este modelo, o solo estará completamente saturado apenas na superfície, mas estará úmido $\left(\mathrm{S}_{\mathrm{f}}\right.$, grau de saturação entre 80 e $\left.90 \%\right)$ abaixo desta até a profundidade $h$. 


\section{Grau de Saturação}

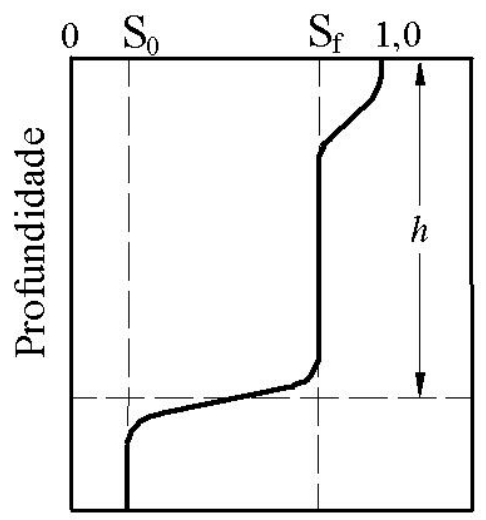

Figura 9. Representação gráfica do modelo de infiltração de LUMB (1975)

Apesar do modelo de LUMB (1975) ter sido amplamente utilizado nas décadas de 70 e 80 para análise de infiltração em taludes, este não considera as condições do talude, fluxos na direção da face do talude, a intensidade da precipitação, ou mais importante, a dependência da condutividade hidráulica do solo com relação às sucções atuantes, além de não considerar o efeito do gradiente hidráulico na máxima capacidade de infiltração do solo.

SMITH et al. (2002) discutem o avanço da frente de umedecimento, a partir de modelo computacional de fluxo transiente em uma coluna de solo, sujeita a um perfil de sucção inicial hidrostático. Os autores argumentam que a redução inicial na sucção na superfície é bastante rápida, mas com o decréscimo da sucção, a condutividade hidráulica aumenta facilitando a penetração mais profunda da frente de umedecimento dentro da coluna de solo. Assim a redução da sucção torna-se mais lenta com o passar do tempo. Com a continuação da precipitação, a pressão neutra superficial tende a diminuir para um limite estabilizado em que a sucção na frente de umedecimento corresponde ao valor da sucção quando a condutividade hidráulica eqüivale a taxa de infiltração. Uma vez que a condutividade hidráulica e a velocidade de infiltração sejam iguais, não haverá posterior diminuição da sucção durante o processo de infiltração. Apenas se a taxa de infiltração exceder a condutividade hidráulica saturada, em regime transiente e para gradientes superiores a um, a frente de umedecimento irá causar a destruição completa da sucção em superfície. $\mathrm{Na}$ Figura 10 onde esta discussão é ilustrada, pode-se verificar que ocorre elevação do nível freático no decorrer da infiltração antes mesmo que a sucção seja anulada em superfície. 


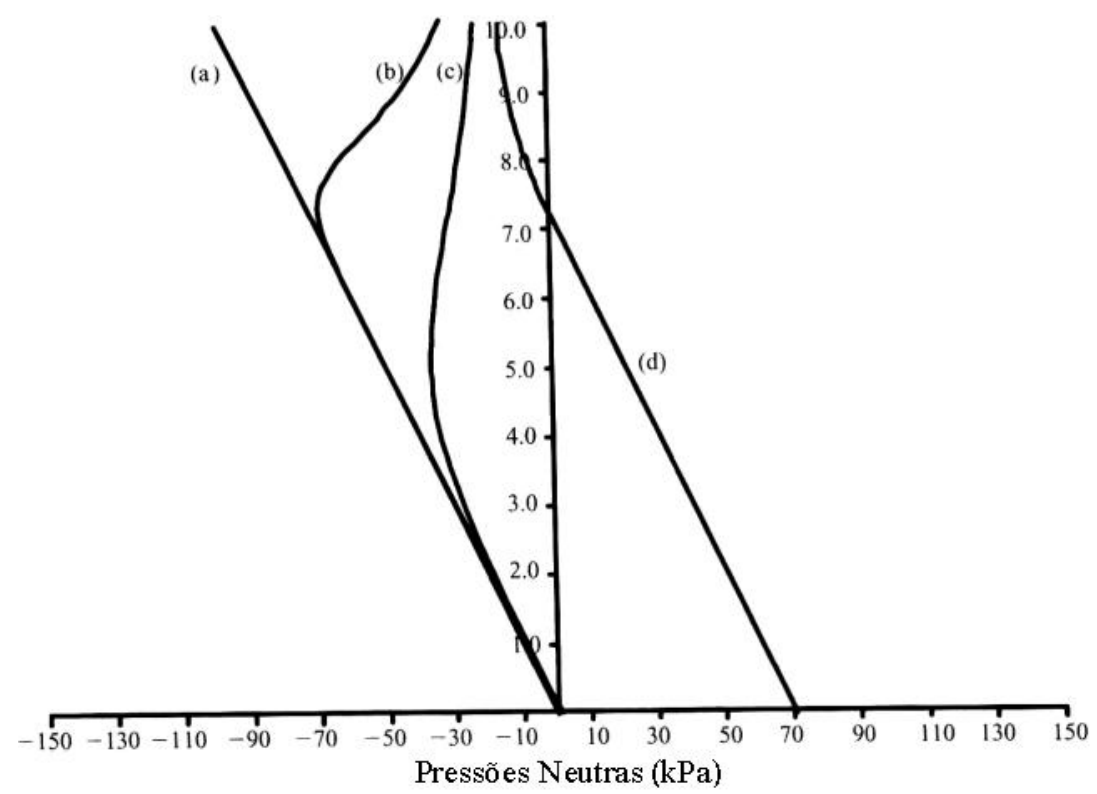

Figura 10. Evolução da frente de umedecimento. (a) Perfil de sucção inicial (b) Perfil após início da infiltração $t=t b(c)$ Perfil após início da infiltração $t=t c$, com tc $>t b(d)$ Elevação do Nível freático devido ao armazenamento de água dentro do solo (SMITH, 2002).

LIM et al (1996) apresentam estudo a respeito da influência da cobertura no desenvolvimento do perfil de sucção em um talude através de um programa de instrumentação de um talude em solo residual. As variações na sucção matricial e no perfil de sucção foram analisadas abaixo de: 1) uma seção com grama coberta com lona; 2) uma seção com grama; e 3) uma seção descoberta. Os resultados mostram que:

As alterações da sucção matricial devido a mudanças climáticas decrescem com a profundidade, tanto como resposta da evaporação como resposta da precipitação;

As alterações são mais significativas na seção com superfície descoberta e menos significativas na seção com grama e coberta com a lona; e

- $\quad$ O decréscimo da sucção matricial após uma precipitação é uma função da sucção matricial imediatamente antes da precipitação. 


\section{6 - Estabilidade de talude em solo não saturado}

Neste item são apresentados exemplos de análise de estabilidade em solo não saturado, além das as principais hipóteses e conclusões de cada trabalho citado.

Uma análise possível para considerar o efeito da sucção no solo, e sua influência na estabilidade do talude é incorporar a contribuição da sucção matricial na coesão do solo, denominado método de "coesão total". Outra análise possível envolve a redefinição do fator de segurança para incorporar ambas pressões neutras positivas e negativas. Uma envoltória de resistência ao cisalhamento não linear com relação à sucção matricial também pode ser incorporada na análise de estabilidade de talude. (FREDLUND, 1993)

CAMPOS (1985) através de retroanálises de casos históricos estima o perfil de sucção presente na ocasião da ruptura destes taludes. Foi adotado o modelo de envoltória de resistência proposta por FREDLUND et al. (1978). Neste trabalho, a variação da pressão neutra com a profundidade não considera o avanço da frente de umedecimento com o tempo, ou seja, desconsidera a teoria de infiltração e adota fluxo estabilizado. Foram utilizadas diferentes formas para o perfil de sucção, de maneira que a contribuição da coesão aparente garantisse Fator de Segurança igual a um. Os perfis de sucção ajustados foram do tipo constante com a profundidade, linear, parabólico do segundo grau e parabólico do terceiro grau, como podem ser vistos na Figura 11b:

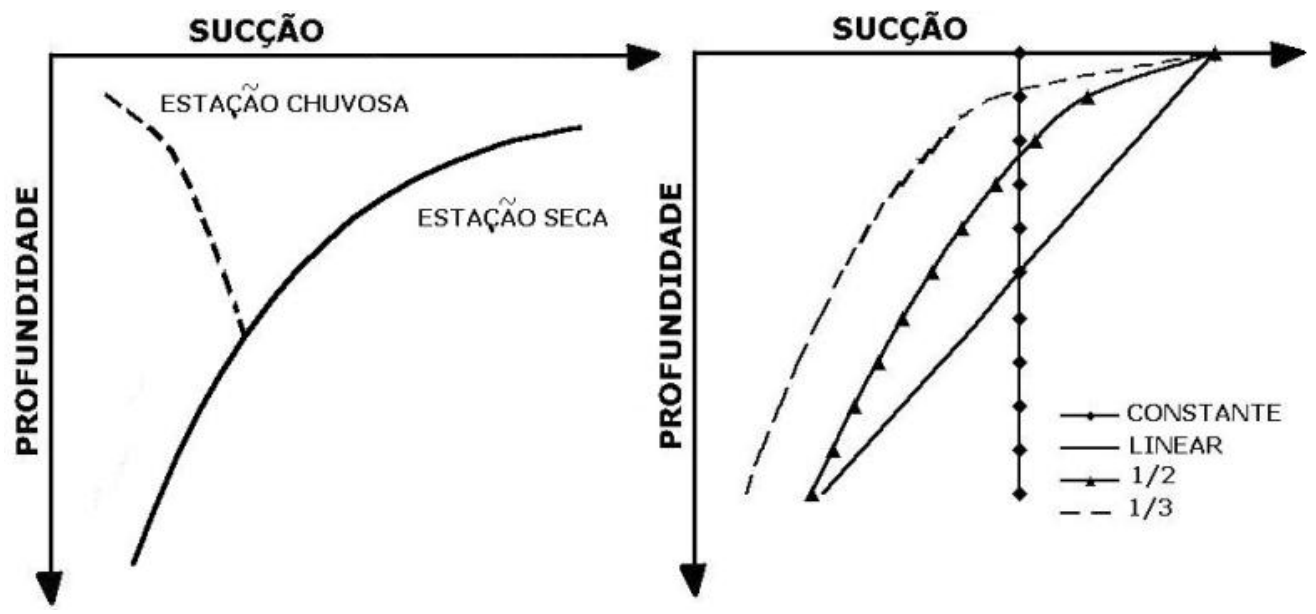

Figura 11. a) Esquema da distribuição da sucção versus profundidade. b) Esquema de ajuste de perfil de sucção para Fator de Segurança igual a um (CAMPOS, 1985). 
KHRAN (1989) demonstra o efeito da sucção matricial na estabilidade "superficial" de taludes em solo. Este trabalho apresenta caso real de taludes laterais de base de ferrovia, construídos com silte lacustrino, em baixas declividades, que se tornaram instáveis após muitos anos de sua construção. Segundo o autor, com o decorrer do tempo a resistência diminuiu com a dissipação das pressões neutras negativas presentes na construção deflagrando os escorregamentos. Foram efetuadas medidas de sucção matricial em campo com tensiômetros, e ensaios laboratoriais para a determinação dos parâmetros de resistência segundo a envoltória de resistência proposta por FREDLUND et al. (1978). A partir da adoção de um perfil de sucção homogêneo para o talude, a análise da estabilidade mostra a sensibilidade da superfície do talude a variações da coesão total do solo, e consequentemente das variações da sucção matricial atuante.

WOLLE \& HACHICH (1989) concluem através de retroanálise de rupturas de taludes nas escarpas da Serra do Mar que a redução da sucção matricial do solo coluvionar superficial foi a principal causa destas instabilizações. Para tanto foram efetuados ensaios laboratoriais (ABRAMENTO \& CARVALHO, 1989), que conduziram a uma envoltória de resistência ao cisalhamento com crescimento potencial da coesão total com a sucção matricial, e medidas com tensiômetros em campo (ABRAMENTO \& CARVALHO, 1989). O perfil de sucção foi adotado como sendo homogêneo e a infiltração da precipitação no solo foi considerada segundo a proposta de LUMB (1975), para que fosse possível a determinação de uma correlação precipitação/deslizamento.

ALONSO et al. (1995) apresentam análise de estabilidade de talude em solos não saturados utilizando modelo acoplado que leva em consideração deformações derivadas da alteração do estado de tensões e de sucção. O perfil de sucção inicial (pré-ruptura) foi assumido em equilíbrio com o nível d'água (hidrostático) e a envoltória de resistência adotada foi a proposta por FREDLUND et al. (1978). O processo de infiltração devido à precipitação foi simulado considerando os efeitos da saturação parcial e resolvendo simultaneamente as equações de condutividade de ar, de água e equilíbrio mecânico. Este trabalho apresenta ainda uma análise paramétrica que avalia a influência de diversos fatores na estabilidade do talude, tais como tipo 
de solo (areia, silte ou argila), a intensidade de precipitação, e a graduação do solo. Dentre as conclusões apresentadas vale a pena ressaltar:

Podem ocorrer combinações específicas de condutividade hidráulica e intensidade de precipitação que conduzem a decréscimos do fator de segurança mesmo após o término da precipitação, independente do tipo de solo, como se pode verificar na Figura 12a;

- Quanto mais siltoso o solo que compõe o talude, mais demorada é a redução do Fator de Segurança;

- Quanto mais mal graduado o solo que compõe o talude, mais rápida é a redução do Fator de Segurança, como se pode verificar na Figura $12 b$.
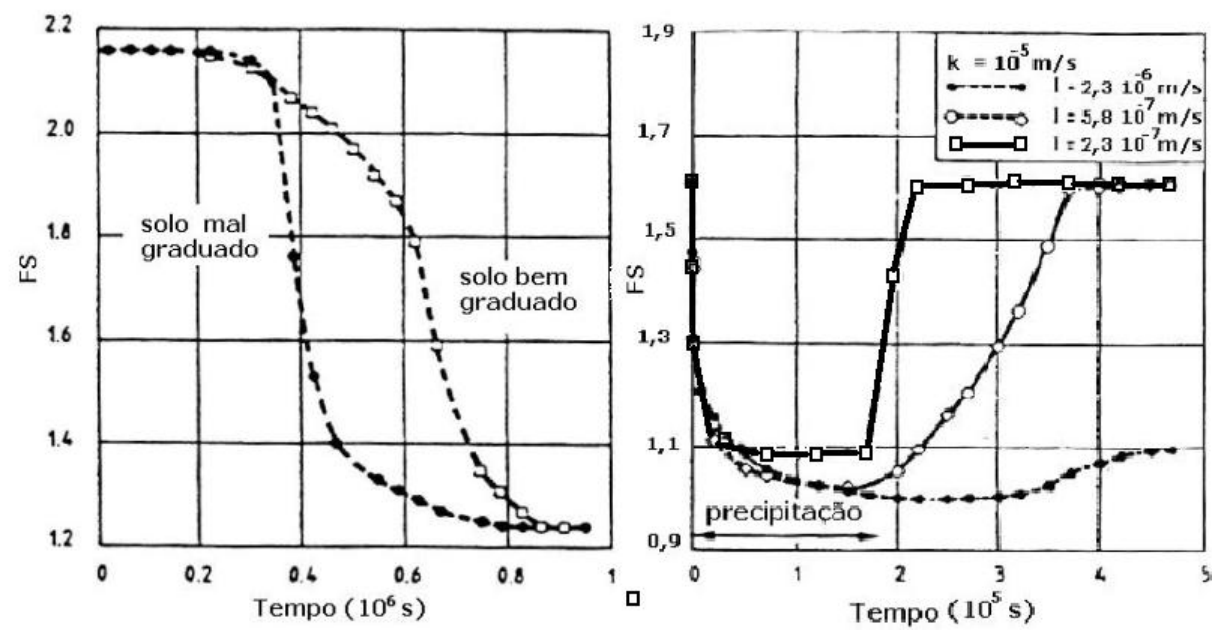

Figura 12. a) Redução do fator de segurança de talude composto por solo arenoso sujeito a diferentes intensidades de precipitação. b) Redução do fator de segurança de talude composto por solos de diferente graduação (ALONSO et al., 1995).

SHIMADA et al. (1995) apresenta uma análise de estabilidade utilizando um modelo "mola-corpo rígido" proposto por KAWAI \& TOI (1977) apud SHIMADA et al (1995), que avalia a energia de deformação armazenada nas molas componentes do sistema, e emprega o critério de resistência de Coulomb e lei de fluxo associado para a relação plástica constitutiva. O desempenho deste método é comparado com o método de Bishop simplificado apresentando fator de segurança muito próximo, para os mesmo parâmetros de resistência e superfície de ruptura. Os parâmetros $c$ e $\phi$ foram assumidos variáveis com a sucção e extraídos da literatura a partir de 
ESCARIO et al. (1986). O perfil de sucção inicial foi adotado como sendo homogêneo ao longo de todo talude. A análise de sensibilidade do modelo de estabilidade apresentado analisa a influência da função condutividade hidráulica, da curva de retenção e de diferentes intensidades de precipitação na estabilidade de taludes. Para a análise da influência dos dois primeiros fatores foram utilizados três tipos de solo: Solo A - mais arenoso, Solo B - mais siltoso e Solo C solo fictício com a função condutividade hidráulica (pontos claros) do Solo A e a curva de retenção (pontos escuros) do Solo B, como apresentado na Figura 13.

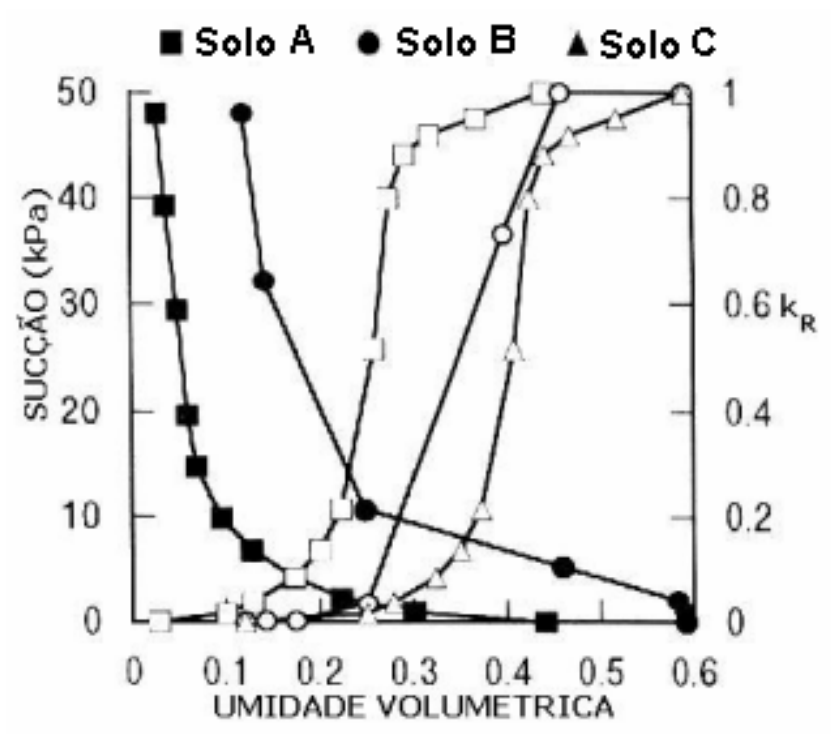

Figura 13. Curva de Retenção e Função Condutividade Hidráulica dos Solos A (arenoso), B (siltoso) e C (fictício). (SHIMADA et al., 1995)

Conforme apresentado, nota-se que existe diferença entre as funções condutividade hidráulica dos solos A e C, contrariando a explicação do autor. Neste caso, aparentemente, a função condutividade do solo $\mathrm{C}$ foi deslocada para que sua pressão de entrada de ar fosse nula, compatibilizando assim esta função com a curva de retenção do solo $\mathrm{C}$.

O perfil de pressão uniforme do talude em questão foi adotado como homogêneo, com uma sucção de $47,1 \mathrm{kPa}$ atuando sobre todo o talude.

Dentre as conclusões apresentadas, pode-se ressaltar que, aparentemente, a curva de retenção pouco influencia a redução do fator de segurança do Talude em resposta a infiltração para o modelo estudado, tendo a função condutividade hidráulica influência muito mais marcante. Este comportamento parece estar associado à pequena diferença entre as pressões de entrada de ar para os três tipos de 
solo, ou seja, as relações entre a pressão de entrada de ar e a sucção inicial nos três tipos de solo são muito próximas, o que permite que a função condutividade hidráulica determine o desenvolvimento do perfil de pressão de água.

A Figura 14 apresenta o comportamento do talude composto pelo solo fictício C, comportamento similar ao talude composto pelo solo B.

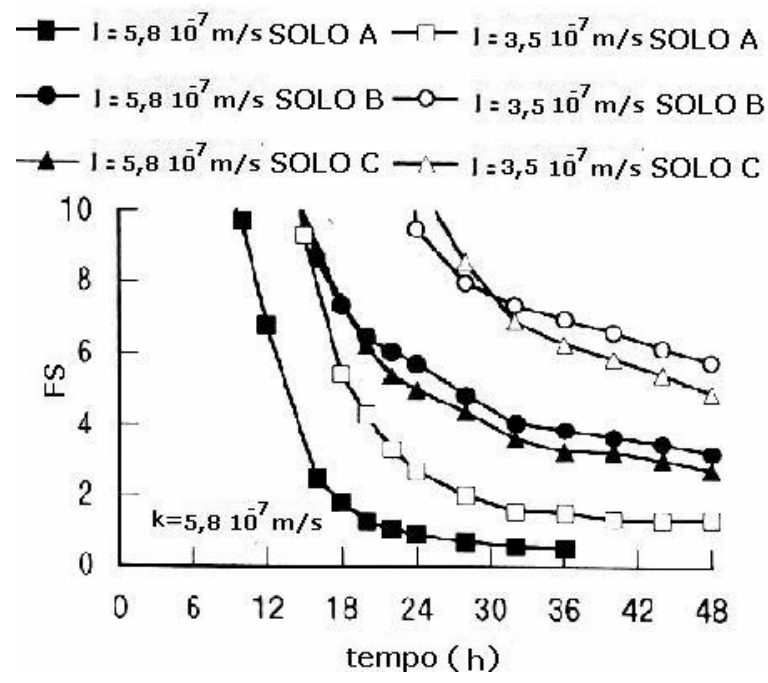

Figura 14. Influência da curva retenção e da função condutividade hidráulica na redução do fator de segurança de taludes devido à infiltração. (SHIMADA et al., 1995)

NG \& SHI (1998) apresentam um estudo paramétrico usando elementos finitos em que avaliam os efeitos de: isotropia e anisotropia na condutividade hidráulica do solo, da posição inicial do nível d'água, da intensidade e da duração de precipitação na estabilidade de talude em solo residual. A envoltória de resistência adotada foi a proposta por FREDLUND et al. (1978). O perfil de sucção inicial adotado é hidrostático, ou seja, linear com a profundidade e em equilíbrio com o nível d'água. Como conclusões relevantes são apresentadas:

A posição inicial do nível d'água é significativa na estabilidade do talude, provavelmente devido à condição de sucção antecedente à precipitação e a geometria particular do perfil apresentado;

As chuvas antecedentes também têm influência significativa na estabilidade do talude;

Para precipitações com mesmo período de retorno, entretanto com intensidade e durações diferentes, as de menor duração (e maior 
intensidade) reduzem mais significativamente o Fator de Segurança que as de maior duração;

O fator de segurança do talude diminui com o decréscimo da condutividade hidráulica, porém para os solos altamente permeáveis esta influência é pequena se comparada com a influência da intensidade da precipitação;

O fator de segurança é extremamente sensível a anisotropia, decrescendo com o acréscimo da relação $K_{X} / K_{Y}$.

GASMO et al. (2000) desenvolvem um estudo numérico da infiltração de precipitação em um talude para determinar a porção de uma chuva aplicada que se torna infiltração, e como a taxa de infiltração varia com a intensidade de precipitação, tempo e localização no talude. Ainda no mesmo trabalho é feito estudo de estabilidade de talude real baseado nas informações obtidas em estudo numérico, instrumentação em campo (tensiômetros) e ensaios laboratoriais (condutividade hidráulica saturada, determinação da curva de retenção e ensaios triaxiais). A partir destas informações é realizada verificação dos resultados obtidos no estudo numérico. Para as diversas camadas de solo componentes do talude, foi adotada a envoltória de resistência proposta por FREDLUND et al. (1978). O perfil de sucção foi modelado a partir dos dados obtidos pelos tensiômetros, assim como sua evolução com o tempo, entretanto quando da ocorrência de precipitações o modelo matemático de infiltração não produziu estimativas razoáveis para a condição evidenciada pelos tensiômetros. Como conclusões relevantes pode-se ressaltar:

Em análise de fluxo permanente o estudo numérico mostrou que a maior infiltração ocorre na crista do talude, seguido pela face, e então pelo pé do talude;

- Taxas de infiltração maiores que $K_{s}$ são possíveis para intensidades de precipitação altas, justificadas pelo gradiente hidráulico na lei de Darcy, $\mathrm{v}=K_{s} i$ em regime transiente como apresentado na Figura 15; 
A análise de estabilidade, baseada nas medidas de sucção em campo, evidenciou a importância das chuvas antecedentes na redução do fator de segurança para o caso estudado (talude em solos com condutividade hidráulica baixa, $K_{s}<10^{-6} \mathrm{~m} / \mathrm{s}$ ).

Os resultados encontrados por GASMO et al. (2000) com taxas de infiltração superiores a $K_{s}$, parecem não estar condicionados pela geometria do problema, uma vez que a geometria do talude analisado é simples e os resultados são similares para diversas regiões analisadas no talude (crista, face e pé).

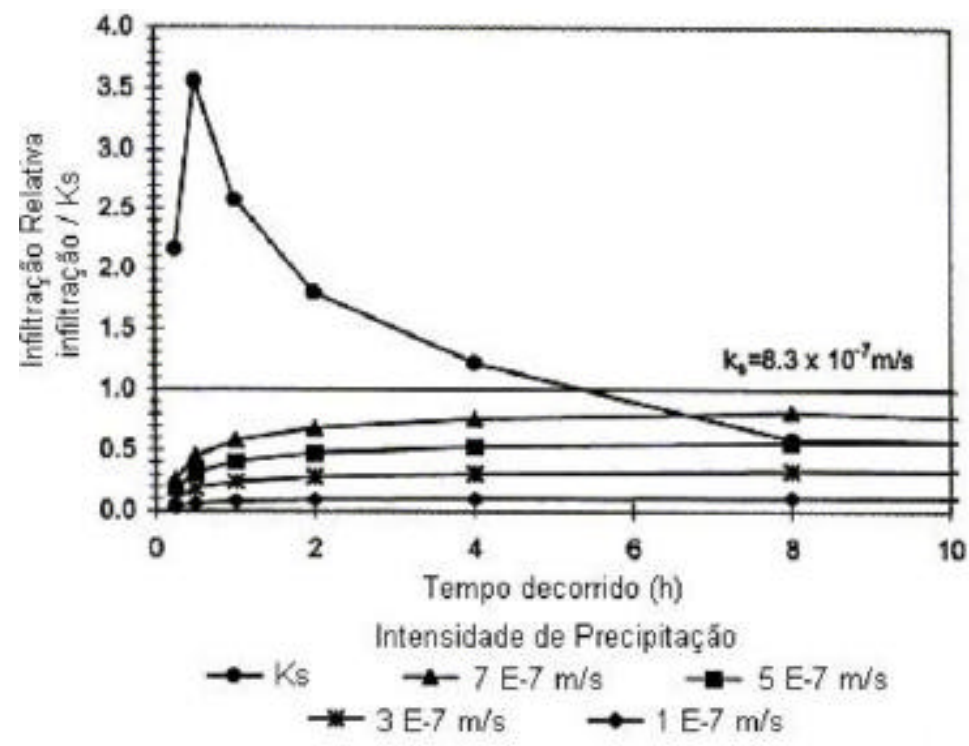

Figura 15. Resultados de Análise Transiente de Infiltração (GASMO et al., 2000).

CALLE (2000) desenvolve uma análise paramétrica para avaliar o efeito da precipitação na estabilidade de um talude que sofreu ruptura. A partir de ensaios laboratoriais e de campo foram avaliadas características hidrológicas e de resistência do solo. Para as camadas de solo componentes do talude, foi adotada a envoltória de resistência proposta por FREDLUND et al. (1978). O perfil de sucção inicial adotado foi ajustado a partir dos valores máximos de sucção obtidos por tensiômetros no local da ruptura e do nível d'água assumido em profundidade. Este trabalho apresenta valores de sucção de até $60 \mathrm{kPa}$ observados pelos tensiômetros na região de São Carlos (SP) e indica que os taludes desta região, que tipicamente apresentam-se com declividades altas $\left(>60^{\circ}\right)$, são estáveis devido à contribuição da sucção para a resistência ao cisalhamento. 
CHO \& LEE (2001) analisam o mecanismo de ruptura de talude por meio de análise acoplada de fluxo e deformação. Foi adotada a envoltória de resistência proposta por FREDLUND et al. (1978). O perfil de sucção inicial adotado é hidrostático até que seja atingido o valor de $60 \mathrm{kPa}$, a partir do qual o perfil de sucção é assumido constante até atingir a superfície. O talude analisado foi submetido a uma precipitação de $20 \mathrm{~mm} / \mathrm{h}$ durante 66 horas. Os autores argumentam, a partir da análise da trajetória de tensões em diferentes elementos discretizadores do talude, que se a condutividade hidráulica do solo componente do talude é pequena comparada com a taxa de infiltração, rupturas rasas superficiais são esperadas em curto intervalo de tempo, como apresentado pelas Figuras 16 a) e b) e pela Figura 17. Ao contrário, se a condutividade hidráulica é suficiente para permitir uma infiltração significativa então rupturas profundas podem ocorrer em tempo relativamente grande após a precipitação. O trabalho apresenta ainda a comparação de rupturas com forma definida (circular) e com forma qualquer, concluindo que análises partindo de rupturas circulares podem incluir rupturas localizadas, superestimando o fator de segurança do talude.
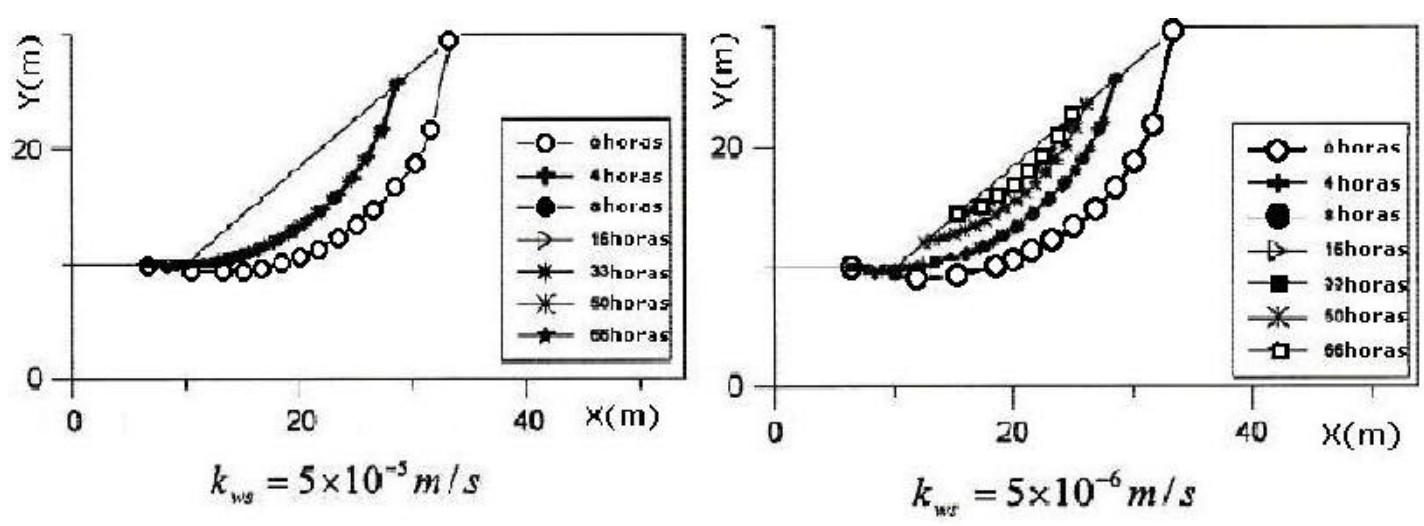

Figura 16. a) Superfícies de Ruptura de Talude sujeito à infiltração, $k_{s}=5 E-5 \mathrm{~m} / \mathrm{s}$, precipitação de $20 \mathrm{~mm} / \mathrm{h}$. b) Superfícies de Ruptura de Talude sujeito à infiltração, $k_{s}=5 E-6 \mathrm{~m} / \mathrm{s}$, precipitação de $20 \mathrm{~mm} / \mathrm{h}$. (CHO \& LEE, 2001). 


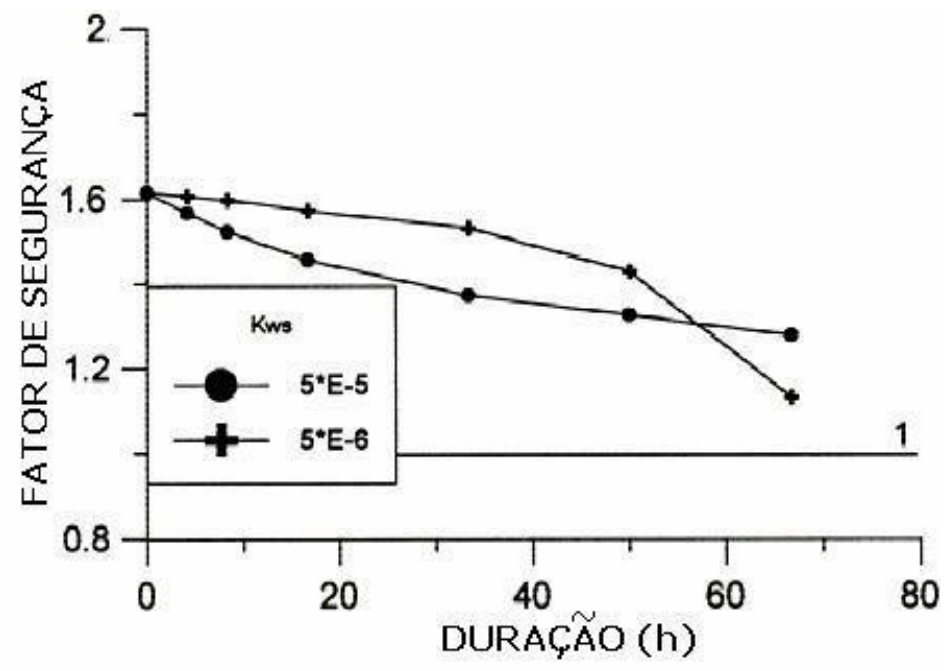

Figura 17. Influência da condutividade hidráulica saturada na redução do fator de segurança de taludes sujeitos a infiltração (CHO \& LEE, 2001).

MERIGGI et al. (2002) desenvolvem análise paramétrica da estabilidade de taludes compostos por solos coluvionares em que a influência da geometria das camadas constituintes do talude e a influência da condutividade hidráulica são analisadas. Para tanto, foi adotada a envoltória de resistência proposta por FREDLUND et al. (1978). O perfil de sucção inicial adotado é proporcional à distância do substrato rochoso, assumido como determinante do nível d'água. Assim devido às configurações geométricas, a crista do talude, com maiores valores de sucção, apresenta menor condutividade hidráulica inicial que o restante do talude. As análises dos fatores mencionados na estabilidade dos taludes em questão foram desenvolvidas a partir de fluxo transiente em que a precipitação foi dividida em dois eventos: precipitação antecedente de 24 horas com pequena intensidade e evento crítico de mesma duração, entretanto com intensidade de precipitação 10 vezes maior que o anterior. Dentre as conclusões apresentadas, pode-se ressaltar:

Para mesma intensidade de precipitação, taludes compostos por solos com condutividade hidráulica intermediária atingem a ruptura mais rapidamente que os compostos por solos com condutividade hidráulica alta;

O tipo de ruptura depende da geometria do talude, de forma que para solos mais permeáveis a ruptura global ocorre devido a rupturas localizadas no pé do talude; 
Se a condutividade hidráulica é menor que a intensidade de precipitação, o solo absorve apenas parte da água da chuva e a infiltração ocorre em condições mais favoráveis para a estabilidade do talude;

A geometria do talude influencia o processo de infiltração e consequentemente a estabilidade. A redução da espessura de solo no pé do talude é maior, o aumento mais lento do nível d'água permite que o talude permaneça estável por mais tempo. 


\section{3 - MATERIAIS E MÉTODOS}

Para garantir que a análise paramétrica realizada neste trabalho possa ser reproduzida, além de permitir a continuidade de pesquisas com mesma orientação que esta, serão apresentadas as hipóteses adotadas, suas principais implicações e limitações, assim como uma breve descrição dos programas utilizados, além das principais dificuldades encontradas no decorrer da modelagem do problema.

\section{1 - Materiais}

As condições e hipóteses utilizadas neste trabalho podem ser divididas da seguinte forma:

- $\quad$ Características do talude

- $\quad$ Características dos solos

- $\quad$ Características da precipitação

- $\quad$ Hipóteses de análise de estabilidade

\subsection{1 - Características do talude}

Para a realização da análise paramétrica foi utilizado um único talude de referência com geometria fixada conforme a inclinação típica para taludes em areia argilo siltosa, característica do Centro-Oeste do estado de São Paulo (Fig.18): 


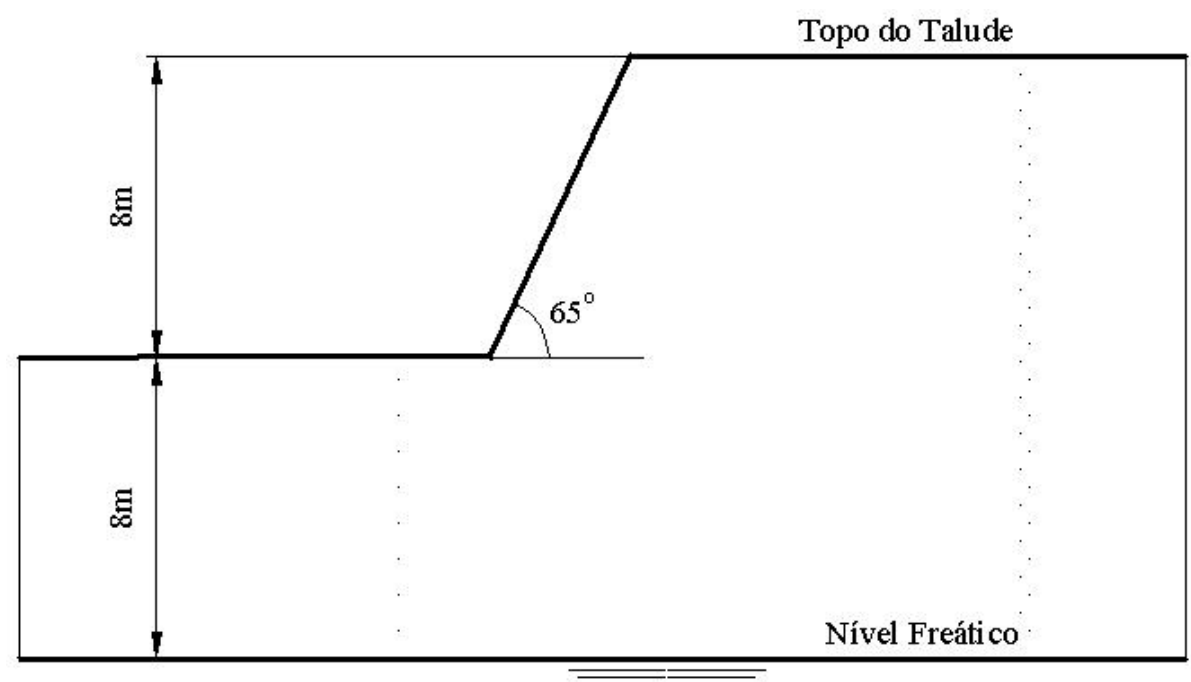

Figura 18. Geometria do talude de referência, conforme inclinação típica para taludes em areia argilo siltosa característica do Centro-Oeste do estado de São Paulo.

O talude de referência é composto por um único tipo de solo homogêneo e isotrópico.

O nível freático inicial foi adotado como posicionado a uma profundidade igual a altura do talude, ou seja, a 8 metros de profundidade (Figura 18).

O perfil de sucção inicial (pré-precipitação - Figura 19), válido para todos os tipos de solos utilizados na análise paramétrica, foi adotado como estabilizado e obtido para a condição em que ocorresse equilíbrio entre o nível freático e a condição de sucção de $50 \mathrm{kPa}$ na superfície do talude, condição verificada como freqüente por CALLE (2000) na região de São Carlos (Fig.20).

Para a obtenção dos perfis de pressão de água, inicial e no talude sujeito à precipitação, foi utilizado o programa SEEP/W. A modelagem do problema de fluxo, bem como a descrição do programa SEEP/W serão apresentadas no item 3.2.1. 


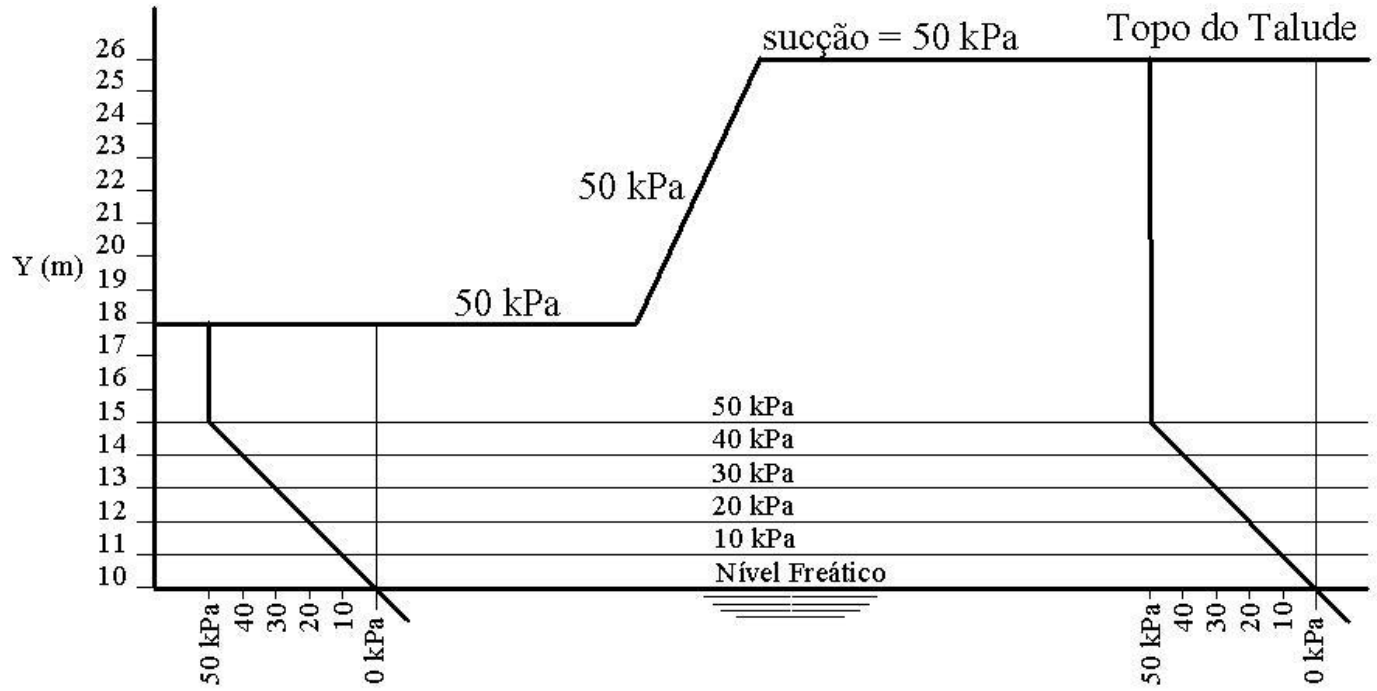

Figura 19. Perfil de sucção inicial (antes da precipitação).
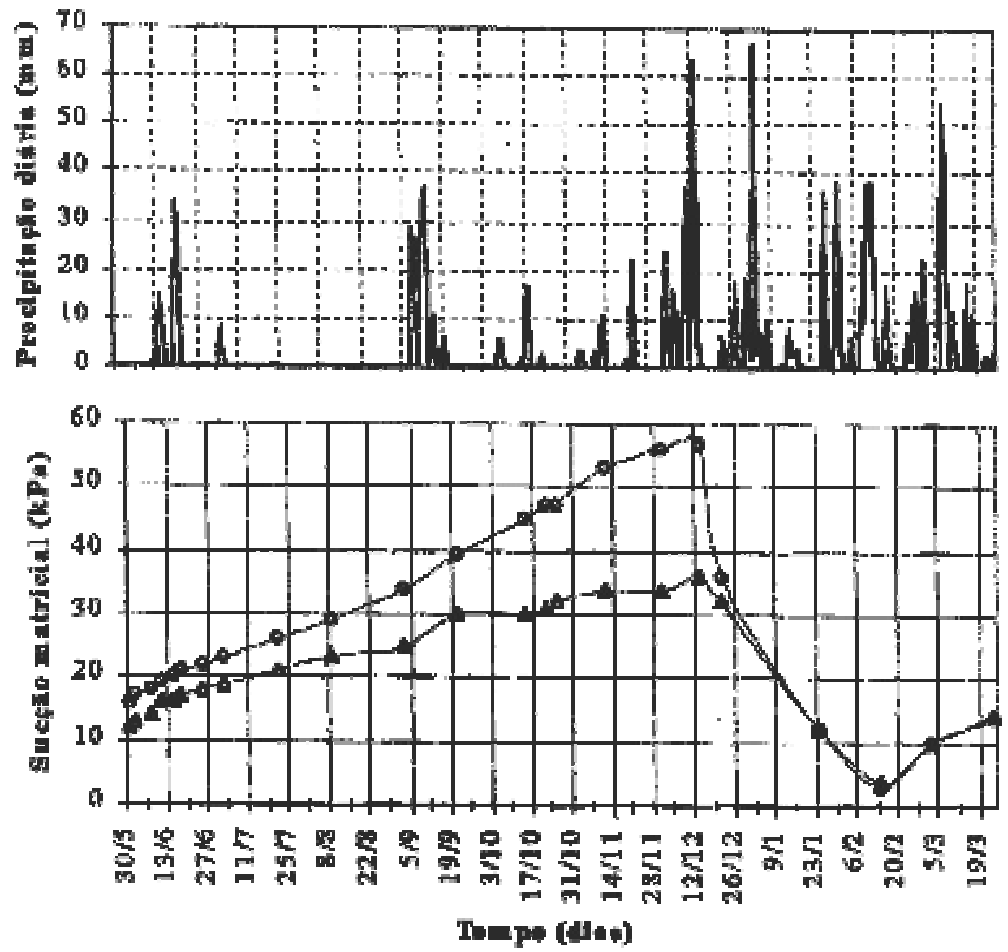

Figura 20. Precipitação diária e sucções de campo obtidas por CALLE (2000). 


\subsection{2 - Características dos solos}

$\mathrm{Na}$ análise paramétrica, foram analisados casos do talude de referência compostos por diferentes tipos de solo:

- $\quad$ Solo A: Areia

- $\quad$ Solo B: Silte argiloso

- $\quad$ Solo C: Areia argilo siltosa

Para reduzir o número de parâmetros analisados e obter melhor controle sobre o comportamento estudado foram adotados os mesmos índices físicos e os mesmos parâmetros de resistência para os três tipos de solos como apresentado na Tabela 1.

Além disto, não foi considerada variação no peso específico devido ao acréscimo de água no solo, ou seja o peso específico durante o umedecimento é igual ao peso específico aparente (condição natural);

Assim estes solos diferenciam-se apenas por sua função condutividade hidráulica, condutividade hidráulica saturada e curva de retenção.

O modelo de resistência do solo não saturado adotado foi o de FREDLUND et al. (1978), conforme apresentado no item 2.4.

Tabela 1: Parâmetros dos solos analisados

\begin{tabular}{|c|c|c|c|}
\hline Solo & A: Areia & B: Silte argiloso & C: Areia argilo siltosa \\
\hline$\theta_{\mathrm{s}}\left(\mathrm{m}^{3} / \mathrm{m}^{3}\right)$ & 0,534 & 0,534 & 0.534 \\
\hline$\gamma\left(\mathrm{kN} / \mathrm{m}^{3}\right)$ & 17 & 17 & 17 \\
\hline$c^{\prime}, \phi^{\prime}$ & & $5 \mathrm{kPa}, 35^{\circ}$ & \\
\hline$\phi_{\mathrm{b}}$ & & $20^{\circ}$ & \\
\hline Curva de retenção & A & $\mathrm{B}$ & $\mathrm{C}$ \\
\hline $\begin{array}{c}a ; m ; n\left(R^{2}\right) \\
\text { (FREDLUND \& XING, 1994) }\end{array}$ & $\begin{array}{c}6,9 ; 0,155 ; 18,66 \\
(0,9912) \\
\end{array}$ & $\begin{array}{c}31,5 ; 0,297 ; 4,37 \\
(0,9949) \\
\end{array}$ & $\begin{array}{c}1,3 ; 0,366 ; 2,65 \\
(0,9982) \\
\end{array}$ \\
\hline $\mathrm{k}(\theta)$ & A & $\mathrm{B}$ & $\mathrm{C}$ \\
\hline $\mathrm{k}_{\mathrm{s}}(\mathrm{m} / \mathrm{s})$ & $1 \mathrm{E}-6 \quad 5 \mathrm{E}-6 \quad 5 \mathrm{E}-7 \quad 5 \mathrm{E}-5$ & $1 \mathrm{E}-9 \quad 1 \mathrm{E}-8 \quad 1 \mathrm{E}-7 \quad 1 \mathrm{E}-6$ & $1 \mathrm{E}-7$ \\
\hline
\end{tabular}

As curvas de retenção (Fig.21), função condutividade hidráulica (Fig.22) dos solos A (areia) e B (silte argiloso) foram retiradas do banco de dados do programa SEEP/W. Os solos A e B, ainda segundo esta base de dados, foram retirados dos trabalhos de HO (1979) e Bruch (1993) respectivamente. 


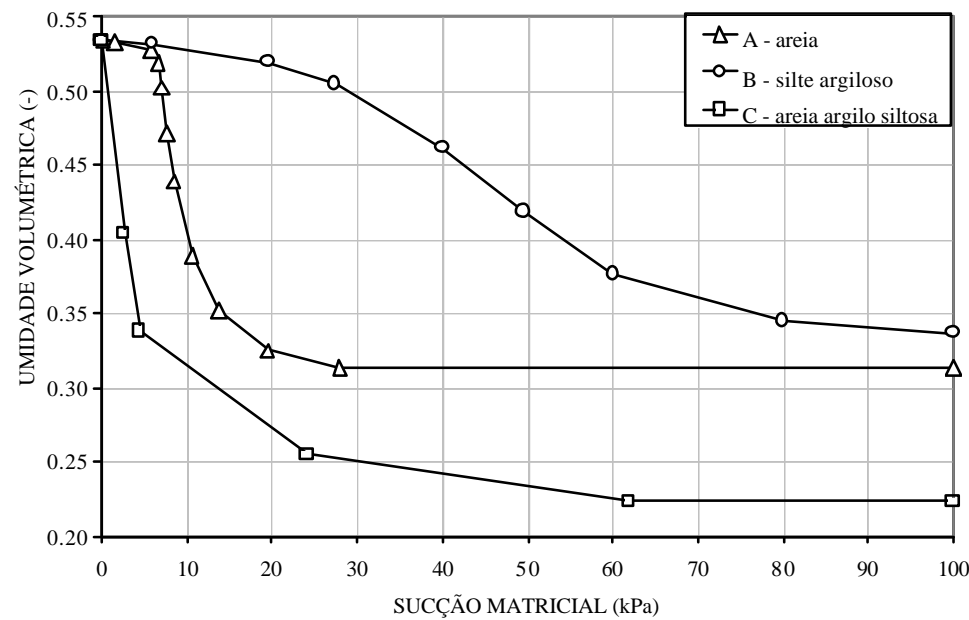

Figura 21. Curva de Retenção - Areia, silte e areia argilo siltosa.

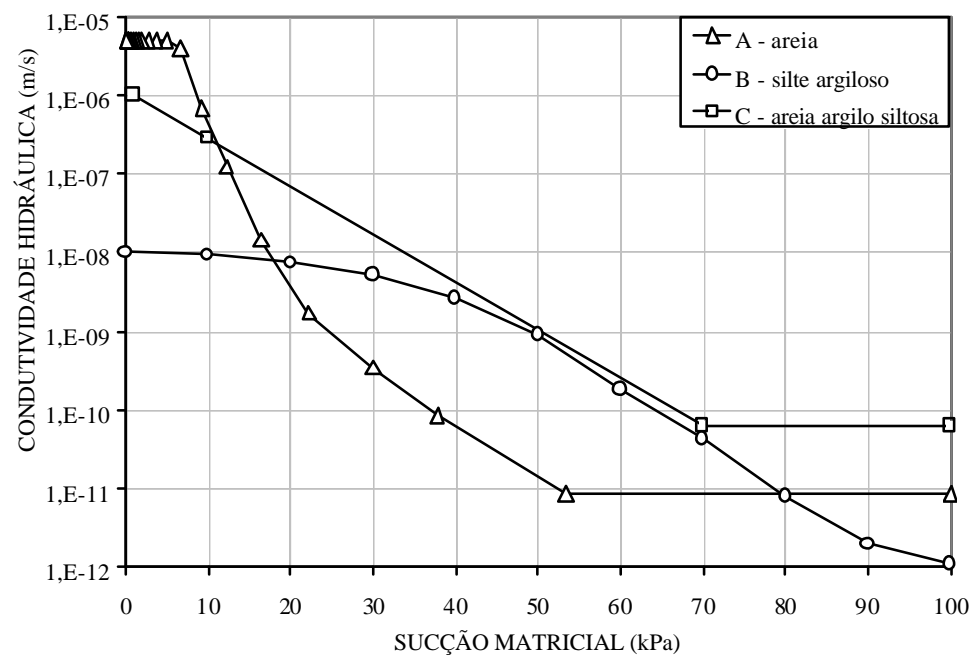

Figura 22. Função condutividade hidráulica - Areia, silte e areia argilo siltosa.

O solo C é um solo real da Região de São Carlos para o qual, a inclinação de talude mencionada é corrente, e teve sua curva de retenção (Fig.21) e função condutividade hidráulica (Fig.22) determinadas por CALLE (2000).

Para ressaltar as peculiaridades deste material em suas condições naturais, e caracterizar melhor o problema de infiltração no talude de referência é apresentada uma descrição geotécnica detalhada do mesmo.

\subsubsection{1 - Solo C - Areia argilo siltosa}

O solo da região de São Carlos pode ser caracterizado como um sedimento cenozóico originado a partir do retrabalhamento dos materiais do Grupo Bauru e das 
formações Serra Geral e Botucatu. Devido às condições climáticas, estes sedimentos se apresentam laterizados, com altas concentrações de óxidos e hidróxidos de ferro e alumínio. Logo abaixo destes sedimentos encontram-se solos residuais de arenitos do Grupo Bauru, os quais, muitas vezes, se separam dos sedimentos por uma linha de seixos, freqüentemente encontrada nas profundidades entre seis e oito metros. (MACHADO, 1998)

Sua granulometria é predominantemente arenosa, refletindo certa correspondência com seu grau de hterização e a litologia recoberta (mais siltosa e argilosa sobre siltitos, argilitos e proximidades de rochas basálticas). (IPT, 1991)

CALLE (2000) apresenta ensaios de caracterização deste sedimento, realizados em amostras retiradas em talude situado na rodovia SP - 318, $\mathrm{km} \mathrm{216:}$

$$
\begin{aligned}
& \gamma_{\text {natural }}=16 \mathrm{kN} / \mathrm{m}^{3} \\
& \mathrm{LL}=32 \text { a } 44 \% \\
& \mathrm{LP}=20 \text { a } 24 \% \\
& \gamma_{\mathrm{s}}=29 \mathrm{kN} / \mathrm{m}^{3}
\end{aligned}
$$

Segundo o Manual de Orientação para diagnóstico e soluções de problemas de taludes em rodovias do DER (IPT, 1991), este solo por apresentar uma porcentagem de argila consideravelmente elevada, deveria ser bastante impermeável. Entretanto, em seu estado natural, ele se encontra com índice de vazios elevado e com partículas agregadas de tal forma que se formam macroporos, pelos quais a água flui com maior facilidade. É freqüente que no estado natural estes solos apresentem coeficiente de condutividade hidráulica da ordem de $10^{-5} \mathrm{~m} / \mathrm{s}$. Se a estrutura for desfeita mecanicamente e o solo for recolocado com mesmo índice de vazios, a condutividade passa a ser da ordem de $10^{-7} \mathrm{~m} / \mathrm{s}$. Se este mesmo solo for compactado na sua massa específica seca máxima, a condutividade ficará entre $10^{-8}$ e $10^{-9} \mathrm{~m} / \mathrm{s}$.

\subsection{3 - Características da precipitação}

Nas análises de fluxo transiente foram utilizadas as seguintes intensidades de precipitação: 1, 20 e $70 \mathrm{~mm} / \mathrm{h}$ ou $2 . .7$ E-7, 5.6 E-6 e 1.9 E-5 m/s respectivamente. 
Estas intensidades foram consideradas como constantes ao longo de todo o decorrer de cada evento de precipitação.

A precipitação foi aplicada igualmente sobre todo o talude (topo, face e pé), sendo que foi considerado que o volume precipitado que não infiltra escoa pela superfície instantaneamente, ou seja, não ocorre a formação de poças. O método para que esta condição de fluxo fosse simulada será descrito no item 3.2.1 (Descrição do Programa SEEP/W).

Para melhor situar os eventos de precipitação estudados à realidade local são apresentadas as seguintes informações para a Região de São Carlos:

Dados do posto D4-075 - São Carlos (DAEE)

- $\quad$ Índice pluviométrico anual: $~ 1350 \mathrm{~mm} / \mathrm{ano}$

- $\quad$ Máximos mensais: $\quad 550 \mathrm{~mm} / \mathrm{mês} \mathrm{(Janeiro} \mathrm{ou} \mathrm{Fevereiro)}$

- $\quad$ Equação de chuva (RIGHETO, 1998):

$$
I=\frac{1519 . T^{0,236}}{(d+16)^{0,935}}
$$

Onde:

$I$ : intensidade de precipitação $(\mathrm{mm} / \mathrm{h})$;

$T:$ Tempo de Retorno (anos) e;

$d$ : duração (min).

A partir da Equação 16, a Tabela 2 apresenta as durações $(d)$ para as intensidades de precipitação $(I)$ utilizadas na análise paramétrica em alguns tempos de Retorno ( $T$ ): 
Tabela 2: Duração da precipitação para alguns Tempos de Retorno a partir da Equação de chuva para a região de São Carlos

\begin{tabular}{|c|c|c|c|c|}
\hline & \multicolumn{4}{|c|}{ durac̃ão (min) } \\
\hline $\mathrm{I}(\mathrm{mm} / \mathrm{h})$ & $\mathrm{T}=1$ ano & $\mathrm{T}=5$ anos & $\mathrm{T}=10$ anos & $\mathrm{T}=20$ anos \\
\hline 1 & 2512 & 3779 & 4504 & 5368 \\
\hline 20 & 87 & 138 & 168 & 203 \\
\hline 70 & 11 & 24 & 32 & 41 \\
\hline
\end{tabular}

\subsection{4 - Hipóteses da análise de estabilidade}

Para análise de estabilidade do talude de referência, foi utilizado o método proposto por BISHOP (1955), conhecido como método de Bishop simplificado. Este método é classificado como um método de fatias, pois divide a massa acima da superfície de ruptura, no caso circular (Fig. 23a), em fatias para efeito de integração numérica.

Os esforços atuantes em uma fatia genérica são apresentados na Figura 23, sendo $W_{i}$, seu peso; $S i$, a força cisalhante na base da fatia $\left(S_{i}=\tau_{i} l\right.$, onde $\tau_{I}$ é a tensão cisalhante na base da fatia e $l$ é a largura da base da fatia); $P^{\prime}{ }_{i}$, a força normal efetiva na base da fatia; $U i$, a força devida à pressão neutra na base da fatia; $X$, a componente vertical da força lateral e $E$, a componente horizontal da força lateral, como apresentado na Figura 23b.
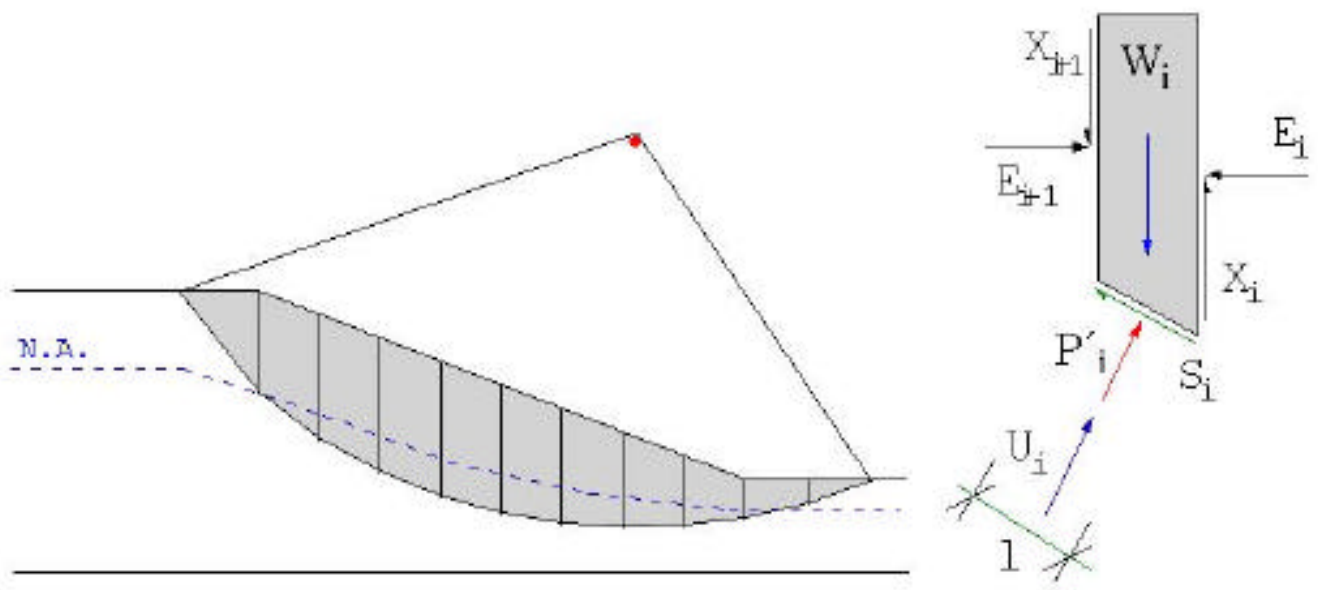

Figura 23. a) Superfície de ruptura para o método das fatias b) Esforços em uma fatia. 
Nos métodos das fatias, o fator de segurança é definido como a razão entre a tensão cisalhante de ruptura e a tensão cisalhante atuante na base de cada fatia. $\mathrm{Na}$ maioria destes métodos o fator de segurança é admitido como constante ao longo da superfície de ruptura, o que implica que o valor do fator de segurança que definirá a relação dos esforços na base de uma fatia será representativo da segurança de toda a superfície, ou seja como uma média.

Para determinar o valor do fator de segurança utilizam-se fundamentos da estática, ou seja, o equilíbrio de forças nas duas direções e o equilíbrio de momentos, além do critério de ruptura. O problema é indeterminado, sendo necessárias algumas hipóteses para resolver o problema no caso geral.

No caso do método Bishop Simplificado é admitido que em cada lamela:

$$
\sum\left(X_{i}+X_{i+1}\right)=0
$$

E para a determinação do fator de segurança, as seguintes hipóteses estáticas são verificadas:

$$
\begin{aligned}
& F S=\frac{\sum M R}{\sum M A} \\
& \sum V=0
\end{aligned}
$$

A análise de estabilidade foi realizada utilizando o programa SLOPE/W. Este programa permite importar o perfil de pressões de água obtido na análise de fluxo realizada utilizando o programa SEEP/W. Este perfil é utilizado então para cálculo da contribuição da sucção para a resistência e para o cálculo do Fator de Segurança. 


\section{2 - Métodos}

Com relação aos programas utilizados, as análises de fluxo foram realizadas utilizando o programa SEEP/W (GEO-SLOPE INTERNATIONAL, 1998a) enquanto as análises de estabilidade foram conduzidas utilizando o programa SLOPE/W(GEOSLOPE INTERNATIONAL, 1998b).

No anexo A são apresentadas rotinas para a utilização do programa SEEP/W (DEFINE e SOLVE).

\subsection{1 - Programa SEEP/W}

O programa SEEP/W é um programa de elementos finitos que pode ser utilizado para modelar o movimento e a distribuição de pressão de água dentro de materiais porosos tais como solo e rocha, podendo ser utilizado para modelar tanto o fluxo saturado quanto o fluxo não saturado.

Este programa resolve a equação de Richards para a determinação do fluxo em meios porosos em regimes transiente e permanente. Pode-se ainda utilizar materiais anisotrópicos como constituintes do problema analisado.

Dentre as principais limitações do programa SEEP/W pode-se citar:

- $\quad$ supõe que o solo seja homogêneo;

- $\quad$ é formulado para condição de tensão total constante;

- $\quad$ há dificuldades na convergência de problemas de solos com função condutividade hidráulica com grande declividade (materiais arenosos);

- $\quad$ esta dificuldade também ocorre em problemas com nível de água profundo.

O programa SEEP/W apresenta interface gráfica que opera nas bases Microsoft Windows 95 e Windows NT. Esta interface torna fácil a utilização deste programa, especialmente se o usuário já for familiarizado ao ambiente MS Windows.

O uso do programa SEEP/W compreende as seguintes etapas: 
- Definição do problema (SEEP/W DEFINE)

- definição do espaço de desenho

(tamanho do papel, escala, origem do sistema de coordenadas)

- desenho do problema (esquemas e pano de fundo)

- especificação dos materiais

(curva de retenção e função condutividade hidráulica)

- discretização do problema em elementos finitos

- definição das condições de contorno

- Resolução do problema por processo iterativo (SEEP/W SOLVE)

- Visualização dos resultados (SEEP/W CONTOUR)

(mapas, gráficos, tabelas de valores, superfícies freáticas...)

\subsubsection{1 - Definição do problema (Programa SEEP/W DEFINE)}

O talude estudado foi discretizado segundo a malha de elementos finitos apresentada na Figura 24, onde também está apresentado o sistema de coordenadas utilizado no decorrer deste trabalho. A malha utilizada foi definida com elementos de dimensão de $0.2 \mathrm{~m}$ na direção do fluxo principal (direção y) e $1 \mathrm{~m}$ na outra direção (x). A partir da face do talude até uma distância de 5 metros também foi utilizada uma malha com elementos de 20 centímetros, tendo em vista uma melhor definição do perfil de pressão nesta região.

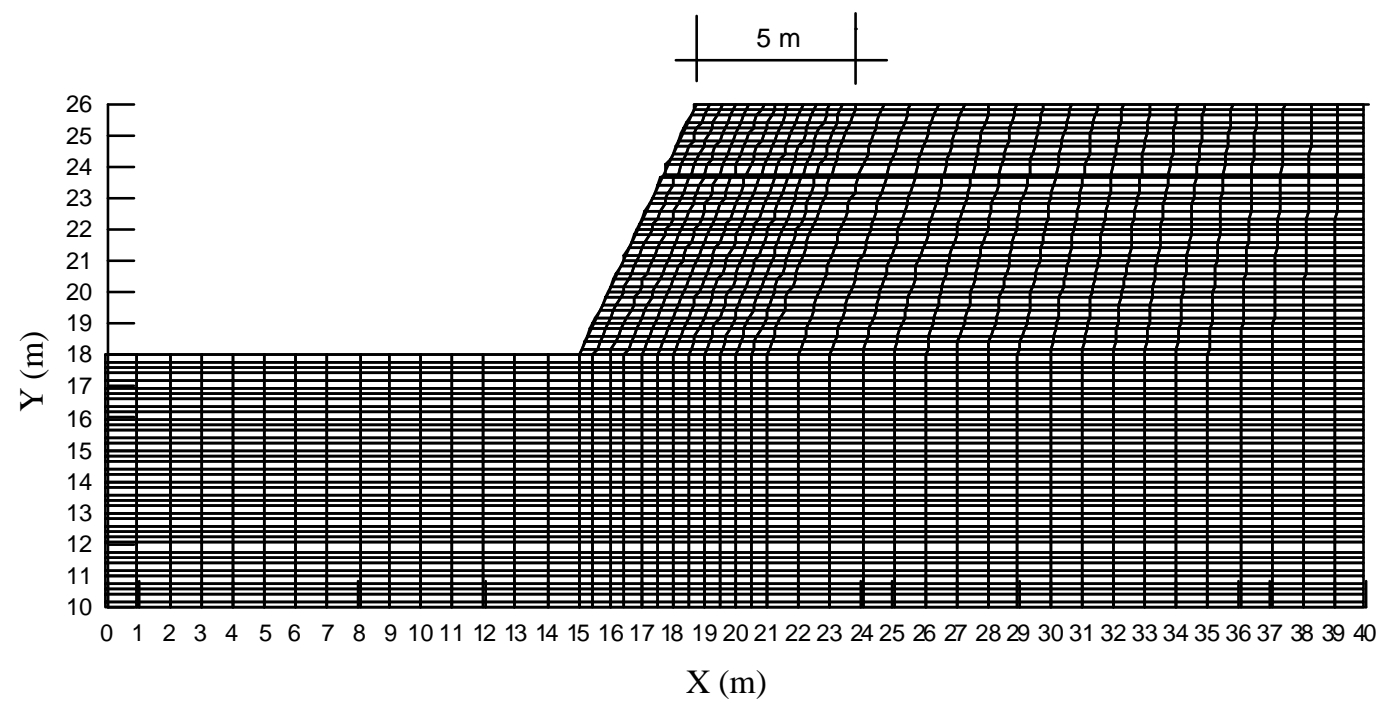

Figura 24. Malha de elementos finitos e sistema de coordenadas utilizado no programa $S E E P / W$ 
Durante a definição do problema, especial atenção deve ser destinada à definição das condições de contorno e na resolução do problema.

$\mathrm{Na}$ análise de fluxo estabilizado, para obtenção do perfil de pressão inicial, foi utilizada uma condição de contorno do tipo $H$ (carga hidráulica total em metros), tendo sido adotado os valores:

- Para $\mathrm{y}=10$ $\mathrm{H}=10$, Nível de água;

- Para nós da superfície $\mathrm{H}=\mathrm{y}-5$, Carga hidráulica total $-\left(50 \mathrm{kPa} / \gamma_{\text {água }}\right)$ com $\gamma_{\text {água }}=10 \mathrm{kN} / \mathrm{m}^{3}$.

O perfil de pressão encontrado na análise de fluxo estabilizado foi utilizado como inicial para as análises de fluxo transiente.

Nas análises de fluxo transiente foi utilizada uma condição de contorno do tipo $q$ (fluxo através de superfície) com a opção de revisão pela pressão máxima. Nestes termos, o fluxo é aplicado de forma a não permitir o desenvolvimento de pressões neutras positivas na superfície de fluxo.

\subsubsection{2 - Resolução do Problema por processo iterativo (Programa SEEP/W SOLVE)}

Segundo artigo disponível no site dos fabricantes do pacote GEO-SLOPE, "o proble ma de modelagem da infiltração em um solo com nível freático profundo pode ser muito desafiador, especialmente quando se lida com solo relativamente grosseiro com uma função condutividade hidráulica com grande declividade”. Este é o caso das funções condutividade hidráulica apresentadas para os solos A (areia) e C (areia argilo siltosa) com queda de até quatro ordens de grandeza na condutividade hidráulica para sucção da ordem de $50 \mathrm{kPa}$. (GEO-SLOPE INTERNATIONAL, 2003a)

Esta dificuldade na modelagem está associada à definição de parâmetros de controle de convergência do processo iterativo de resolução do problema.

Segundo o Manual do usuário do programa SEEP/W (GEO-SLOPE INTERNATIONAL, 2003b): 
"Infelizmente, não há regras rígidas para a seleção de parâmetros que conduzirão a convergência. Normalmente, em caso de difícil convergência, é necessário tentar várias combinações de parâmetros até que uma solução razoável seja atingida".

Nesta análise paramétrica, também foram encontradas tais dificuldades, ilustradas por picos localizados de valores de sucção maiores que os iniciais no solo sujeito à infiltração (Fig. 25).

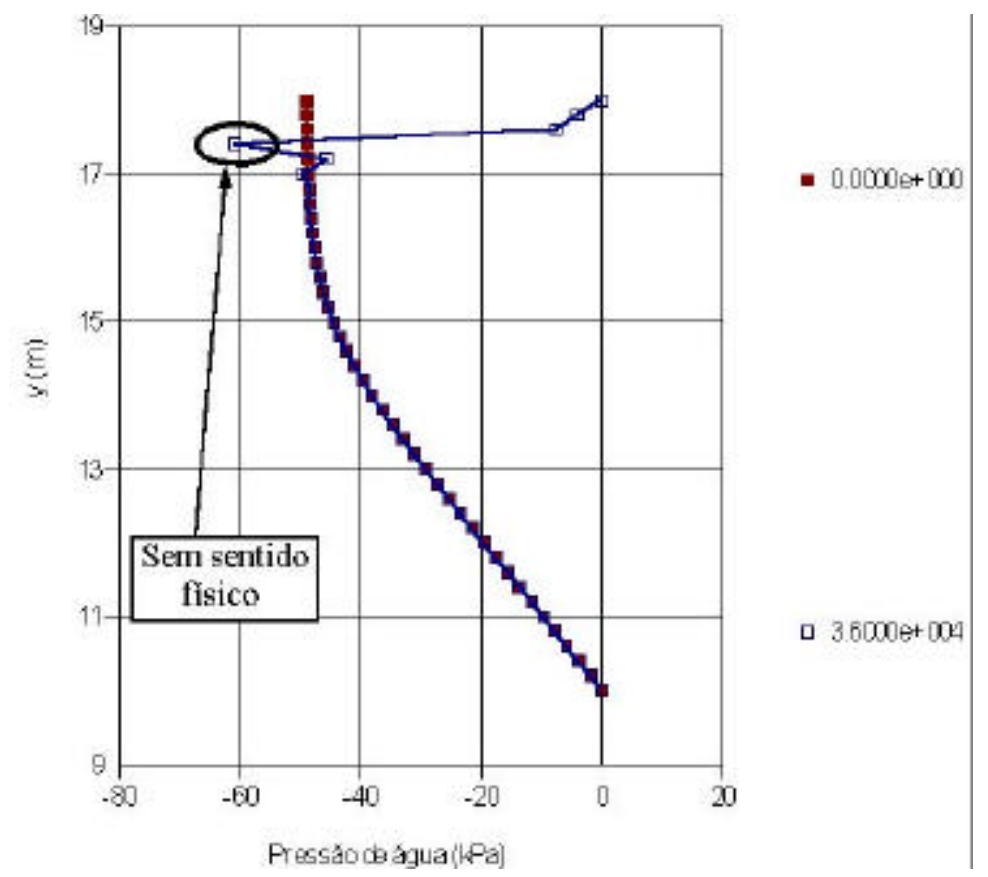

Figura 25. Pontos sem sentido físico em perfis de pressão de água durante a infiltração

O problema foi contornado refinando a malha de elementos finitos tilizada inicialmente, diminuindo assim a importância destes pontos isolados uma vez que a região em que ocorre sua influência também é pequena.

Considera-se que para fins de análise de estabilidade, tal imprecisão tem pouca influência sobre a evolução do Fator de Segurança.

O Anexo B apresenta valores típicos para os parâmetros de convergência utilizados nos diversos casos de fluxo estudados.

\subsection{2 - Programa SLOPE/W}

O Programa SLOPE/W é um programa que utiliza a teoria do equilíbrio limite para calcular o Fator de Segurança de taludes em solo ou rochas. Este programa tem 
a habilidade de modelar diferentes tipos de solo, estratigrafias complexas além de geometrias complexas de superfície de escorregamento, e condições de pressão neutra variáveis utilizando uma grande variedade de modelos de solos.

Para a análise de estabilidade do talude sujeito à infiltração, o programa SLOPE/W permite importar o perfil de pressões de água atuantes no talude, utilizando-o para o cálculo da contribuição da sucção para a resistência e do Fator de Segurança do talude.

O método de análise de estabilidade utilizado foi o método proposto por BISHOP (1955), conhecido como método de Bishop simplificado, já descrito anteriormente.

A livre busca da superfície crítica foi realizada a partir da definição de:

- $\quad$ malha de possíveis centros de rotação da superfície circular (Fig.26);

- $\quad$ linhas que definem o raio da superfície (Fig.26) e;

- $\quad$ limites nos quais a superfície crítica deve estar inserida (Fig.26).

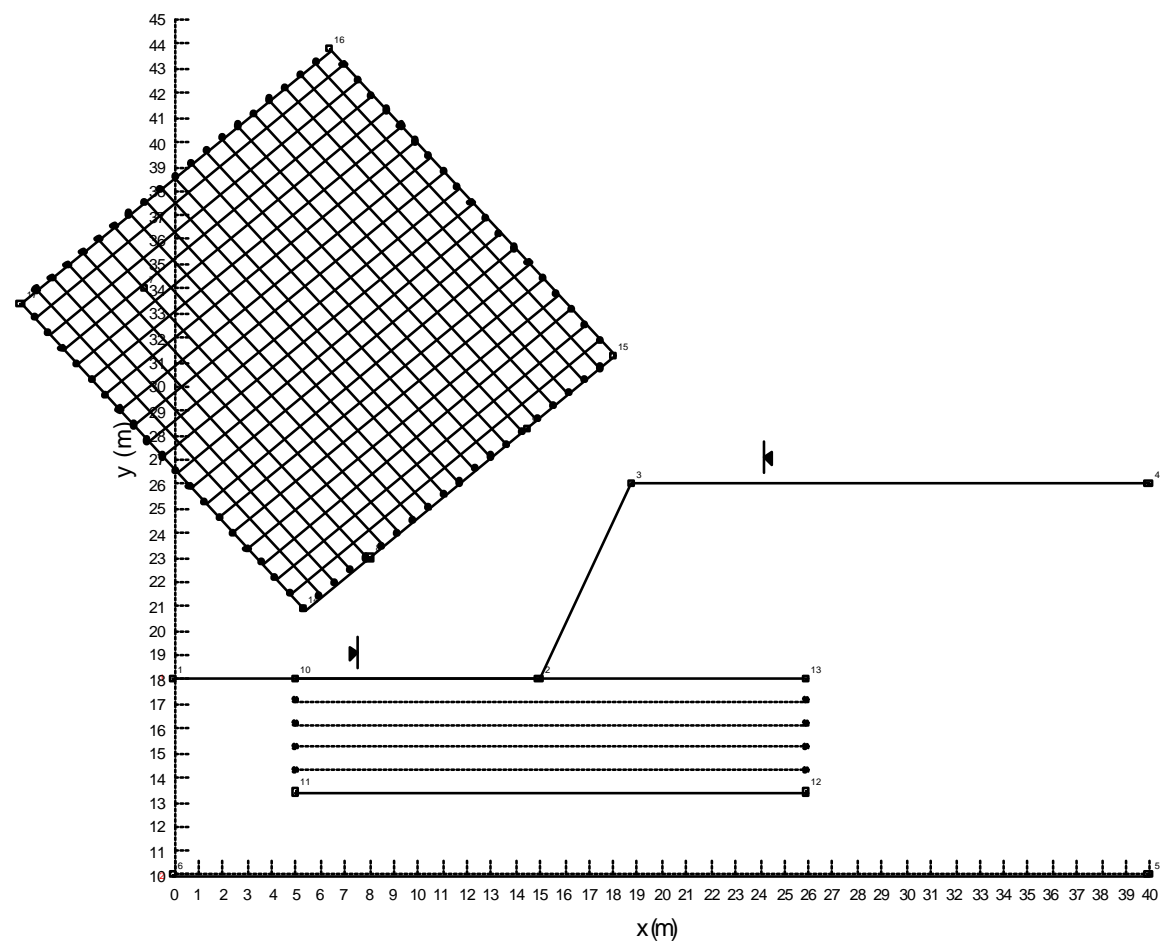

Figura 26. Definição da malha de centros de rotação, raios e limites para busca da superfície crítica circular utilizada no programa SLOPE/W

Por se tratar de programa de fácil utilização, não serão apresentados maiores detalhes ou rotinas de utilização para o programa SLOPE/W. 
Antes da apresentação dos resultados obtidos nas análises de estabilidade, vale a pena discorrer sobre a evolução da pressão de água durante a infiltração, a fim de permitir uma melhor compreensão da variação do Fator de Segurança do talude de referência submetido à precipitação. Assim são apresentados exemplos de perfis de pressão de água no solo do talude sujeito à infiltração, bem como uma análise paramétrica das características do solo que interferem na infiltração.

\section{1 - Perfis de pressão de água durante a Infiltração}

Todos os perfis de pressão apresentados neste item estão associados ao mesmo sistema de coordenadas utilizado na simulação de fluxo do programa SEEP/W, e estão posicionados a 5 metros do topo do talude (Figura 27).

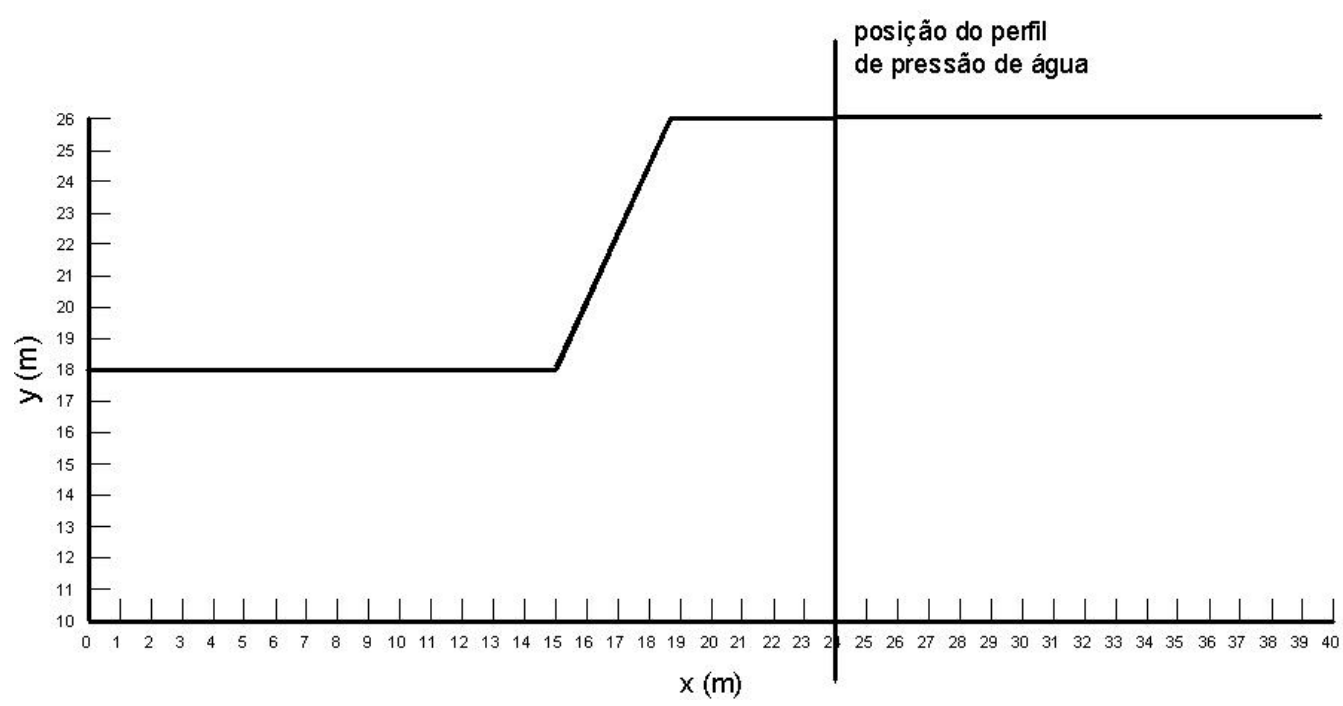

Figura 27. Posição de estudo do perfil de pressão de água nas análises de infiltração 
Esta seção foi selecionada por representar de maneira satisfatória o comportamento do perfil de pressão de água em outras regiões do talude, porém este comportamento observado pode ocorrer em momentos distintos para cada parte do talude (crista, face e pé), uma vez que a distância entre a superfície de fluxo e o Nível freático não é a mesma para todas as regiões do talude.

Para uma análise inicial do avanço da frente de umedecimento, foi adotada a mesma condutividade hidráulica saturada $\left(\mathrm{k}_{\mathrm{s}}=1 \mathrm{E}-6 \mathrm{~m} / \mathrm{s}\right)$ para os solos analisados $(\mathrm{A}$, $\mathrm{B}$ e C), sem que a curva condutividade hidráulica relativa $k_{r}=k\left(u_{a}-u_{w}\right) / k_{s}$ fosse alterada, obtendo-se as curvas apresentadas na Figura 28.

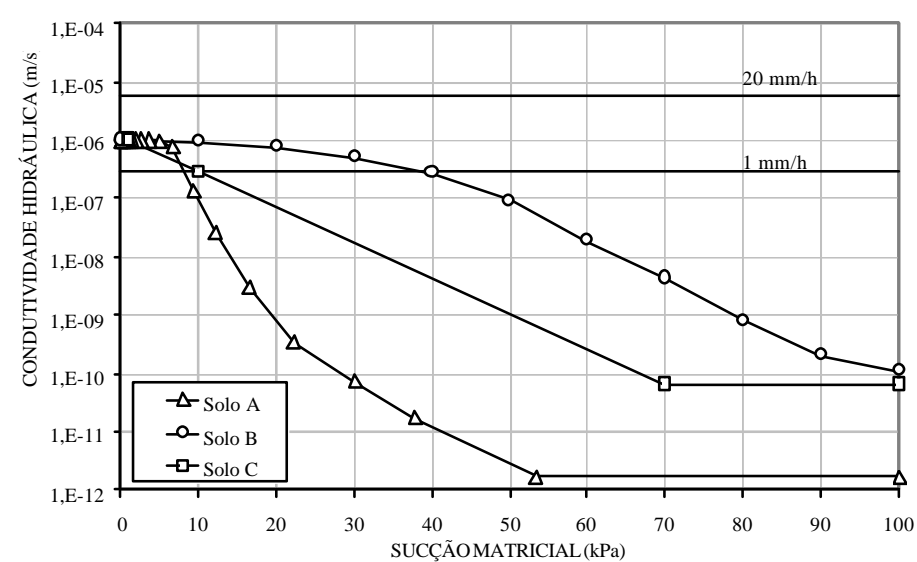

Figura 28. Condutividade hidráulica dos solos A, B e C, $k_{s}=1 E-6 \mathrm{~m} / \mathrm{s}$ e precipitações aplicadas.

Os taludes compostos por tais solos foram submetidos às intensidades de precipitação de 1 e $20 \mathrm{~mm} / \mathrm{h}$. A precipitação de $20 \mathrm{~mm} / \mathrm{h}$ excede a máxima capacidade de infiltração destes solos, configurando uma condição de precipitação excedente, ou seja, ocorre escoamento superficial.

A Figura 29 apresenta os perfis de pressões de água nos solos (A, B e C) em determinados intervalos de tempo, quando sujeitos a precipitação com intensidade igual a $1 \mathrm{~mm} / \mathrm{h}$. 

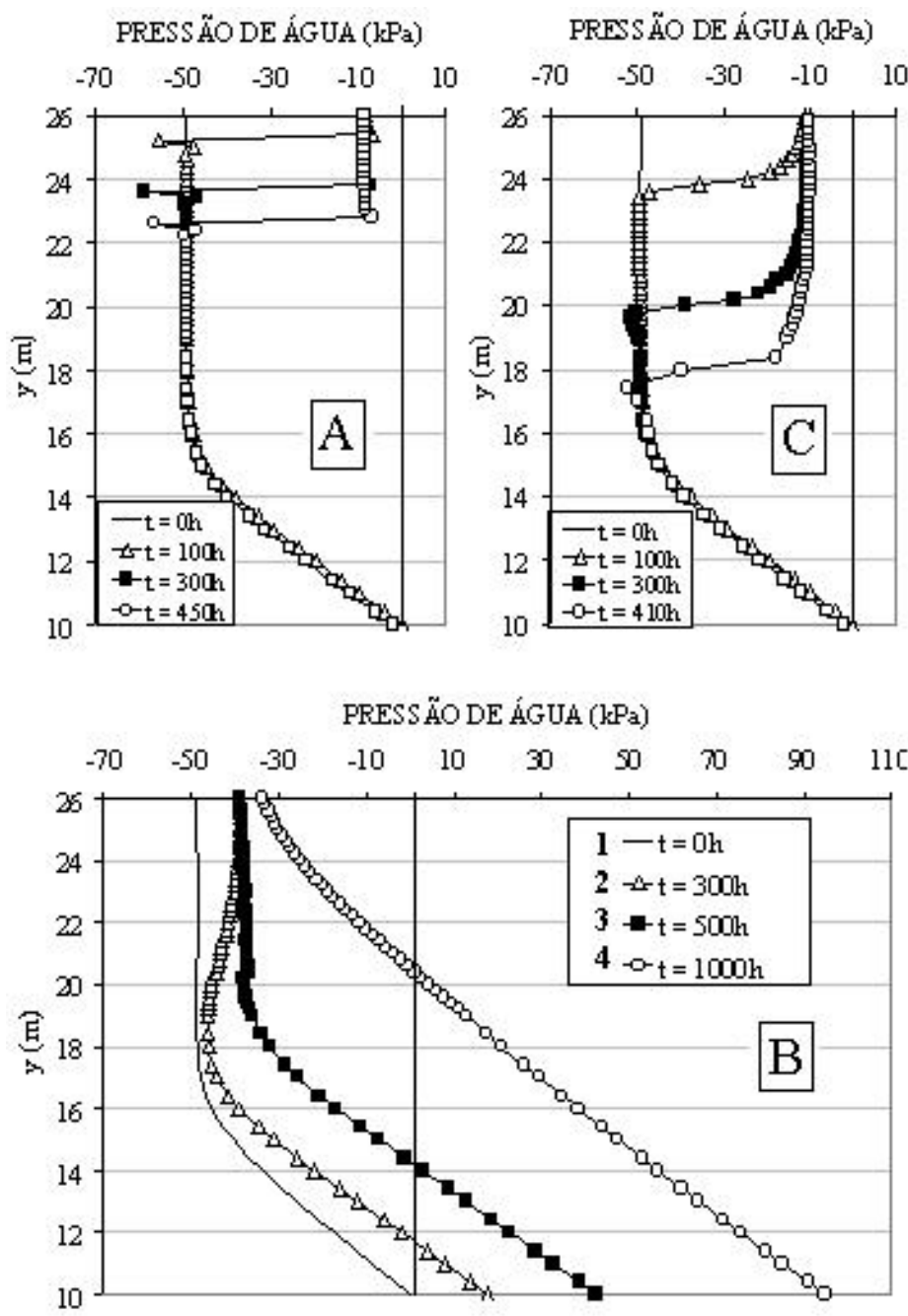

Figura 29. Perfil de pressão de água ao longo do tempo - Solos A e C (acima), e B (abaixo), $k_{s}=1 E-6 \mathrm{~m} / \mathrm{s}$, precipitação $=1 \mathrm{~mm} / \mathrm{h}$.

A partir da Figura 28, percebe-se que para a taxa de infiltração de $1 \mathrm{~mm} / \mathrm{h}$, a sucção seria da ordem de $40 \mathrm{kPa}$ no solo B. Verifica-se na Figura 29 que, partindo da sucção inicial (50 kPa), ocorre uma tendência à uniformização da sucção ao longo da profundidade no valor correspondente à infiltração de $1 \mathrm{~mm} / \mathrm{h}$. Este quadro só se altera após um tempo maior, quando principia a ascensão do lençol freático. Nos perfis apresentados para os solos $\mathrm{A}$ e $\mathrm{C}$ as sucções na frente de umedecimento seriam de 8 e $10 \mathrm{kPa}$, respectivamente, também correspondentes à taxa de infiltração de $1 \mathrm{~mm} / \mathrm{h}$.

A evolução do perfil de pressão para o solo B, apresentada na Figura 29 pode ser descrita da seguinte forma:

o perfil de sucção inicial determina a condutividade hidráulica inicial do solo (n'. 1 na Fig. 29); 
- $\quad$ com a infiltração sobre a superfície do solo, ocorre uma diminuição da sucção até que esta se iguale à intensidade de precipitação ( $n^{\circ} .2$ na Fig. 29);

ocorre o avanço da frente de umedecimento de maneira que todo o solo pelo qual a frente já houver passado permaneça a um valor de sucção em que a condutividade hidráulica seja igual à intensidade de precipitação (ñ . 3 na Fig. 29);

- $\quad$ Se não ocorrer saída de água do sistema, ocorre elevação do nível freático até que o perfil de pressão de água atuante esteja em equilíbrio hidrostático com a sucção do solo na superfície, correspondente, no caso, a condutividade hidráulica que seja equivalente à intensidade de precipitação (n .4 na Fig. 29);

- a partir de então, com o prosseguimento da precipitação, ocorre redução da sucção em superfície até que seja atingida a completa saturação da superfície.

Vale a pena ressaltar que a evolução do perfil apresentada pelo solo B (Fig. 29), em que o Nível freático sobe, ocorre em qualquer tipo de solo desde que a precipitação seja prolongada o suficiente para tanto. A Figura 30 apresenta a evolução do perfil de pressão de água para o solo A, onde também ocorre elevação do Nível freático (este perfil de pressão foi obtido a partir de uma seção vertical posicionada a $5 \mathrm{~m}$ do pé do talude). 


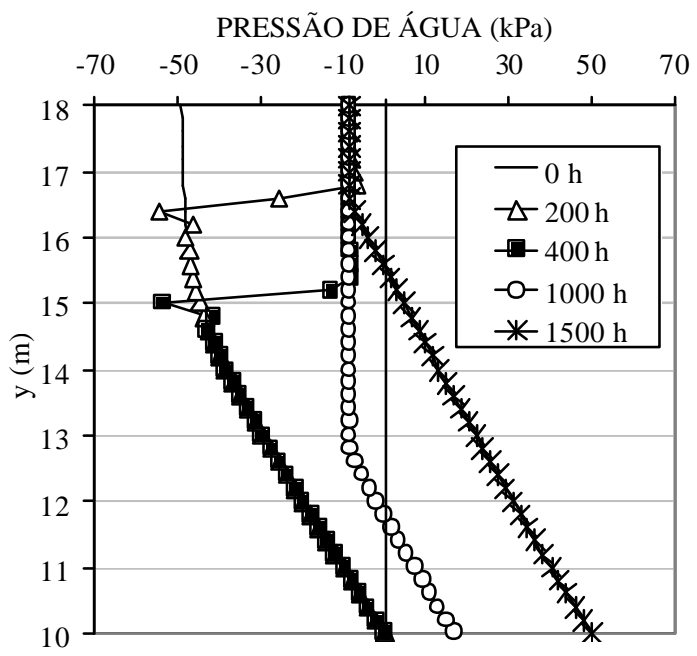

Figura 30. Perfil de pressão de água ao longo do tempo - Solo A, $k_{s}=1 E-6 \mathrm{~m} / \mathrm{s}$, precipitação $=1 \mathrm{~mm} / \mathrm{h}$, posicionada a $5 \mathrm{~m}$ do pé do talude.

A Figura 31 apresenta os perfis de pressões de água nos solos (A, B e C) em determinados intervalos de tempo, quando sujeitos a precipitação com intensidade igual a $20 \mathrm{~mm} / \mathrm{h}$.
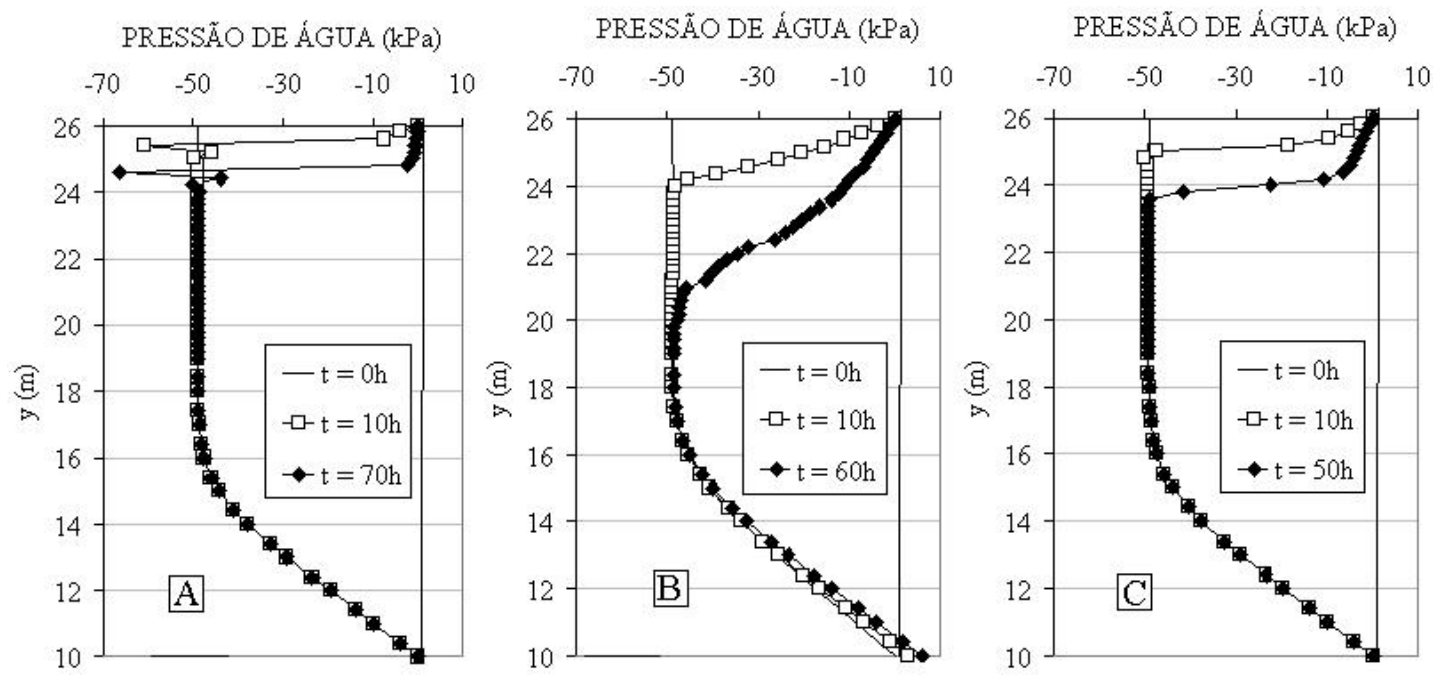

Figura 31. Perfil de pressão de água ao longo do tempo - Solos A, B e C respectivamente, precipitação $=20 \mathrm{~mm} / \mathrm{h}$.

Na Figura 31, o perfil de pressões para o solo A demonstra oscilações sem significado físico, resultantes de imprecisão, ruído numérico ou erro no processo de convergência do programa SEEP/W, conforme discutido no item 3.2.1.2 (Resolução do Problema por processo iterativo). 
Para o solo A, o maciço praticamente satura superficialmente, entretanto a velocidade de avanço da frente de saturação é pequena e só após 70 horas de precipitação esta frente atinge cerca de $1,5 \mathrm{~m}$ de profundidade.

Analisando os perfis de pressão nota-se que o umedecimento para solo B (mais siltoso) ocorre mais rapidamente que para os demais, além de não ocorrer a formação nítida de uma frente de saturação, ou seja, o umedecimento não ocorre uniformemente.

Ao contrário do esperado, o comportamento do solo $\mathrm{C}$ apresenta-se como intermediário aos dos solos A (mais arenoso) e B (mais siltoso). Vale a pena ressaltar que a menor pressão de entrada de ar do solo $\mathrm{C}$ em relação aos demais caracterizaria sua curva de retenção como a de um solo mais arenoso que a do solo A.

Possivelmente este comportamento esteja associado à condutividade hidráulica inicial (pré-precipitação) do solo. A partir da Figura 28 pode-se observar que para a sucção de $50 \mathrm{kPa}$ (perfil inicial de sucção) os solos $\mathrm{A}$, B e C apresentam condutividade hidráulica igual a 3E-12, 1E-7 e 1E-9 m/s, respectivamente, ou seja, nesta condição o solo A (areia) é o mais impermeável dentre estes, enquanto o solo B (silte argiloso) é o mais permeável.

Assim sendo, a partir dos perfis de pressão de água já apresentados, pode-se propor, tentativamente, os seguintes padrões de comportamento do perfil de pressão de água (Fig.32):

Perfil Tipo 1: ocorre saturação da superfície, e a frente de umedecimento é bem definida, ou seja, todo o maciço percorrido por esta frente encontra-se totalmente ou quase totalmente saturado. Ocorre nos solos arenosos (A e C) quando a precipitação é maior que $\mathrm{k}_{\mathrm{s}}$. A profundidade da frente de saturação é proporcional ao tempo e à condutividade hidráulica não saturada, quanto menor a condutividade associada ao valor inicial da sucção, mais rasa é a frente de saturação;

- $\quad$ Perfil Tipo 2: ocorre saturação da superfície, mas a frente de saturação não é bem definida, ou seja, o umedecimento não é uniforme. Ocorre nos solos siltosos (B) quando a precipitação é maior que $\mathrm{k}_{\mathrm{s}}$;

Perfil Tipo 3: não ocorre saturação da superfície, a frente de umedecimento pode ou não ser uniforme com a profundidade. Ocorre 
em todo tipo de solo, desde que a precipitação seja menor que $\mathrm{k}_{\mathrm{s}}$. A sucção na frente de umedecimento se estabiliza a um valor de sucção em que a condutividade hidráulica correspondente do solo seja igual a taxa de infiltração;

Perfil tipo 4: ocorre elevação do Nível Freático até que seja atingido equilíbrio hidrostático com a sucção atuante em superfície. Ocorre em todos os tipos de solo, desde que a duração da precipitação seja tal que permita a ascensão do nível freático.

Vale a pena ressaltar que o Perfil Tipo 4 é ilustrativo pois ocorreria na remota hipótese de precipitações com durações muito acima da precipitação média anual registrada para a região de São Carlos, podendo ocorrer como resultado da alteração dos demais tipos de Perfil de pressão de água.

Estes perfis tipos serão particularmente úteis na análise paramétrica da estabilidade do talude de referência, cujo comportamento de estabilidade está diretamente associado a estes perfis de pressão de água.

As Figuras 33 a 36 apresentam exemplos da distribuição destes perfis ao longo de todo o talude.

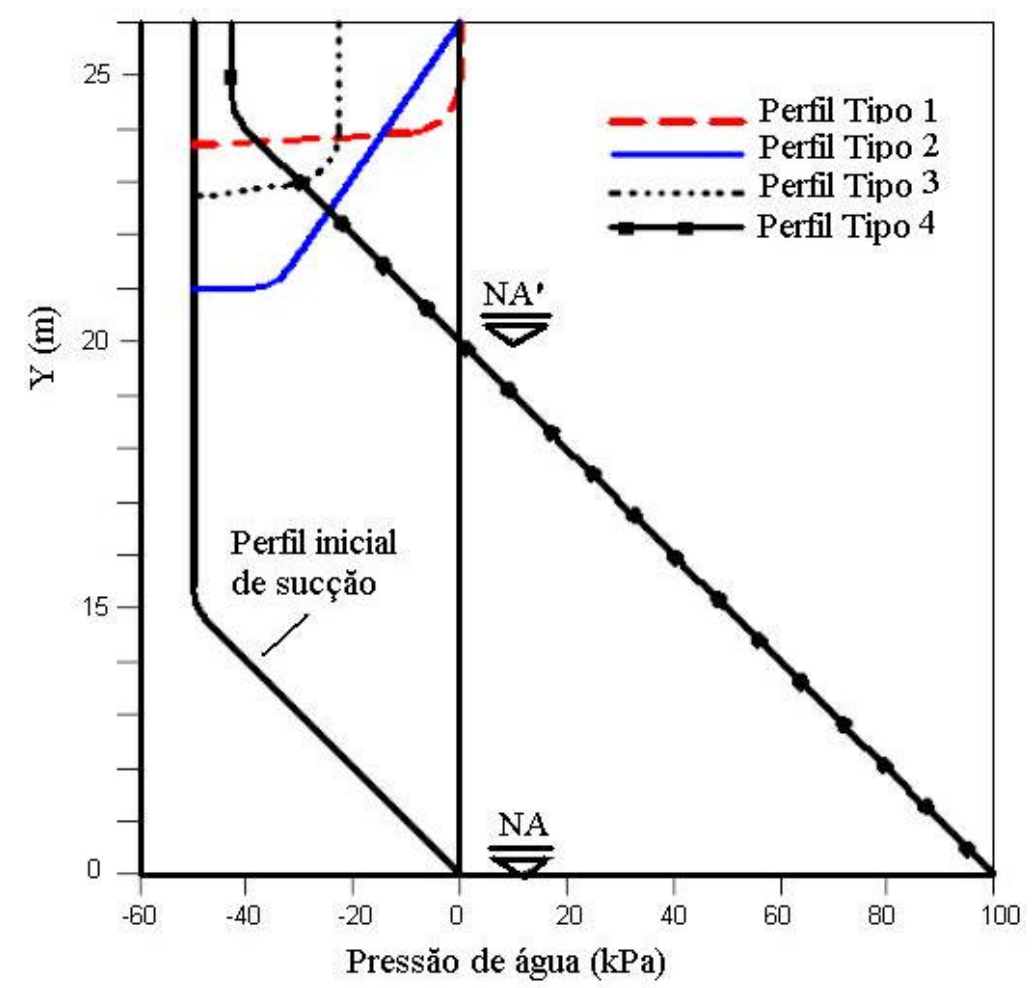

Figura 32. Padrões de Comportamento do perfil de pressão de água no decorrer da precipitação. 


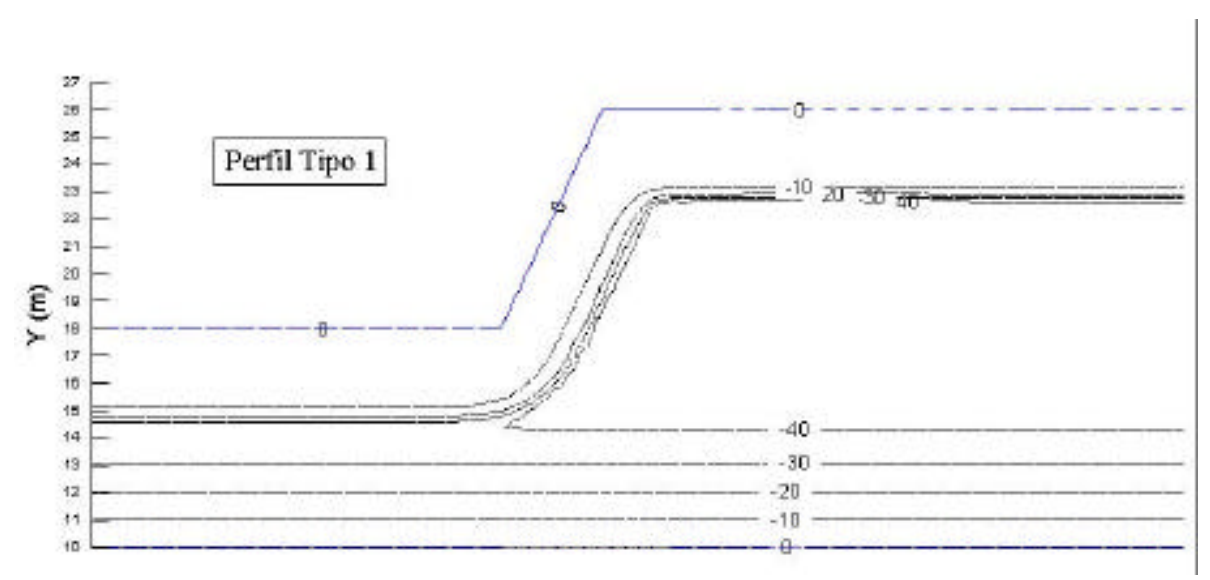

Figura 33. Distribuição de pressão de água ao longo de todo o talude, Perfil Tipo 1.

(Solo C, precipitação igual a $70 \mathrm{~mm} / \mathrm{h}$, $k_{s}$ igual a $10^{-6} \mathrm{~m} / \mathrm{s}$ e t igual a 90 horas)

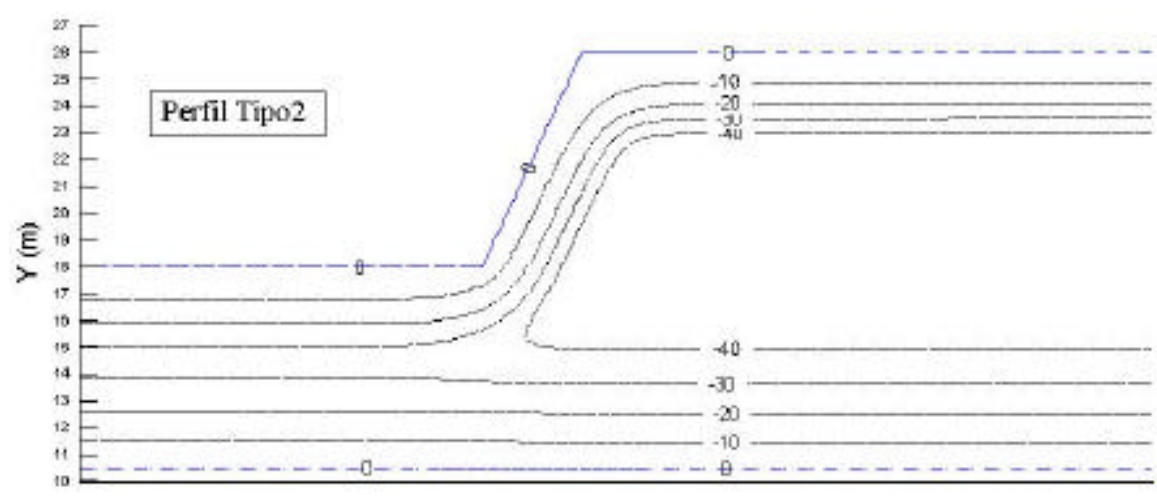

Figura 34. Distribuição de pressão de água ao longo de todo o talude, Perfil Tipo 2.

(Solo B, precipitação igual a $20 \mathrm{~mm} / \mathrm{h}, k_{s}$ igual a $10^{-8} \mathrm{~m} / \mathrm{s}$ e t igual a 3000 horas)

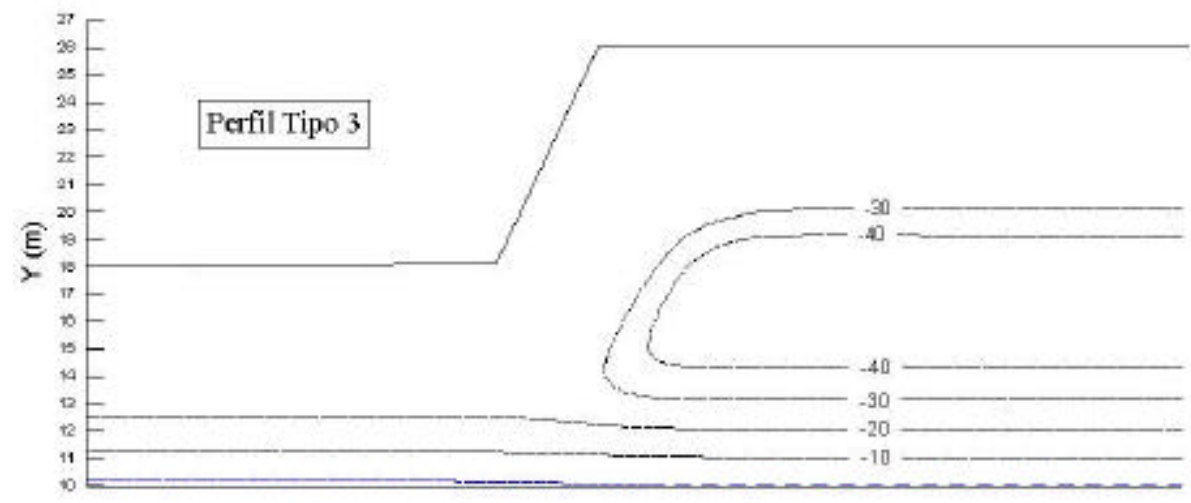

Figura 35. Distribuição de pressão de água ao longo de todo o talude, Perfil Tipo 3. (Solo C, precipitação igual a $1 \mathrm{~mm} / \mathrm{h}, k_{s}$ igual a $10^{-5} \mathrm{~m} / \mathrm{s}$ e tigual a 140 horas) 


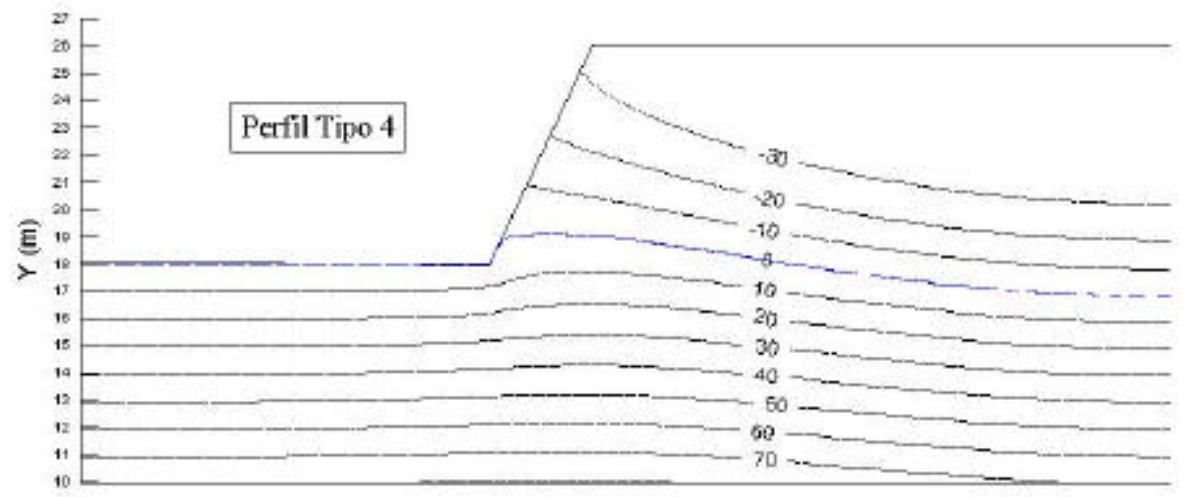

Figura 36. Distribuição de pressão de água ao longo de todo o talude, Perfil Tipo 4.

(Solo B, precipitação igual a $1 \mathrm{~mm} / \mathrm{h}, k_{s}$ igual a $10^{-6} \mathrm{~m} / \mathrm{s}$ e t igual a 780 horas)

Para uma melhor compreensão da evolução do perfil de pressão de água, será apresentada uma análise paramétrica das seguintes características do solo:

Condutividade hidráulica saturada

Função condutividade hidráulica

- Declividade da função condutividade hidráulica

- $\quad$ Curva de Retenção

- $\quad$ Pressão de entrada de ar

- $\quad$ Parâmetro $a$ da equação de FREDLUND \& XING (1994)

- $\quad$ Parâmetro $m$ da equação de FREDLUND \& XING (1994)

- $\quad$ Parâmetro $n$ da equação de FREDLUND \& XING (1994)

- $\quad$ Parâmetro $\phi^{\mathrm{b}}$ da equação de FREDLUND et al.(1978)

Para toda a análise paramétrica da infiltração serão utilizados: solos com condutividade hidráulica saturada de $1 \mathrm{E}-6 \mathrm{~m} / \mathrm{s}$ e intensidade de precipitação de $20 \mathrm{~mm} / \mathrm{h}$ (Condição de precipitação excedente), com exceção do item em que é avaliada a influência da condutividade hidráulica saturada.

A título de síntese serão apresentados exemplos de perfis de pressão de água em apenas um tipo de solo para cada característica analisada. Entretanto vale a pena ressaltar que a influência observada destes parâmetros é a mesma para todos os tipos de solo, salvo indicações em contrário apresentadas durante o texto.

No decorrer das análises serão criados solos fictícios para auxiliar o estudo de parâmetros isolados do solo. Estes podem não representar materiais reais e para 
ressaltar este ponto, terão suas denominações apresentadas entre aspas (Ex: "C1", "RetC-CondB", etc.).

\subsection{1 - Influência da Condutividade hidráulica saturada}

Para avaliar a influência da condutividade hidráulica saturada, a partir do solo C já apresentado, foi alterada a ordem de grandeza deste parâmetro sem que a função condutividade hidráulica relativa $\left(k_{r}=k\left(u_{a}-u_{w}\right) / k_{s}\right)$ fosse alterada.

Para todos os casos analisados neste item foi adotada a mesma curva de retenção (Solo C). As curvas de condutividade hidráulica obtidas, bem como a precipitação aplicada $(1 \mathrm{~mm} / \mathrm{h})$ são apresentadas na Figura 37:

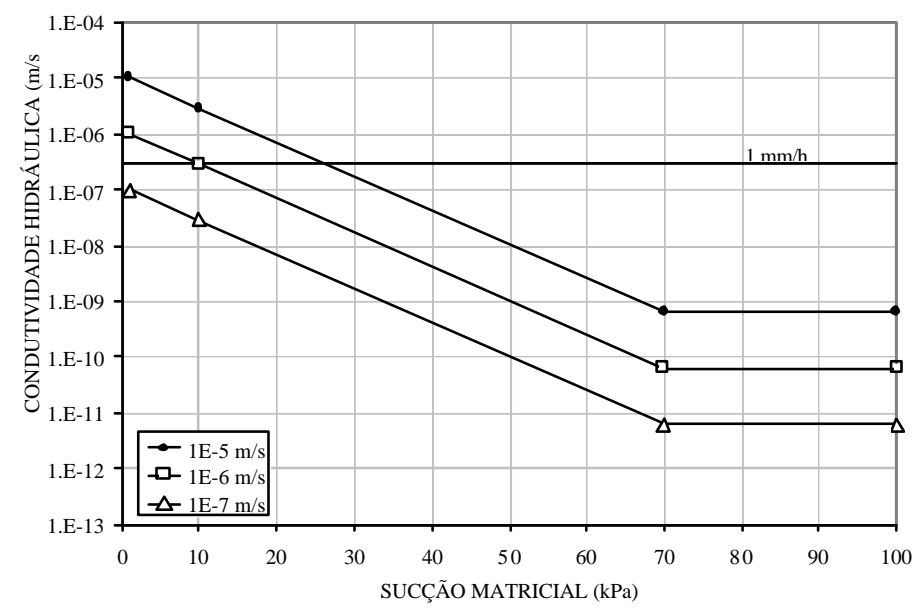

Figura 37. Intensidade de precipitação $(1 \mathrm{~mm} / \mathrm{h})$ e curvas condutividade hidráulica Solo $C, k_{s}=1 E-5,1 E-6$ e $1 E-7 \mathrm{~m} / \mathrm{s}$.

A Figura 38 apresenta o perfil de pressão de água ao longo do tempo para os três casos apresentados $\left(\mathrm{k}_{\mathrm{s}}=1 \mathrm{E}-5,1 \mathrm{E}-6\right.$ e $\left.1 \mathrm{E}-7 \mathrm{~m} / \mathrm{s}\right)$ : 

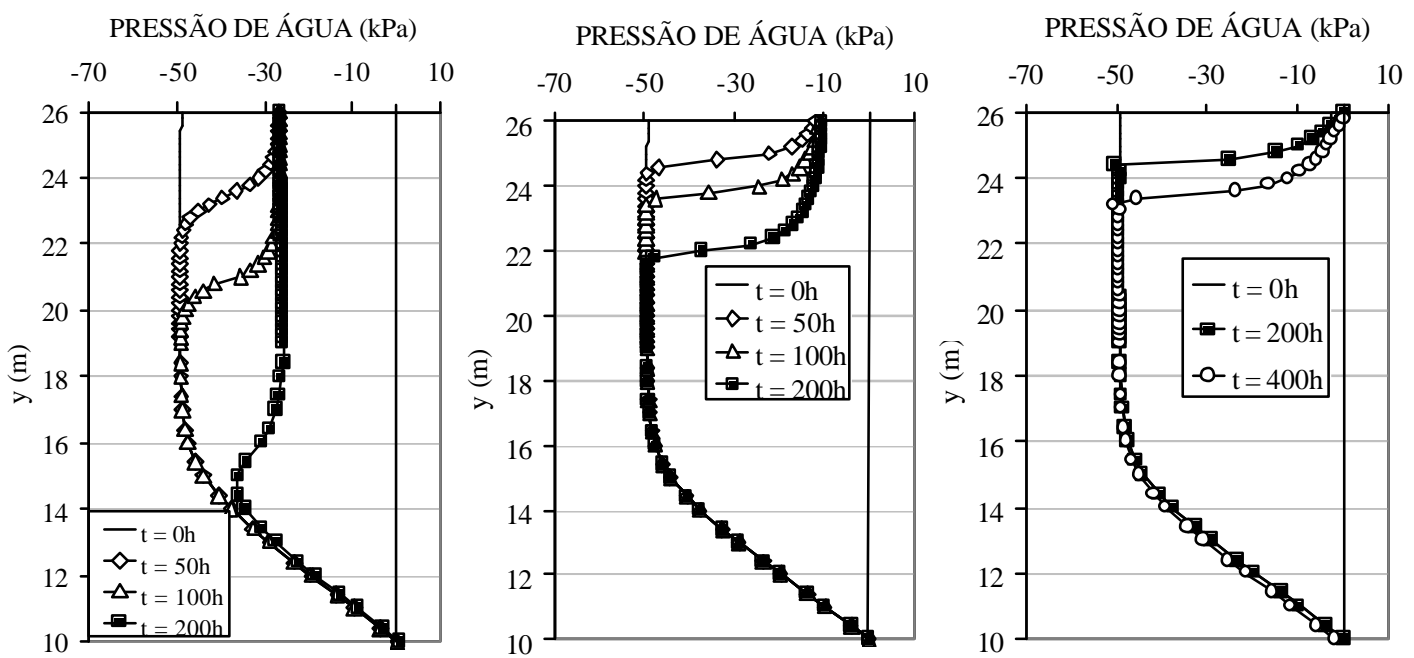

Figura 38. Perfil de pressão de água ao longo do tempo - Solos $C, k_{s}=1 E-5,1 E-6$ e $1 E-7 \mathrm{~m} / \mathrm{s}$ respectivamente, precipitação igual a $1 \mathrm{~mm} / \mathrm{h}$.

Nota-se a partir da Figura 38 que para a condição de precipitação não excedente, ocorreu a redução da sucção dentro da frente de umedecimento para valores em que a condutividade hidráulica corresponde a taxa de infiltração aplicada.

Para os casos em que $\mathrm{k}_{\mathrm{s}}$ é igual a $1 \mathrm{E}-5$ e $1 \mathrm{E}-6 \mathrm{~m} / \mathrm{s}$, dentro da frente de umedecimento, ocorreu a redução da sucção inicial para valores de 27 e $10 \mathrm{kPa}$ respectivamente, que em ambos os casos correspondem a uma condutividade hidráulica igual a $1 \mathrm{~mm} / \mathrm{h}$.

A frente de umedecimento atinge profundidade que variam com $\mathrm{k}_{\mathrm{s}}$, quanto maior a condutividade hidráulica saturada maior a profundidade de umedecimento.

Assim, pode-se constatar que para um mesmo tipo de solo, quanto maior sua condutividade hidráulica saturada, menor será a relação i $/ \mathrm{k}_{\mathrm{s}}$ e maior será o valor da sucção dentro da frente de umedecimento. Isto permite que para um mesmo volume de água infiltrado quanto maior a condutividade hidráulica saturada, maior o avanço da frente de umedecimento.

\subsection{2 - Influência da Função condutividade hidráulica}

Para avaliar a influência da Função condutividade hidráulica, foram criados solos fictícios ("RetC-CondA", "RetC-CondB", Solo C) com a mesma Curva de Retenção (Solo C), mesma condutividade hidráulica saturada $\left(\mathrm{k}_{\mathrm{s}}=1 \mathrm{E}-6 \mathrm{~m} / \mathrm{s}\right) \mathrm{e}$ diferentes Funções condutividade hidráulica (Solo A, Solo B e Solo C) respectivamente. 
Tanto a curva de retenção quanto as funções condutividade hidráulica utilizadas na definição destes solos fictícios já foram apresentadas no item 3.1.2 (Características dos solos).

A Figura 39 apresenta os perfis de pressão de água ao longo do tempo para os três casos apresentados ("RetC-CondA", "RetC-CondB", Solo C):
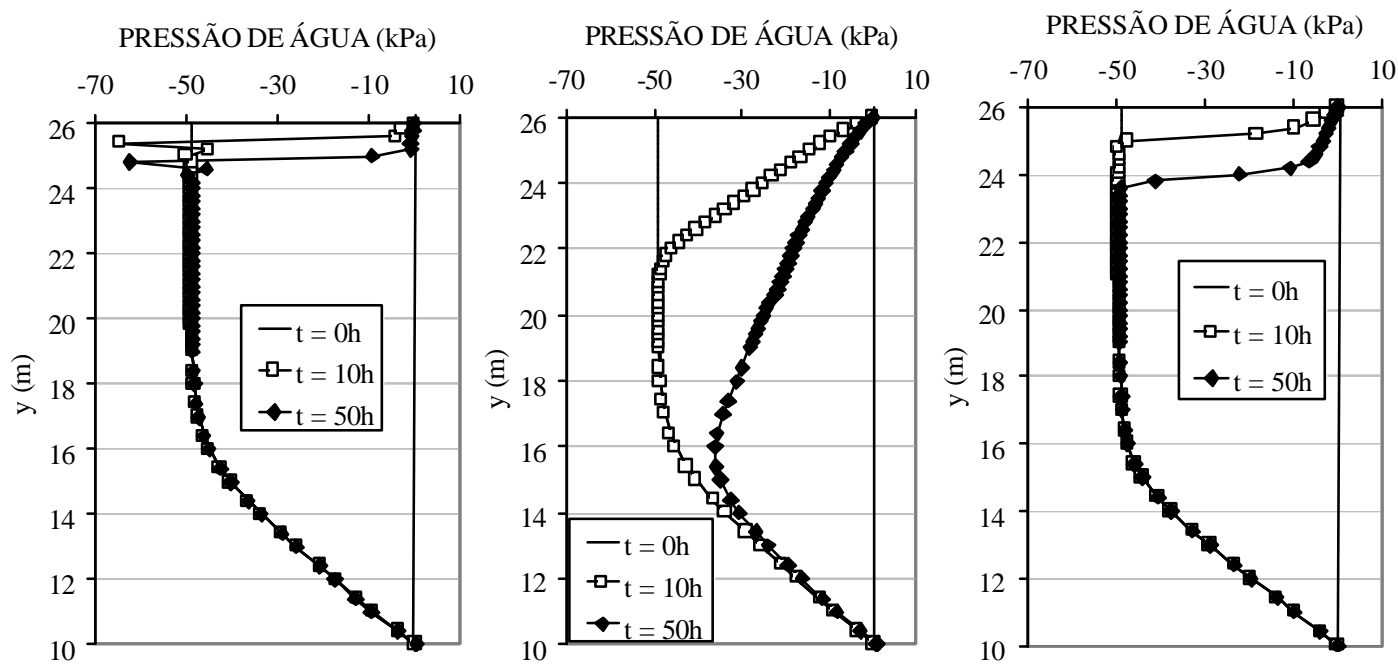

Figura 39. Perfil de pressão de água ao longo do tempo - "RetC-CondA", "RetCCondB" e Solo C respectivamente, precipitação $=20 \mathrm{~mm} / \mathrm{h}$.

O solo "RetC-CondB" foi o que apresentou a maior penetração da frente de umedecimento (não uniforme), em contrapartida o solo "RetC-CondA" foi o que apresentou o menor avanço.

Pode-se supor (a priori) que tanto a forma quanto a velocidade de avanço da frente de umedecimento sejam condicionadas pela função condutividade hidráulica, uma vez que o solo com condutividade hidráulica do solo $\mathrm{B}$ foi o único que apresentou umedecimento não uniforme nítido, além de maior penetração desta frente que os demais.

Assim, faz-se necessária uma análise mais detalhada da forma, mais específico da declividade da função cond utividade hidráulica e de sua influência no processo de infiltração.

\section{a) Influência da declividade da Função condutividade hidráulica}

Para avaliar a influência da declividade da Função condutividade hidráulica, foram criados solos fictícios com a mesma Curva de Retenção (Solo C), mesma 
condutividade hidráulica saturada $\left(\mathrm{k}_{\mathrm{s}}=1 \mathrm{E}-6 \mathrm{~m} / \mathrm{s}\right)$ e Funções condutividade hidráulica com diferentes declividades ("C1", Solo C e "C2"), conforme apresentado na Figura 40.

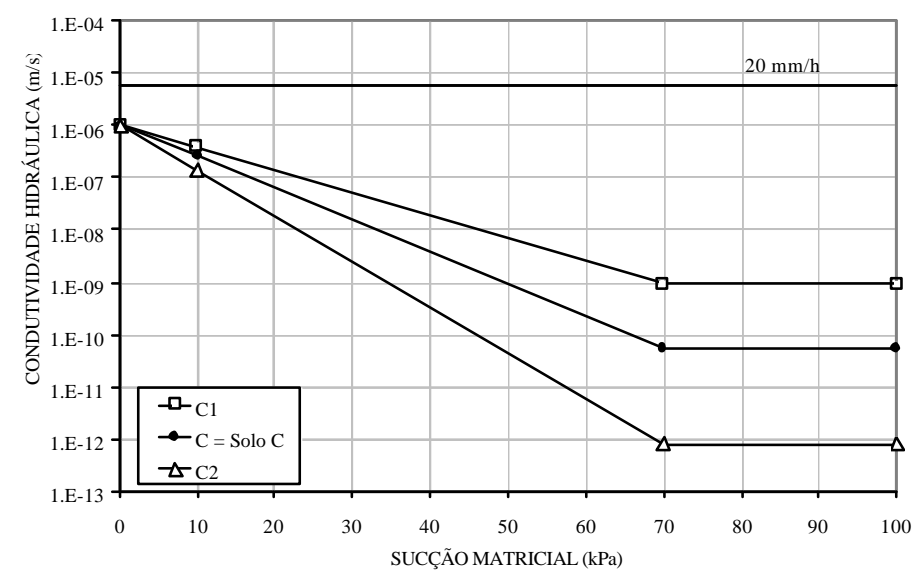

Figura 40. Intensidade de precipitação $(20 \mathrm{~mm} / \mathrm{h})$ e curvas condutividade hidráulica ("C1", Solo $C$ e "C2").

A Figura 41 apresenta os perfis de pressão de água ao longo do tempo para os três casos apresentados ("C1", Solo C e "C2"):
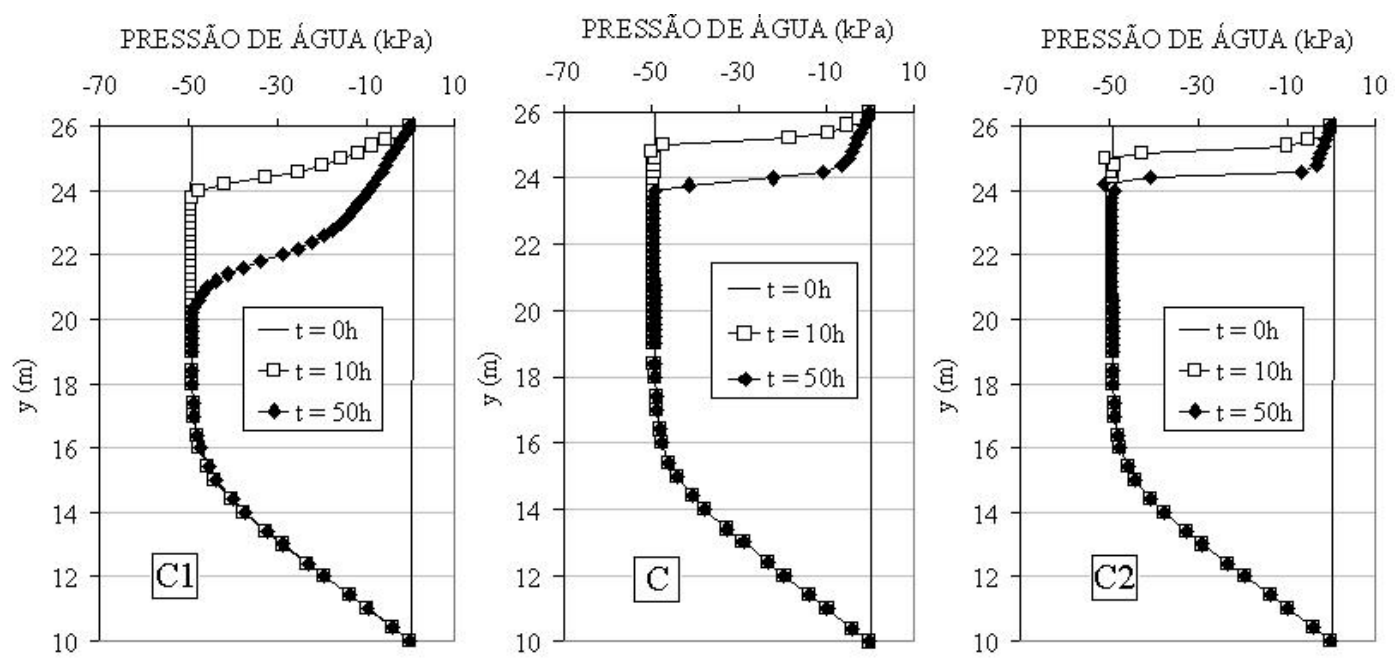

Figura 41. Perfil de pressão de água ao longo do tempo - "C1", Solo Ce "C2" respectivamente, precipitação $=20 \mathrm{~mm} / \mathrm{h}$.

Nota-se que o solo com maior declividade da função condutividade apresenta menor penetração da frente de umedecimento e frente de saturação mais bem definida (umedecimento uniforme).

Desta forma, pode-se constatar que quanto menor a declividade da função condutividade hidráulica maior a velocidade de avanço da frente de umedecimento, além de maior a propensão para a ocorrência de umedecimento não uniforme. 
De maneira geral, a menor declividade na função condutividade hidráulica é característica de materiais mais siltosos, propensos a reter maior quantidade de água.

\subsection{3 - Influência da Curva de Retenção}

Para avaliar a influência da Curva de retenção, foram criados solos fíctícios tendo como base o solo B ("RetA-CondB", Solo B, "RetC-CondB") com a mesma Função condutividade hidráulica (Solo B), mesma condutividade hidráulica saturada $\left(\mathrm{k}_{\mathrm{s}}=1 \mathrm{E}-6 \mathrm{~m} / \mathrm{s}\right)$ e diferentes curvas de retenção (Solo A, Solo B e Solo C, respectivamente).

Tanto as funções condutividade hidráulica quanto a curva de retenção utilizadas na definição destes solos fictícios já foram apresentadas no item 3.1.2 (Características dos solos).

A Figuras 42 e 43 apresentam os perfis de pressão de água ao longo do tempo para os três casos apresentados ("RetA-CondB", Solo B, "RetC-CondB"):
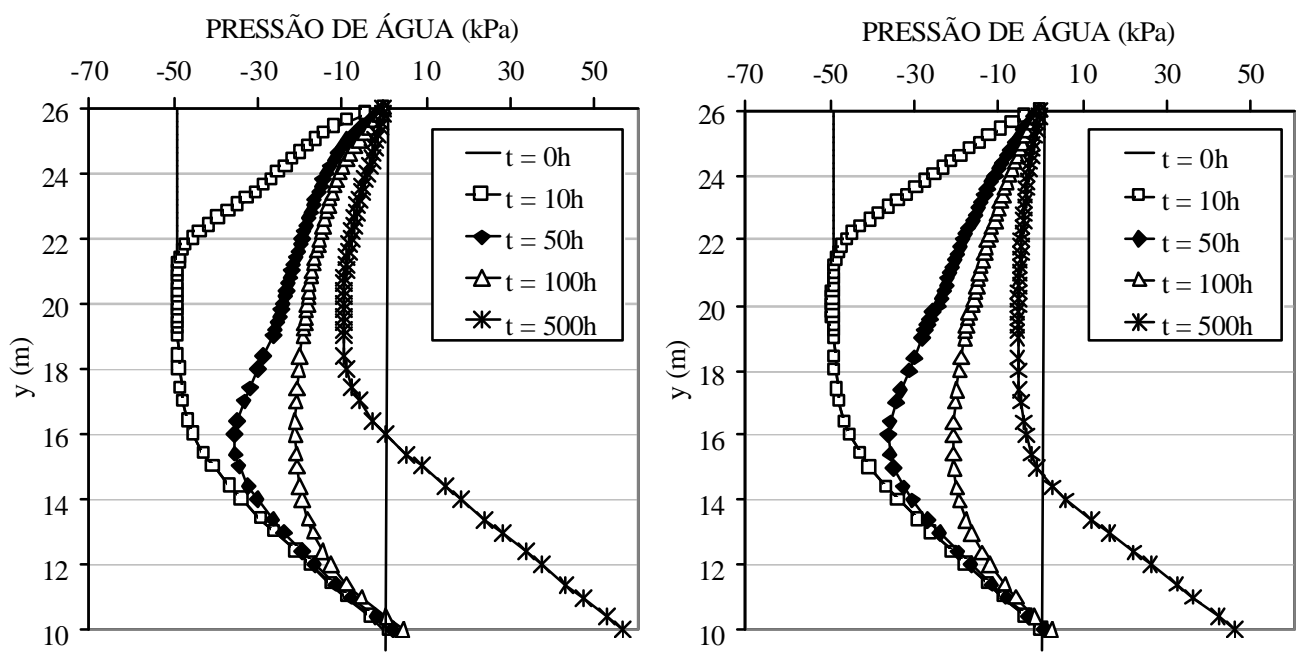

Figura 42. Perfil de pressão de água ao longo do tempo - "RetA-CondB" e "RetCCondB", respectivamente, precipitação igual a $20 \mathrm{~mm} / \mathrm{h}$. 


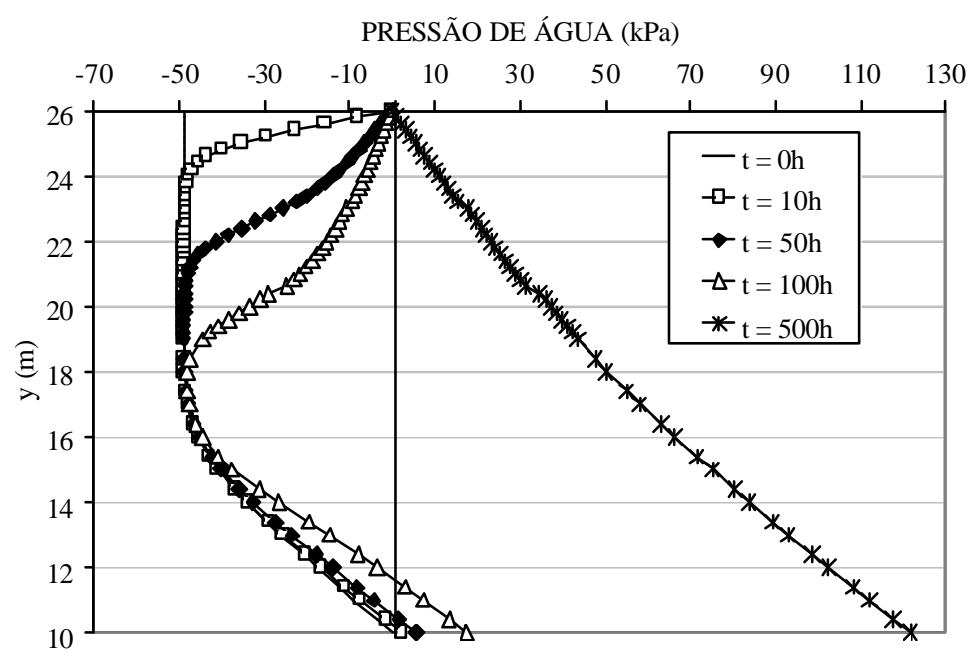

Figura 43. Perfil de pressão de água ao longo do tempo - Solo B, precipitação igual a $20 \mathrm{~mm} / \mathrm{h}$.

Conforme apresentado nas Figuras 42 e 43, aparentemente, quanto mais siltoso o solo mais rápida é a ascensão do nível freático, pois a ascensão é maior no solo com a curva de retenção do solo B e menor no solo com a curva de retenção do solo C.

Entretanto esta relação não parece muito clara para a velocidade de avanço da frente de umedecimento, assim faz-se necessária uma análise mais detalhada dos parâmetros da curva de retenção e de sua influência na infiltração.

\section{a) Influência da Pressão de entrada de ar}

Para avaliar a influência da pressão de entrada de ar na evolução do perfil de pressão durante a infiltração, foram criados, a partir do solo B, solos fictícios ("B10", Solo B, "B+20") com a mesma Função condutividade hidráulica (Solo B - Fig. 28), mesma condutividade hidráulica saturada $\left(\mathrm{k}_{\mathrm{s}}=1 \mathrm{E}-6 \mathrm{~m} / \mathrm{s}\right)$ e diferentes curvas de retenção. As curvas de retenção foram obtidas transladando a curva de retenção do Solo B a partir de sua pressão de entrada de ar, conforme apresentado na Figura 44, ou seja, em um caso reduziu-se a pressão de entrada de ar do solo B em $10 \mathrm{kPa}$ (B10) e noutro, essa pressão foi aumentada em $20 \mathrm{kPa}(\mathrm{B}+20)$ : 


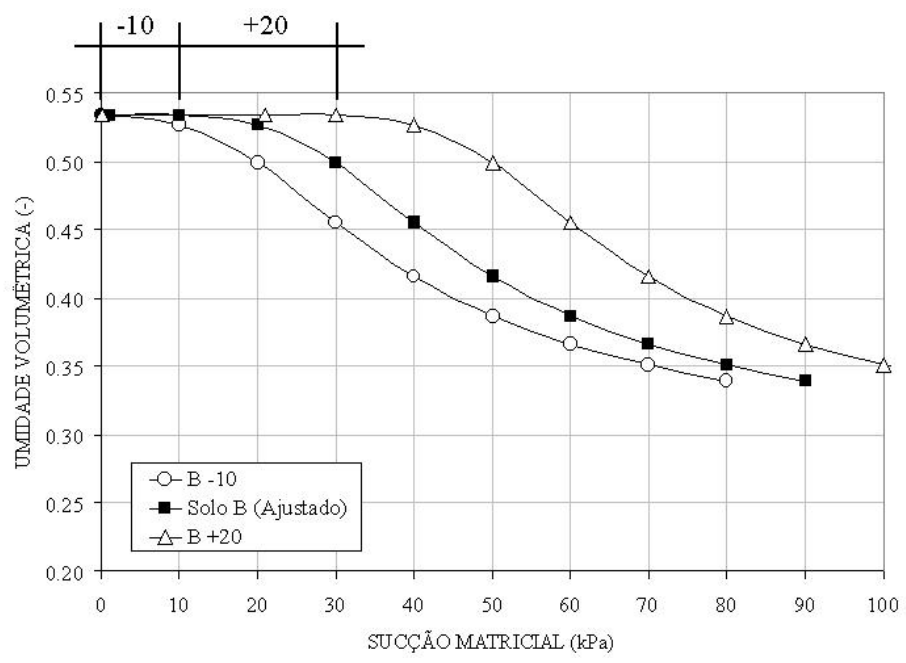

Figura 44. Curvas de Retenção ("B-10", Solo B e "B+20").

Vale a pena ressaltar que estes solos fictícios não representam a realidade, pois foi utilizada a mesma função condutividade hidráulica para os três solos, desprezando o efeito da pressão de entrada de ar sobre a função condutividade.

As Figuras 45 e 46 apresentam os perfis de pressão de água ao longo do tempo para os três casos apresentados ("B-10", Solo B, "B+20").

Percebe-se que quanto maior a pressão de entrada de ar, mais rapidamente ocorre o avanço da frente de umedecimento e a ascensão do nível freático. Mais especificamente, quanto mais próximas a pressão de entrada de ar e a condição de sucção inicial, mais rapidamente ocorre a redução desta sucção atuante, além de mais rapidamente ocorrer a ascensão do nível de água.
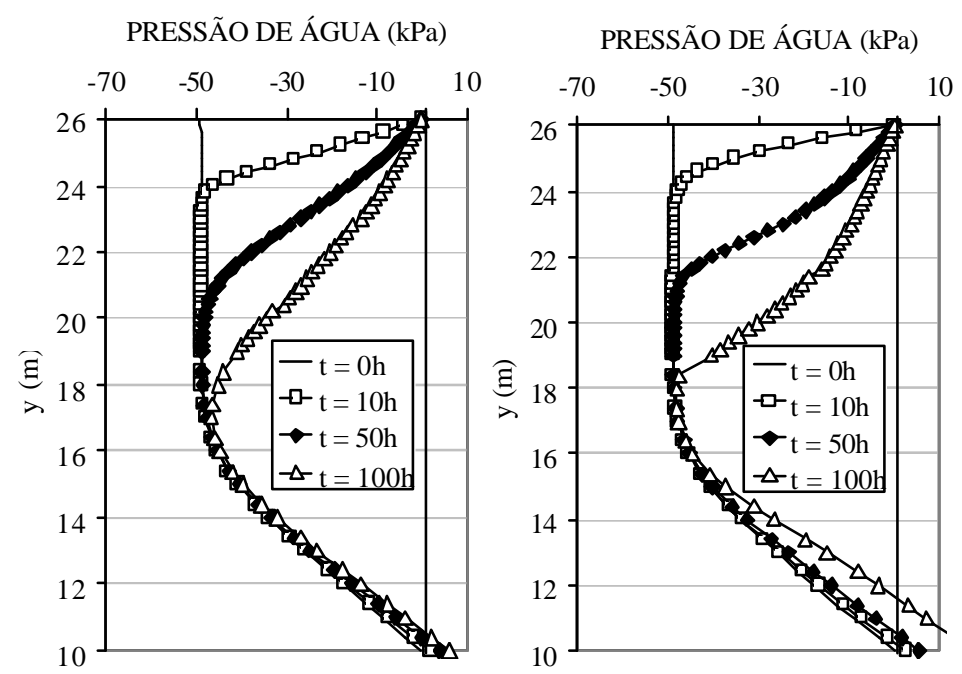

Figura 45. Perfil de pressão de água ao longo do tempo - "B-10" e Solo B, respectivamente, precipitação igual a $20 \mathrm{~mm} / \mathrm{h}$. 


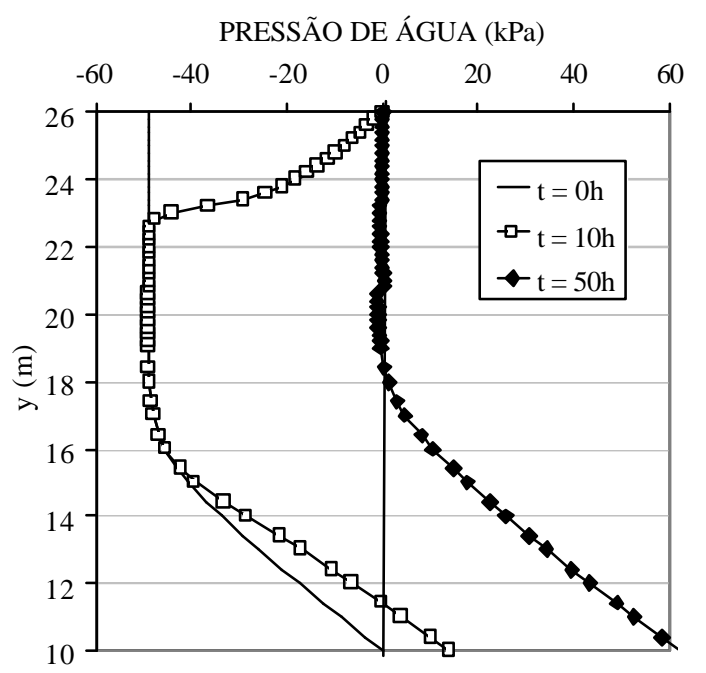

Figura 46. Perfil de pressão de água ao longo do tempo - " $B+20$ ", respectivamente, precipitação igual a $20 \mathrm{~mm} / \mathrm{h}$.

Este comportamento pode ser explicado da seguinte forma: quanto mais próxima a pressão de entrada de ar menor a diferença entre a umidade volumétrica de saturação e a umidade volumétrica inicial (antes do início da precipitação), sendo necessária menor quantidade de água para saturar o solo e permitir a ascensão do nível freático.

Assim é de se esperar que solos com pressão de entrada de ar muito próxima da sucção inicial sejam mais suscetíveis à completa saturação do solo e à ascensão do nível freático. Este efeito ainda é intensificado pela influência da pressão de entrada de ar sobre a função condutividade hidráulica. A condutividade hidráulica começa a decrescer somente a partir de sucções maiores que a pressão de entrada de ar. Assim, quanto mais próximos sejam os valores de pressão de entrada de ar e a sucção de campo, mais permeável será o solo.

Este comportamento descrito pode justificar rupturas de taludes no fim de períodos chuvosos, uma vez que no decorrer destes períodos a sucção prossegue diminuindo e aproxima-se dos valores de pressão de entrada de ar, o que pode tornar o solo mais suscetível a infiltração, e possibilitar que um único evento de precipitação deflagre um escorregamento. Em solos argiloso este comportamento é amenizado devido aos baixos valores de condutividade hidráulica saturada que dificultam a infiltração e a perda da sucção e de sua contribuição para a resistência. 
b) Influência do Parâmetro "a" de FREDLUND \& XING (1994)

Para tornar a análise da influência da curva de retenção sobre o processo de infiltração, as simulações de fluxo serão realizadas tomando como base a equação proposta por FREDLUND \& XING (1994) para descrever a curva de retenção.

Deve-se ter em vista que a alteração de qualquer um dos parâmetros de ajuste desta equação muda a forma da curva de retenção e consequentemente diz respeito a um tipo de solo diferente do inicial.

O parâmetro $a$ da equação de FREDLUND \& XING (1994) expressa o ponto de mudança de concavidade da função, além de representar uma primeira aproximação para a pressão de entrada de ar.

Para avaliar a influência deste parâmetro de ajuste, foram criados solos fictícios ("B a=15", Solo B,"B a=60") com a mesma Função condutividade hidráulica (Solo B), mesma condutividade hidráulica saturada $\left(\mathrm{k}_{\mathrm{s}}=1 \mathrm{E}-6 \mathrm{~m} / \mathrm{s}\right)$ e diferentes curvas de retenção ( $\mathrm{B} a=15$, Solo $\mathrm{B}$ e $\mathrm{B} a=60$ ). As curvas de retenção foram obtidas alterando-se o valor do parâmetro $a$ da equação de FREDLUND \& XING (1994). A partir do solo $\mathrm{B}(\mathrm{a}=31.54, \mathrm{~m}=0.297, \mathrm{n}=4.367)$ foram adotados os valores de $15 \mathrm{e}$ 60 para o parâmetro $a$, e mantidos os valores dos demais, determinoutse assim as curvas de retenção "B $\mathrm{a}=15$ " e "B a=60" respectivamente, conforme apresentado na Figura 47:

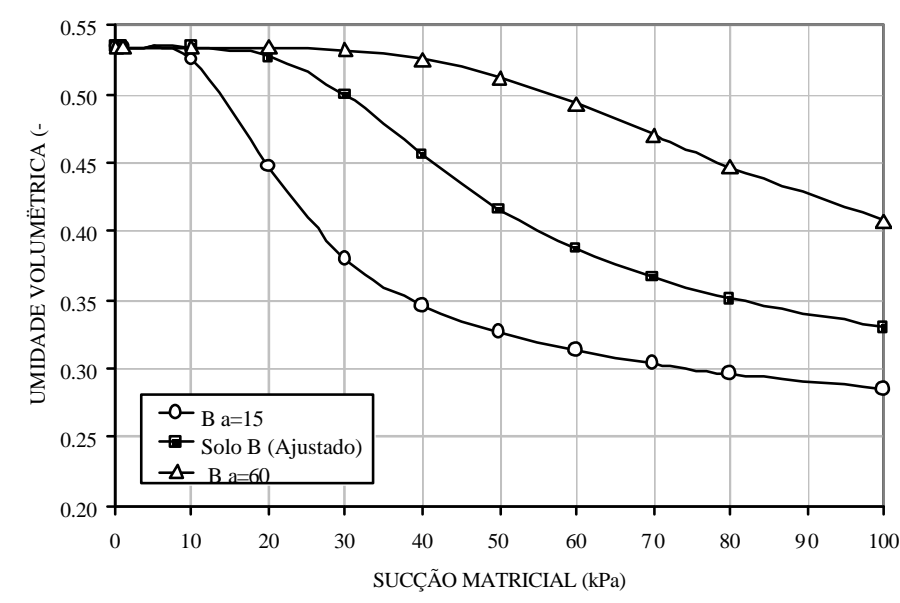

Figura 47. Curvas de Retenção ("B $a=15$ ", Solo B, "B $a=60$ ")

As Figuras 48 e 49 apresentam os perfis de pressão de água ao longo do tempo para os três casos apresentados ("B a=15", Solo B,"B a=60"): 


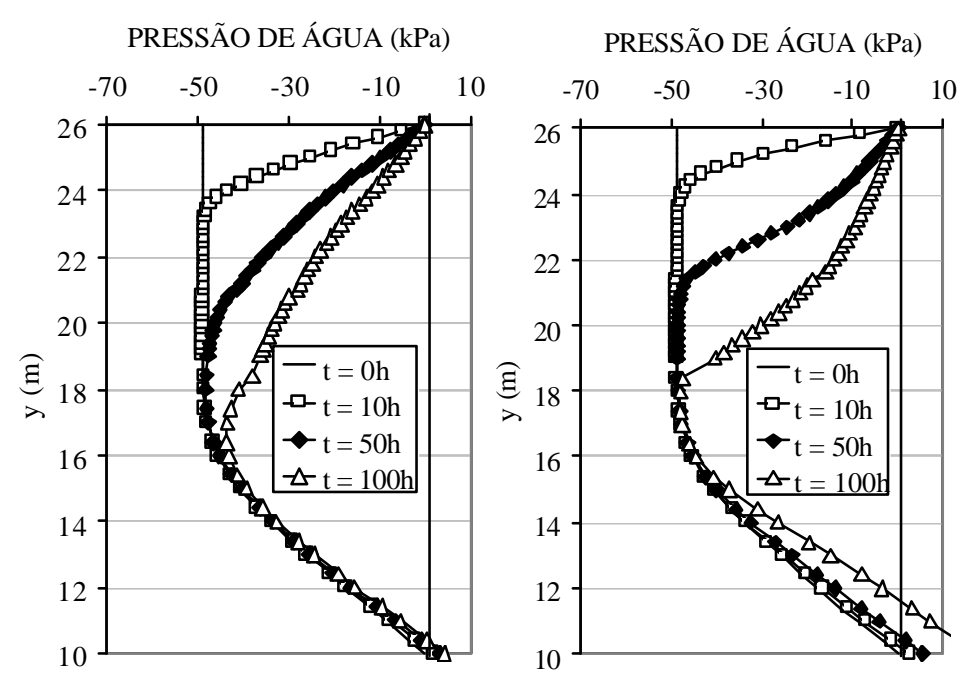

Figura 48. Perfil de pressão de água ao longo do tempo - "B $a=15$ ", Solo B, respectivamente, precipitação igual a $20 \mathrm{~mm} / \mathrm{h}$.

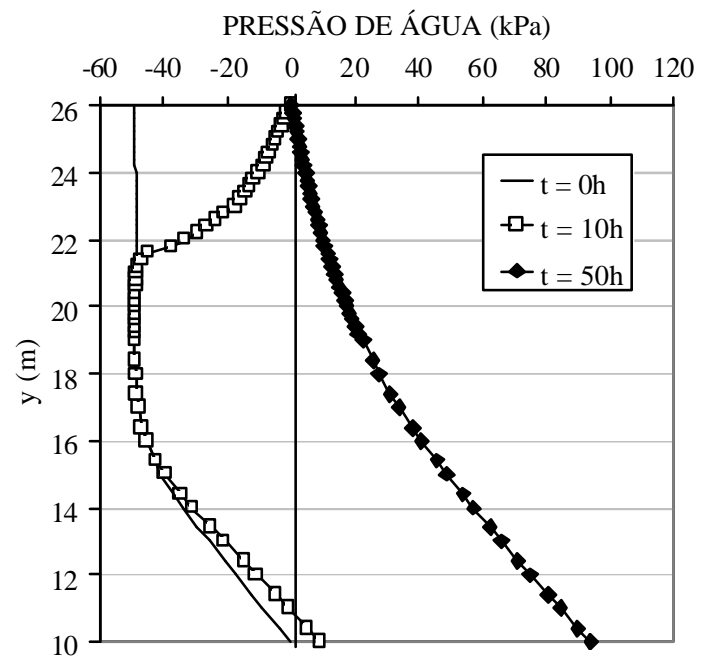

Figura 49. Perfil de pressão de água ao longo do tempo - "B $a=60 "$, precipitação igual a $20 \mathrm{~mm} / \mathrm{h}$.

Nota-se que quanto maior o parâmetro $a$, mais rapidamente ocorre a ascensão do nível freático. Entretanto a velocidade de avanço da frente de umedecimento não pode ser avaliada simplificadamente, pois esta frente apresenta um umedecimento não homogêneo, o que dificulta a avaliação da penetração da mesma no solo.

Este comportamento parece estar relacionado com o valor da pressão de entrada de ar, uma vez que o parâmetro $a$ influi indiretamente na definição desta pressão (Fig.47). Além disto, a análise de fluxo realizada para verificar a influência da pressão de entrada de ar sobre a evolução do perfil de pressão de água conduz a resultados similares aos realizados neste item. Um aumento no parâmetro $a$ produziu 
um efeito muito próximo ao encontrado no caso em que a pressão de entrada de ar foi aumentada.

c) Influência do Parâmetro " $m$ " de FREDLUND \& XING (1994)

Baixos valores do parâmetro $m$ da equação de FREDLUND \& XING (1994) resultam em curvas de retenção com pequena declividade no intervalo de sucções altas. (FREDLUND \& XING, 1994)

Para avaliar a influência deste parâmetro, foram criados solos fictícios ("B m=0.1", Solo B, "B m=0.6") com a mesma Função condutividade hidráulica (Solo B), mesma condutividade hidráulica saturada $\left(\mathrm{k}_{\mathrm{s}}=1 \mathrm{E}-6 \mathrm{~m} / \mathrm{s}\right)$ e diferentes curvas de retenção (B m=0.1, Solo B e B m=0.6). As curvas foram obtidas alterando-se o valor do parâmetro $m$, ou seja, a partir do solo B ( $a=31.54, m=0.297, n=4.367)$ foram adotados os valores de 0,1 e 0,6 para o parâmetro $m$, e mantidos os demais. Assim, determinaram-se as curvas de retenção "B m=0.1" e "B m=0.6" respectivamente, conforme apresentado na Figura 50:

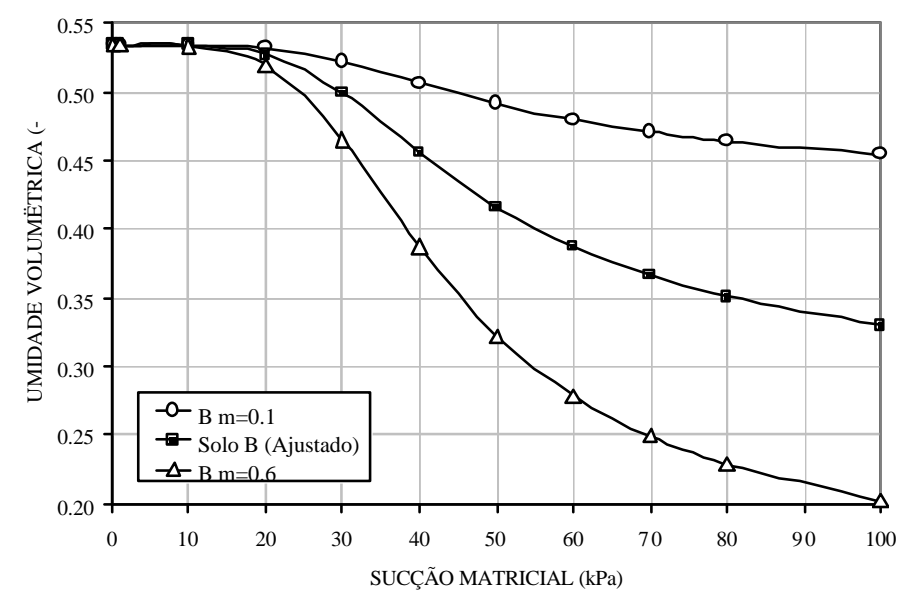

Figura 50. Curvas de Retenção ("B $m=0.1$ ", Solo B, "B $m=0.6$ ").

As Figuras 51 e 52 apresentam os perfis de pressão de água ao longo do tempo para os três casos apresentados ("B m=0.1", Solo B, "B m=0.6"): 

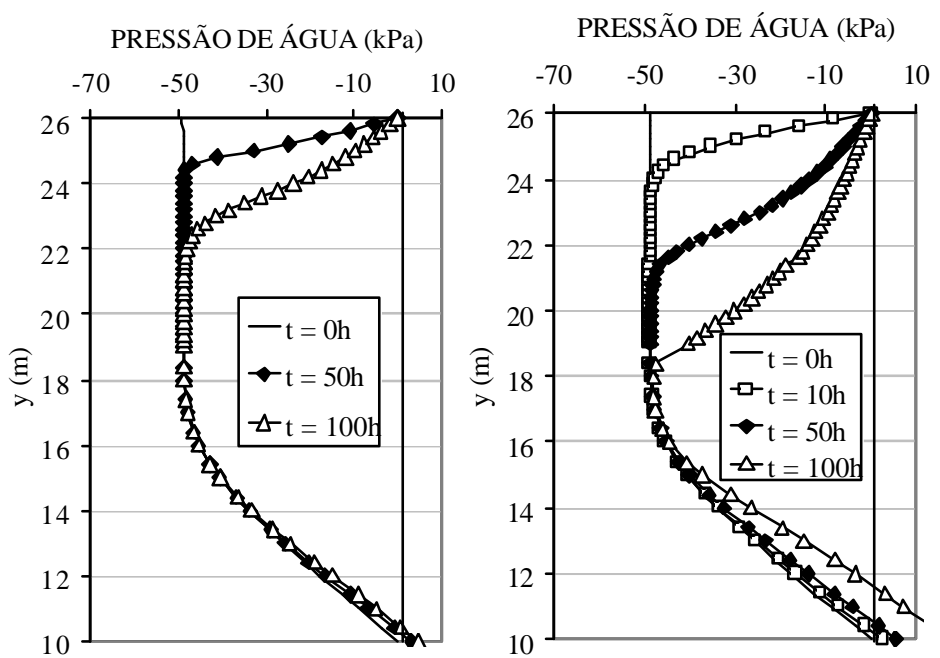

Figura 51. Perfil de pressão de água ao longo do tempo - "B $m=0.6 "$, Solo B, respectivamente, precipitação igual a $20 \mathrm{~mm} / \mathrm{h}$.

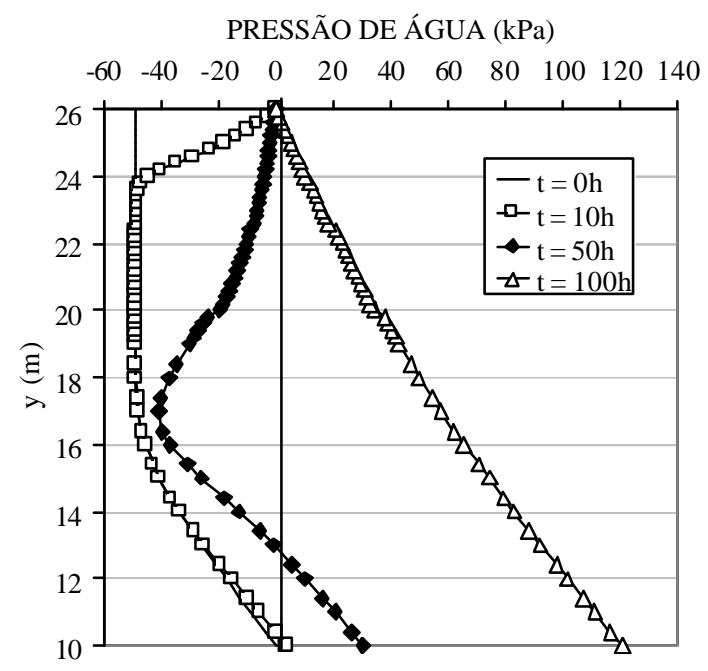

Figura 52. Perfil de pressão de água ao longo do tempo - "B $m=0.1$ ", precipitação igual a $20 \mathrm{~mm} / \mathrm{h}$.

Nota-se que quanto menor o parâmetro $m$, mais rápido ocorre o avanço da frente de umedecimento e a ascensão do nível freático. Uma vez que neste intervalo de variação, o parâmetro $m$ pouco altera a pressão de entrada de ar, pode-se constatar que a diferença entre a umidade volumétrica inicial e a umidade de saturação é a determinante deste comportamento.

Este efeito define melhor a influência da pressão de entrada de ar, uma vez que a aproximação entre esta pressão e a sucção de campo da mesma forma diminui a diferença entre umidade volumétrica inicial e a umidade de saturação. 
Assim quanto menores forem estas diferenças, mais rápidos serão o ava nço da frente de umedecimento e a ascensão do nível freático, pois menor será a quantidade de água necessária para completar a saturação do solo.

d) Influência do Parâmetro " $n$ " de FREDLUND \& XING (1994)

Altos valores do parâmetro $n$ da equação de FREDLUND \& XING (1994) resultam em curvas de retenção com pequena curvatura próxima a pressão de entrada de ar. (FREDLUND \& XING, 1994)

Para avaliar deste parâmetro, foram criados solos fictícios ("B n=2.5", Solo B, "B n=8") com a mesma Função condutividade hidráulica (Solo B), mesma condutividade hidráulica saturada $\left(\mathrm{k}_{\mathrm{s}}=1 \mathrm{E}-6 \mathrm{~m} / \mathrm{s}\right)$ e diferentes curvas de retenção (B $\mathrm{n}=2.5$, Solo B e B n=8). A partir do solo B ( $a=31.54, m=0.297, n=4.367)$ foram adotados os valores de 2,5 e 8 para o parâmetro $n$, e mantidos os demais, foram obtidas as curvas de retenção "B $n=2.5$ " e "B $n=8$ " respectivamente, conforme apresentado na Figura 53:

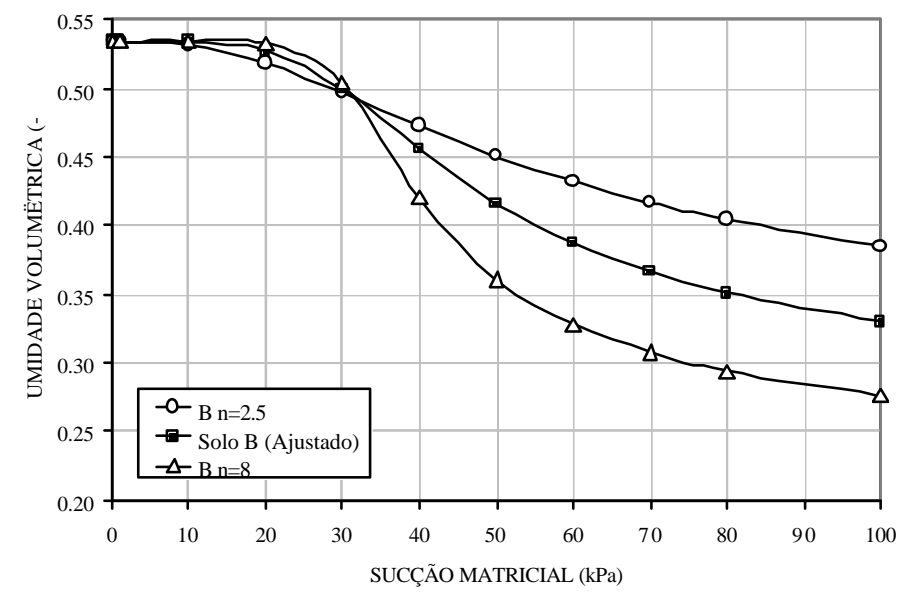

Figura 53. Curvas de Retenção ("B $n=2.5 "$, Solo $B$, "B $n=8 "$ ).

A Figura 54 apresenta os perfis de pressão de água ao longo do tempo para os três casos apresentados ("B n=2.5", Solo B, "B n=8"): 

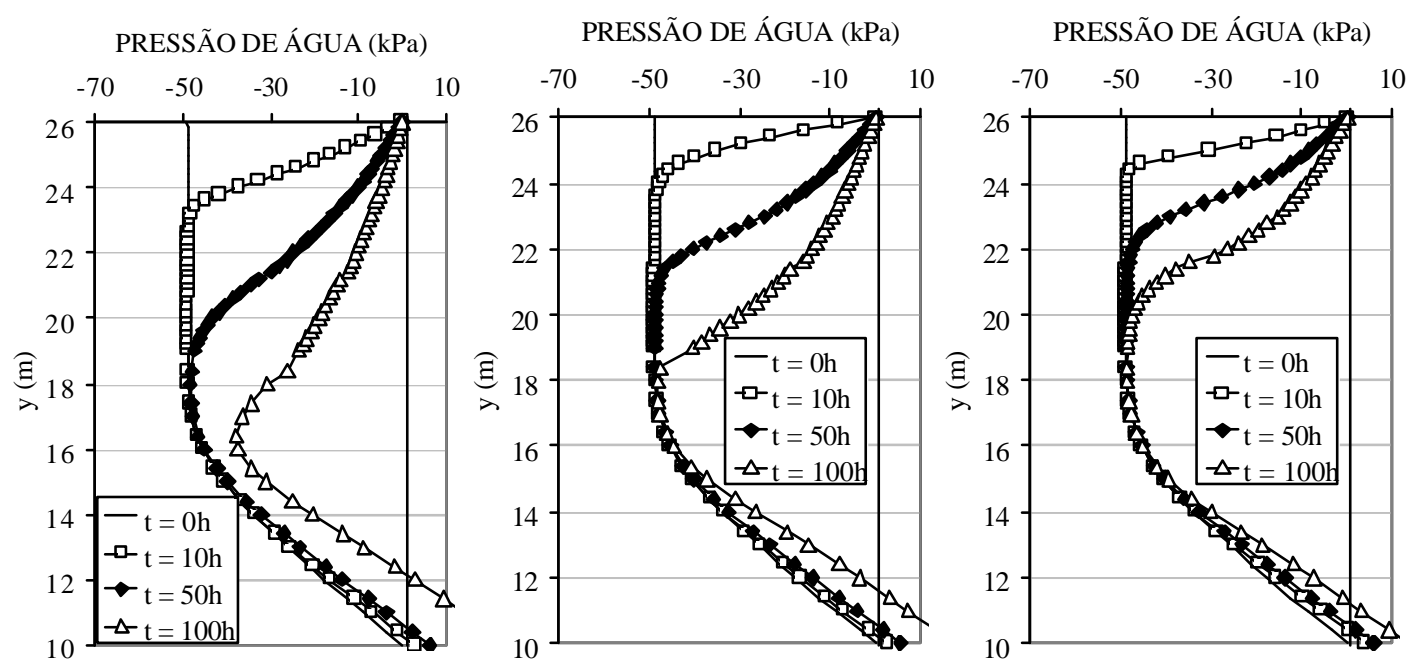

Figura 54. Perfil de pressão de água ao longo do tempo - "B $n=2.5$ ", Solo B, "B $n=8 "$, respectivamente, precipitação igual a $20 \mathrm{~mm} / \mathrm{h}$.

Nota-se que quanto menor o parâmetro $n$ maior a velocidade de avanço da frente de umedecimento e de ascensão do nível freático. Assim como nas análises anteriores, este comportamento parece associado à diferença entre a umidade volumétrica inicial e a umidade de saturação e conseqüentemente associada também à pressão de entrada de ar.

Assim, a partir da análise paramétrica da curva de retenção, pode-se constatar que a principal variável determinante da velocidade de avanço da frente de umedecimento e da velocidade de ascensão do nível freático é a pressão de entrada de ar, pois esta determina quão próxima está a condição de campo da condição de saturação do solo. Esta constatação permite vislumbrar situações em que os parâmetros analisados não interferem (ou interferem muito pouco) na infiltração propriamente dita. Este é o caso do solo C para o qual devido a sua baixa pressão de entrada de ar $(<1 \mathrm{kPa})$ os parâmetros $m$ e $n$ praticamente não alteram esta pressão e conseqüentemente têm pouca influência sobre o processo de infiltração.

\section{2 - Estabilidade do talude de referência}

\subsection{1 - Fator de Segurança Inicial}

Para o perfil de sucção inicial e considerando os parâmetros de resistência não saturada, o Fator de Segurança do talude é igual a 1,75. Este Fator de Segurança é o 
mesmo para todos os taludes estudados nesta análise paramétrica, uma vez que os parâmetros de resistência são os mesmos para todos os solos. A Figura 55 mostra a superfície crítica e o diagrama de sucção inicial para todos os solos.

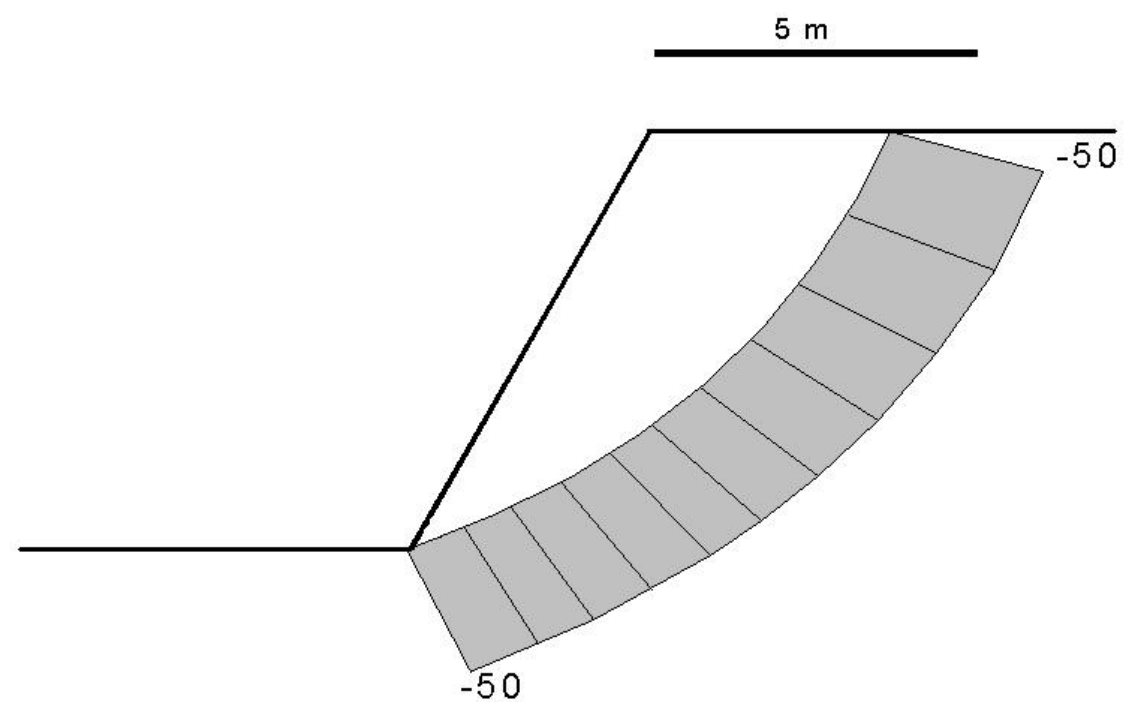

Figura 55. Superfície crítica, Perfil de pressão inicial, válidos para todos os solos.

\subsection{2 - Condição Saturada}

Foi analisada também a estabilidade do talude de referência imaginando que o solo encontra-se saturado, ou seja, não há contribuição da sucção para a resistência ao cisalhamento, pois a pressão de água em todo o talude é nula.

Vale a pena mencionar que esta condição não representa o nível freático em superfície, pois isto ocasionaria pressões de água positivas segundo um perfil hidrostático.

Uma vez que os parâmetros de resistência são os mesmos para os três tipos de solo e que não há pressões de água positivas atuantes no talude, esta análise independe das características hidráulicas do solo, o que é o diferencial entre os solos estudados neste trabalho. Assim, considerando os parâmetros para o solo saturado, c' $=5 \mathrm{kPa}$ e $\phi^{\prime}=35^{\circ}$,

o Fator de Segurança obtido é igual a 0,853 correspondente a superfície 1 da Figura 56, o que evidencia que o talude de referência atingiria a ruptura por perda da coesão aparente. 


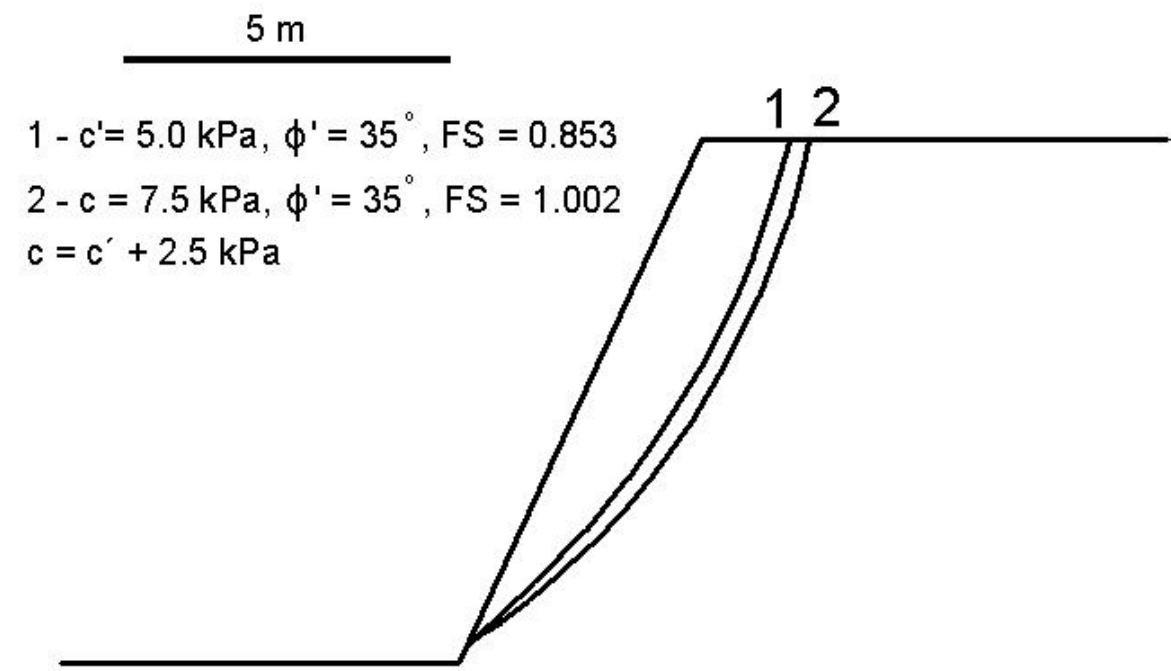

Figura 56. Superfície de Ruptura para condição saturada

Para verificar o efeito de coesão, foi calculado o valor de coesão total necessário para que o talude atingisse Fator de Segurança igual a 1. Assim, pode-se estabelecer quanto de coesão devido a sucção é necessária para um Fator de Segurança igual a 1. Verifica-se que o Fator de Segurança igual a 1 ocorre na superfície 2 assinalada na Figura 56 para uma coesão de 7,5 kPa. Assim, é necessário um adicional de $2,5 \mathrm{kPa}$ de coesão o que corresponde a uma sucção na superfície de ruptura igual a $7 \mathrm{kPa}$.

Assim, quando as precipitações aplicadas conduzirem a valores médios de sucção na superfície crítica da mesma grandeza que os valores médios indicados, espera-se que o talude de referência seja levado a ruptura com Fator de Segurança igual a um.

\subsection{3 - Casos básicos (solos nas condições naturais)}

Foram denominados básicos, os casos de análise de estabilidade do talude de referência composto pelos solos A, B e C em suas condições naturais.

Assim, foi analisada a estabilidade do talude de referência composto pelos solos A, B e C conforme apresentados na base de dados, com condutividade hidráulica saturada igual a 5E-6, 1E-8 e 1E-6 m/s respectivamente. As curvas de retenção, funções condutividade hidráulica e parâmetros de Resistência ao Cisalhamento destes solos foram apresentadas no item 3.1.2. 
A partir do perfil de sucção inicial, foi aplicada uma precipitação de intensidade $1 \mathrm{~mm} / \mathrm{h}$ e acompanhada a evolução do perfil de sucção até que na análise de estabilidade o talude atingisse Fator de Segurança igual a um ou ocorresse estabilização do Fator de Segurança. O mesmo foi repetido para as precipitações com intensidade de 20 e $70 \mathrm{~mm} / \mathrm{h}$.

A evolução do Fator de Segurança (FS) ao longo do tempo para as diversas precipitações é mostrada nas Figuras 57 a 59, para os solos A, B e C, respectivamente.

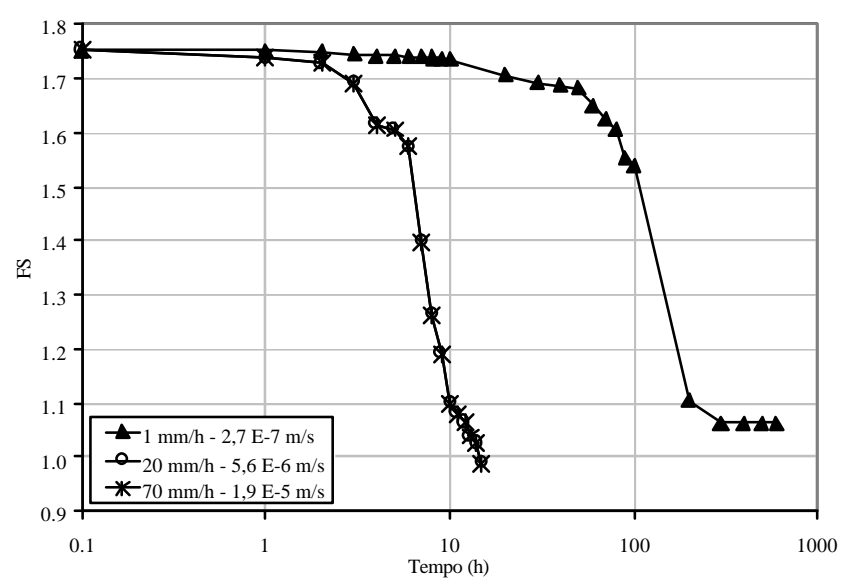

Figura 57. Evolução do Fator de Segurança com o tempo - Solo A, $\phi^{b}=20^{\circ}, k_{s}=5 E-6$ $\mathrm{m} / \mathrm{s}$, precipitações de 1,20 e $70 \mathrm{~mm} / \mathrm{h}$

A condutividade hidráulica saturada adotada para o solo A é maior que a primeira intensidade de precipitação aplicada ( $1 \mathrm{~mm} / \mathrm{h})$, e menor que 20 e $70 \mathrm{~mm} / \mathrm{h}$. Desta forma, o solo na condição saturada permite a infiltração de toda a precipitação com intensidade de $1 \mathrm{~mm} / \mathrm{h}$, ao contrário das demais em que parcela do volume precipitado converte-se em escoamento superficial.

Para as precipitações de 20 e $70 \mathrm{~mm} / \mathrm{h}$, o solo A atinge sua máxima capacidade de infiltração, assim ocorre escoamento superficial e sobreposição da evolução do Fator de Segurança para as duas precipitações. O talude atingiu Fator de Segurança igual a um após 15 horas destas precipitações com perfil de pressão de água do tipo 1 .

A precipitação de $1 \mathrm{~mm} / \mathrm{h}$ conduz o talude a Fator de Segurança igual a 1,063 após 300 horas de duração da precipitação, permanecendo neste patamar até as 600 horas de precipitação, tempo limite para análise de fluxo neste caso. Nestas 
condições, com o prosseguimento da precipitação e a ascensão do nível freático, o talude atingiria Fator de Segurança igual a um com perfil de pressão de água do tipo 4.

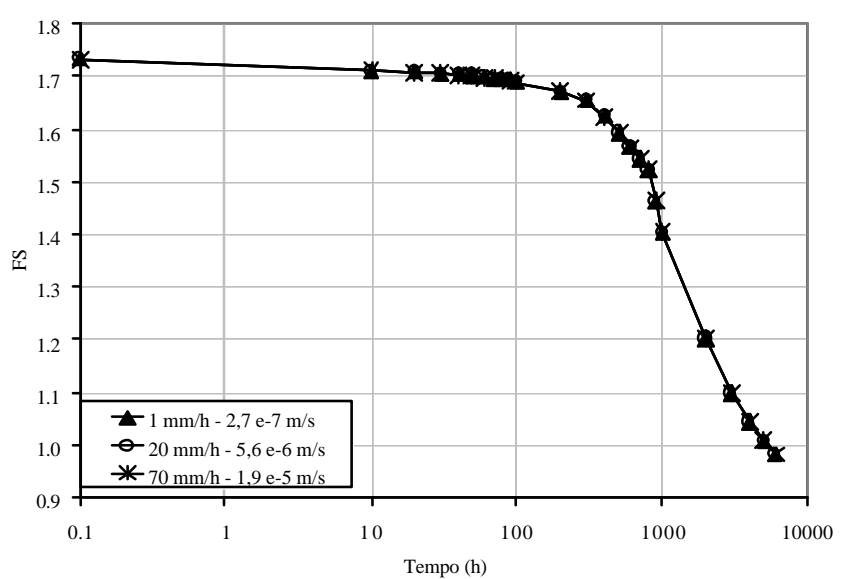

Figura 58. Evolução do Fator de Segurança com o tempo - Solo $B, \phi^{b}=20^{\circ}, k_{s}=1 E-8$ $\mathrm{m} / \mathrm{s}$, precipitações de 1,20 e $70 \mathrm{~mm} / \mathrm{h}$

A condutividade hidráulica saturada adotada para o solo B é muito menor que as intensidades de precipitação aplicadas, ou seja, o solo na condição saturada permite a infiltração de pequena parcela do volume precipitado e o restante é convertido em escoamento superficial.

Neste caso também ocorre a sobreposição das curvas de evolução do Fator de Segurança, uma vez que todas as precipitações aplicadas são maiores que a condutividade hidráulica saturada. O talude atingiu Fator de segurança igual a um após 6000 horas de duração da precipitação.

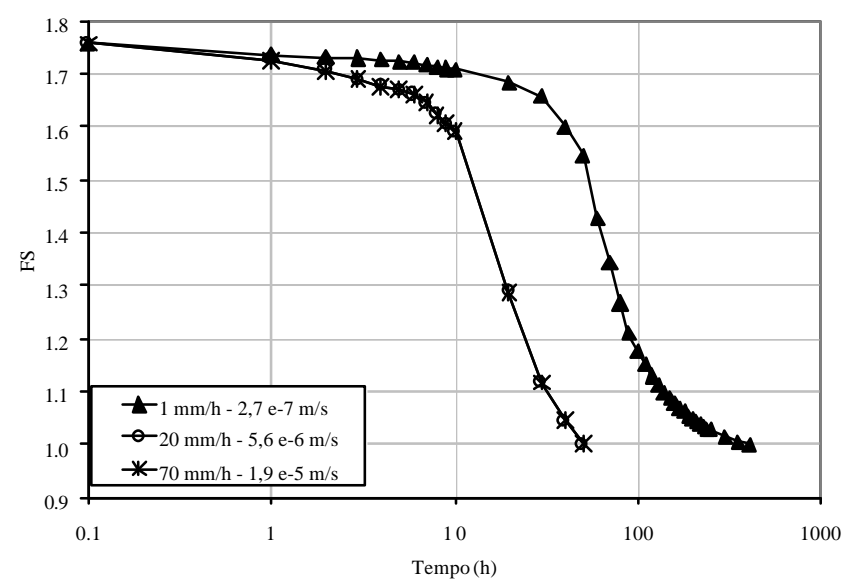

Figura 59. Evolução do Fator de Segurança com o tempo - Solo $C, \phi^{b}=20^{\circ}, k_{s}=1 E-6$ $\mathrm{m} / \mathrm{s}$, precipitações de 1,20 e $70 \mathrm{~mm} / \mathrm{h}$ 
A condutividade hidráulica saturada do solo C é menor que 20 e $70 \mathrm{~mm} / \mathrm{h}$, o que ocasiona escoamento superficial. Entretanto este solo permite a completa infiltração do volume precipitado à taxa de $1 \mathrm{~mm} / \mathrm{h}$.

Ocorre, mais uma vez, a sobreposição da variação do fator de segurança para as precipitações de 20 e $70 \mathrm{~mm} / \mathrm{h}$, sendo que o talude atinge Fator de Segurança igual a um após 50 horas do início destas precipitações. Para a precipitação de $1 \mathrm{~mm} / \mathrm{h}$ de intensidade, o talude atinge Fator de Segurança igual a 1,054 após 190 horas de precipitação, e após 210 horas (tempo limite de análise de fluxo) atinge Fator de Segurança igual a 1,042 .

Comparando os três tipos de solo, constata-se que quanto mais siltoso o solo mais lentamente ocorre a variação do Fator de Segurança. Este comportamento está associado principalmente à baixa condutividade hidráulica deste tipo de solo.

Verifica-se que dado um tipo de solo, o efeito de precipitações maiores que sua condutividade hidráulica é sempre o mesmo, uma vez que sua máxima capacidade de infiltração é atingida. Certamente, este comportamento está associado à hipótese de escoamento superficial instantâneo, pois caso fosse permitido o armazenamento de água na superfície do solo, a infiltração da superfície sujeita a diferentes lâminas de água seria também função do volume precipitado.

Vale a pena ressaltar que precipitações inferiores à condutividade hidráulica saturada podem não ocasionar a ruptura do Talude, e conduzir à estabilização do Fator de Segurança do Talude em patamar inferior ao inicial, com perfil de pressão de água do tipo 3. Entretanto com o prosseguimento da precipitação e a elevação do nível freático ocorreria ruptura com perfil de pressão do tipo 4.

Observa-se ainda que para qualquer intensidade de precipitação maior que a condutividade hidráulica saturada, a evolução do Fator de Segurança é sempre a mesma para um dado solo. Assim nas análises seguintes, quando da aplicação de diferentes intensidades de precipitação, será apresentada apenas uma precipitação com intensidade maior que a condutividade hidráulica para cada caso.

Os exemplos de comportamento apresentados na análise paramétrica da estabilidade do talude de referência são válidos para os três tipos de solo analisados (A, B e C), salvo indicação em contrário. 


\subsection{4 - Influência da condutividade hidráulica saturada}

Para avaliar a influência da condutividade hidráulica saturada, foram analisados três casos de taludes compostos pelo solo $\mathrm{C}$ com diferentes condutividades hidráulica saturada $\left(\mathrm{k}_{\mathrm{s}}=1 \mathrm{E}-5,1 \mathrm{E}-6\right.$ e $\left.1 \mathrm{E}-7 \mathrm{~m} / \mathrm{s}\right)$ e mesma curva de retenção, e submetidos à precipitação de $1 \mathrm{~mm} / \mathrm{h}$. No mais não foram feitas alterações nos parâmetros de resistência. Os perfis de pressão de água ao longo do decorrer da precipitação para estes casos foram apresentados na Figura 38.

Vale a pena ressaltar que a precipitação de $1 \mathrm{~mm} / \mathrm{h}$ é menor que as condutividades hidráulica saturada de 1E-5 e 1E-6m/s, configurando uma condição de precipitação não excedente.

Para o caso em que $\mathrm{k}_{\mathrm{s}}$ é igual a $1 \mathrm{E}-7 \mathrm{~m} / \mathrm{s}$ ocorre a saturação do solo sujeito a precipitação de $1 \mathrm{~mm} / \mathrm{h}$. Já nos casos em $\mathrm{k}_{\mathrm{s}}$ é igual a $1 \mathrm{E}-6$ e $1 \mathrm{E}-5 \mathrm{~m} / \mathrm{s}$, o solo tem sua sucção inicial reduzida, dentro da frente de umedecimento, para 10 e $30 \mathrm{kPa}$ respectivamente, valores para os quais a condutividade hidráulica destes solos correspondem a $1 \mathrm{~mm} / \mathrm{h}$.

A estabilização da sucção dentro da frente de umedecimento em diferentes valores conduz a situações distintas de estabilidade. No caso em que a condutividade hidráulica saturada é igual a $1 \mathrm{E}-7 \mathrm{~m} / \mathrm{s}$ o talude de referência atinge fator de segurança igual a 1 devido a completa perda da contribuição da sucção para a resistência. No caso do solo com condutividade igual a $1 \mathrm{E}-6 \mathrm{~m} / \mathrm{s}$, a sucção é muito próxima daquela (7kPa) que produziria uma contribuição em que o talude apresentasse Fator de segurança igual a 1, assim o talude não mantém-se estável. Já no caso em que a condutividade é igual a $1 \mathrm{E}-5 \mathrm{~m} / \mathrm{s}$ a sução dentro da frente de umedecimento é suficiente para que sua contribuição para a resistência garanta a estabilidade do talude, ocorrendo então uma estabilização momentânea do fator de segurança em patamar inferior ao inicial.

A Figura 60 apresenta a variação do fator de Segurança no decorrer do tempo para os três casos: 


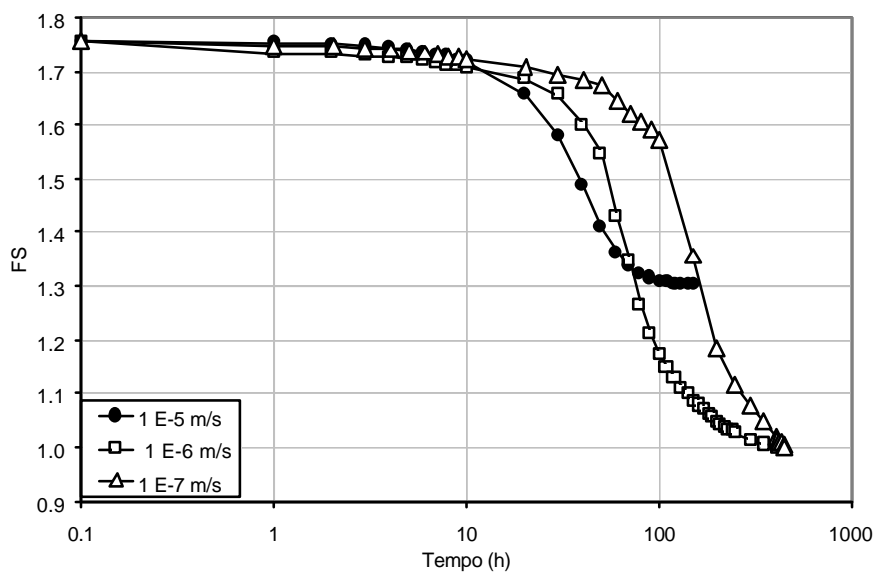

Figura 60. Evolução do Fator de Segurança com o tempo - Solo $C, \phi^{b}=20^{\circ}, k_{s}=1 E$ 5, 1 E-6 e $1 \mathrm{E}-7 \mathrm{~m} / \mathrm{s}$, precipitação igual a $1 \mathrm{~mm} / \mathrm{h}$

Nota-se que para um mesmo tipo de solo, quanto maior sua condutividade hidráulica saturada, menor é a redução do Fator de Segurança.

Este comportamento está diretamente associado ao perfil de pressão desenvolvido em cada caso, pois destacando o perfil de pressão para o solo com $\mathrm{k}_{\mathrm{S}}$ igual a $1 \mathrm{E}-5 \mathrm{~m} / \mathrm{s}$ percebe-se que:

Ocorre uma menor redução da sucção inicial, o que justifica a estabilização do Fator de Segurança do talude;

- $\quad$ A velocidade de avanço da frente de umedecimento é maior, o que faz com que o Fator de Segurança decresça mais rapidamente que nos demais casos.

No entanto, deve-se observar que uma maior condutividade hidráulica propicia a ascensão mais rápida do nível freático, assim esta estabilização do Fator de Segurança é temporária.

Desta forma, o aumento da condutividade hidráulica saturada não pode ser analisado isoladamente, uma vez que caso a ascensão do nível freático seja rápida pode não ocorrer a estabilização mencionada (Solo B). Além disso, se para a taxa de infiltração aplicada, o solo apresentar uma sucção correspondente que não permita a estabilização do fator de segurança, o aumento desta contutividade hidráulica diminuirá o tempo necessário para que o talude atinja Fator de segurança igual a um (Solo C). Necessariamente o efeito do aumento da condutividade hidráulica deverá ser analisado em conjunto com a função condutividade hidráulica do solo, além do perfil de pressão no decorrer da precipitação. 


\subsection{5 - Influência da Função condutividade hidráulica}

Para avaliar a influência da função condutividade hidráulica saturada, foram utilizados três casos de taludes compostos pelos solos fictícios "RetC-CondA", "RetC-CondB" e pelo Solo C já apresentados no item 4.1.2. Estes taludes foram submetidos à precipitação de $20 \mathrm{~mm} / \mathrm{h}$ e avaliadas suas variações do Fator de Segurança (Fig.61).

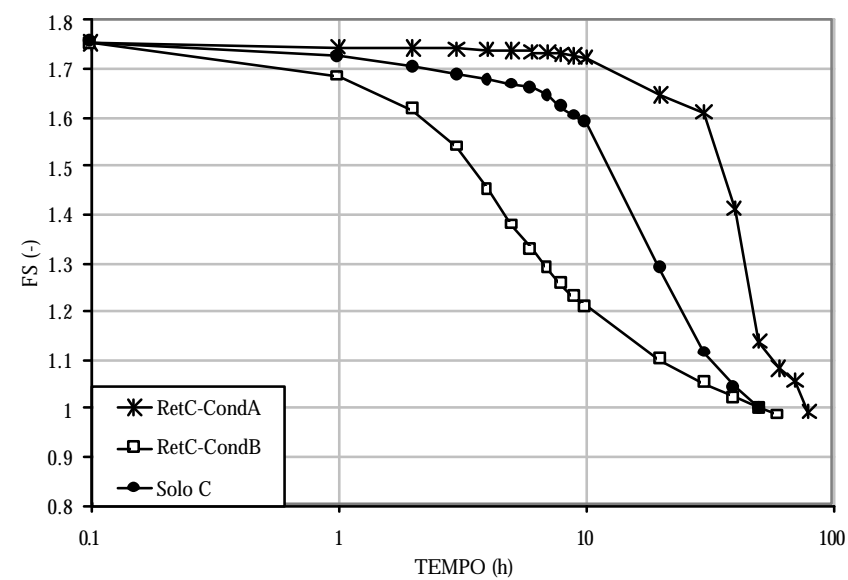

Figura 61. Evolução do Fator de Segurança com o tempo - "RetC-CondA", "RetC-

CondB" e Solo $C, \phi^{b}=20^{\circ}, k_{s}=1 \mathrm{E}-6 \mathrm{~m} / \mathrm{s}$, precipitação igual a $20 \mathrm{~mm} / \mathrm{h}$.

Nota-se que o talude composto pelo solo com menor condutividade hidráulica para a sucção inicial de $50 \mathrm{kPa}$ ("RetC-CondA", Fig.62), e consequentemente com menor velocidade de avanço da frente de umedecimento (Fig.39), apresenta a variação do Fator de Segurança mais lenta, o que acena com uma relação direta entra a velocidade de avanço da frente de umedecimento e a velocidade de decréscimo do Fator de Segurança.

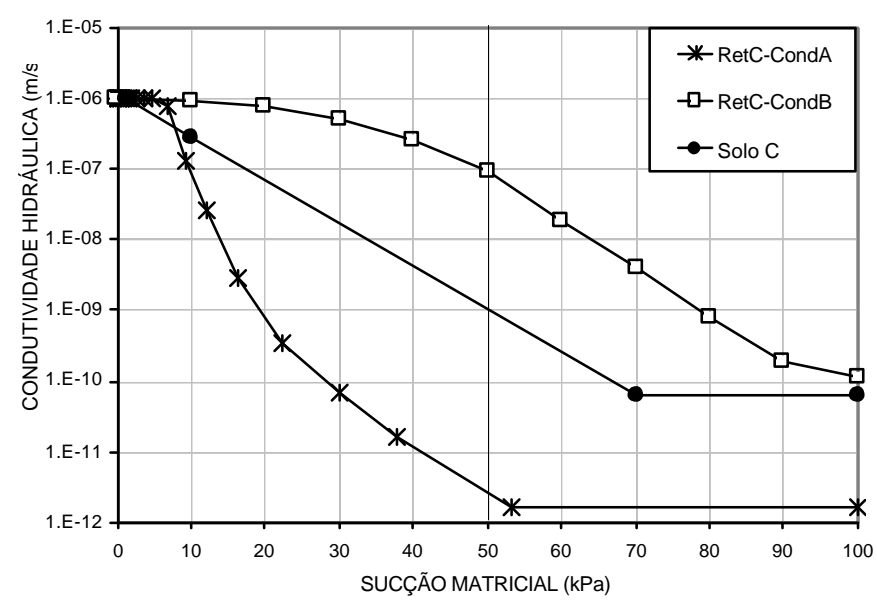

Figura 62. Função condutividade hidráulica:"RetC-CondA", "RetC-CondB", Solo C. 
Para verificar esta relação foi analisada a estabilidade de taludes compostos pelos solos fictícios "C1" e "C2" já apresentados no item 4.1.3, submetidos a precipitação de $20 \mathrm{~mm} / \mathrm{h}$. A variação do Fator de Segurança obtida nestes casos é apresentada na Figura 63. .

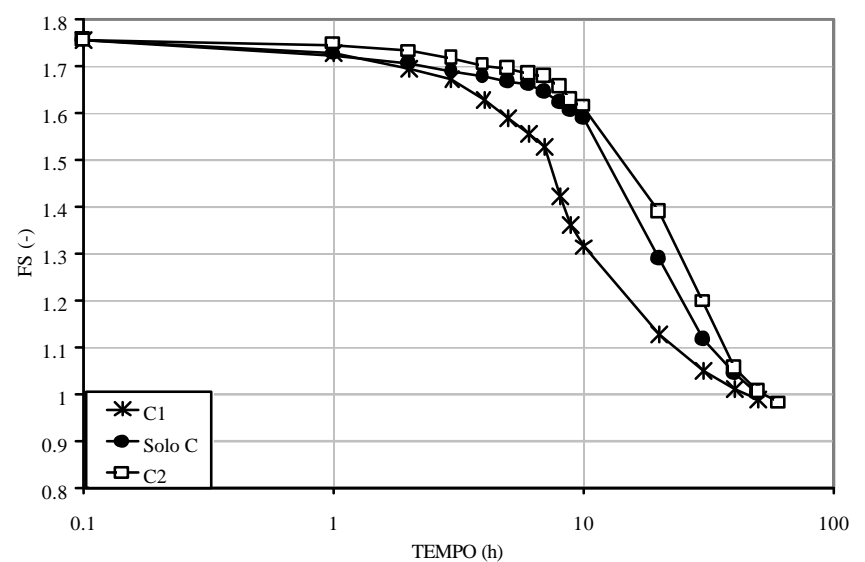

Figura 63. Evolução do Fator de Segurança com o tempo - "C1", "C2" e solo C, $\phi^{b}=20^{\circ}, k_{s}=1 \mathrm{E}-6 \mathrm{~m} / \mathrm{s}$, precipitação igual a $20 \mathrm{~mm} / \mathrm{h}$.

Como nas análises anteriores, o perfil de pressão com menor velocidade de avanço da frente de umedecimento, que corresponde ao talude composto pelo solo com maior declividade da função condutividade hidráulica ("C2"), apresenta a variação do Fator de Segurança mais lenta.

\subsection{6 - Influência da Curva de Retenção (solos híbridos)}

Para avaliar a influência da curva de retenção, foram utilizados três casos de taludes compostos pelos solos fictícios "RetA-CondB", "RetC-CondB" e pelo Solo B já apresentados no item 4.1.4. Estes taludes foram submetidos à precipitação de $20 \mathrm{~mm} / \mathrm{h}$ e avaliadas suas variações do Fator de Segurança (Fig.64). 


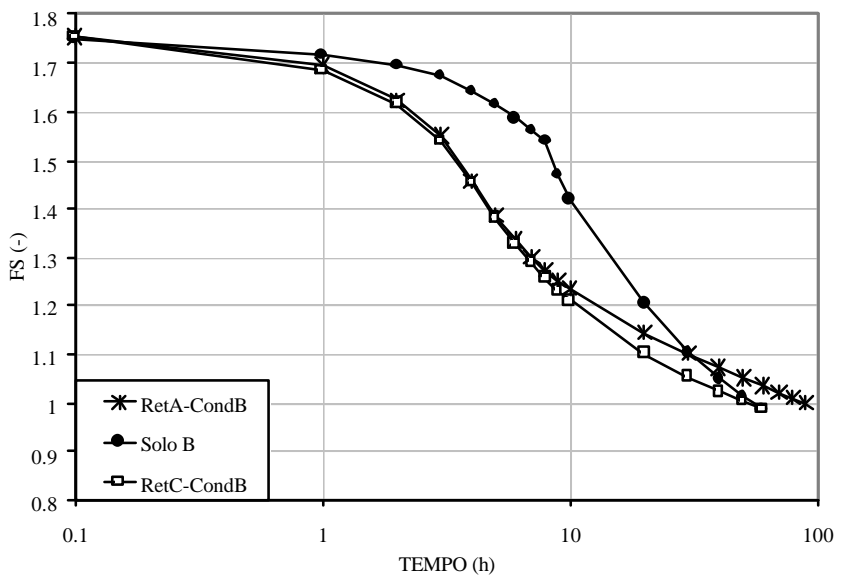

Figura 64. Evolução do Fator de Segurança com o tempo - "RetA-CondB", "RetCCondB" e Solo $B, \phi^{b}=20^{\circ}, k_{s}=1 \mathrm{E}-6 \mathrm{~m} / \mathrm{s}$, precipitação $=20 \mathrm{~mm} / \mathrm{h}$.

A variação do fator de segurança apresentada na Fig.64 dificilmente pode ser associada a uma única característica da curva de retenção, pois ao mesmo tempo em que ocorre o avanço de uma frente de umedecimento não homogênea, também ocorre a ascensão do nível freático. Assim faz-se necessária uma análise da influência da pressão de entrada de ar e da diferença entre a umidade volumétrica inicial e de saturação na estabilidade do talude de referência.

Para avaliar a influência da pressão de entrada de ar na estabilidade do talude de referência, foram utilizados os solos fictícios "B -10 ", "B +20 " e o solo B, conforme apresentados no item 4.1.4. Estes taludes foram submetidos à precipitação de $20 \mathrm{~mm} / \mathrm{h}$ e avaliadas sua s variações do Fator de Segurança (Fig.65).

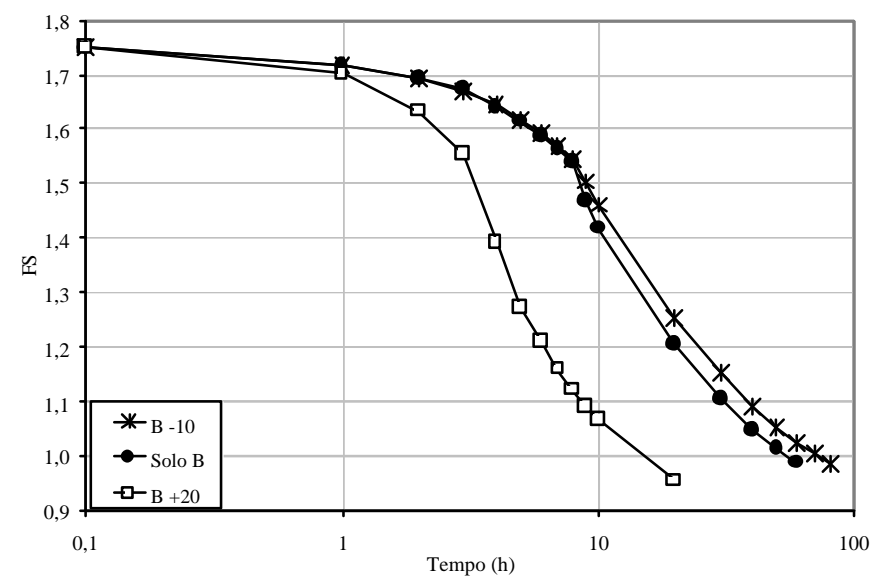

Figura 65. Evolução do Fator de Segurança com o tempo - "B -10”, “B +20” e Solo $B, \phi^{b}=20^{\circ}, k_{s}=1 \mathrm{E}-6 \mathrm{~m} / \mathrm{s}$, precipitação $=20 \mathrm{~mm} / \mathrm{h}$. 
Pode-se constatar que quanto maior a pressão de entrada de ar mais rapidamente ocorre a redução do fator de segurança, o que está de acordo com o efeito deste parâmetro na evolução do perfil de pressão de água. Vale a pena ressaltar que os solos B e "B -10" apresentaram comportamento similar, que pode ser explicado devido a pequena diferença entre as umidades volumétricas iniciais destes dois tipos de solo. O solo "B +20" apresenta pressão de entrada de ar mais próxima à condição de sucção de campo e conseqüentemente apresenta uma menor diferença entre a umidade volumétrica inicial e de saturação, o que faz com que seja necessária menor quantidade de água infiltrada para saturar o solo e permitir a ascensão do Nível freático.

Assim pode-se definir uma espécie de "gatilho" de instabilização determinado pela diferença entre a pressão de entrada de ar e a sucção em campo, pois quanto mais próximas estas pressões, também mais próxima será a condutividade hidráulica da condutividade hidráulica saturada, o que torna o solo muito mais suscetível a infiltração e perda da contribuição da sucção para a resistência.

Para mostrar o efeito determinante da pressão de entrada de ar foi criada uma função condutividade hidráulica para o solo "B +20" em que a redução da condutividade hidráulica ocorre apenas depois de atingida a pressão de entrada de ar. Esta função está mais próxima da realidade que a utilizada na análise paramétrica para este solo, pois reflete a influência da pressão de entrada de ar na função condutividade. (Fig. 66)

Nota-se que nesta situação, a influência determinante da pressão de entrada de ar sobre a evolução do perfil de pressão e estabilidade do talude não é simples pois o solo, nas condições de campo apresenta uma condutividade hidráulica (correspondente a sucção inicial de $50 \mathrm{kPa}$ ) 5 vezes maior que a apresentada pelo solo B, além de necessitar menor quantidade de água para que ocorram a saturação e a ascensão do Nível freático. Enquanto o efeito da pressão de entrada de ar na função condutividade, facilita o avanço da frente de saturação e dificulta a completa saturação do solo (efeito fa vorável), seu efeito sobre a curva de retenção faz com que seja necessária menor quantidade de água para que a saturação ocorra (efeito desfavorável). A Figura 67 mostra a variação do Fator de Segurança para o talude composto pelo solo "B+20 kf ", que apresenta o efeito da pressão de entrada de ar na 
função condutividade hidráulica. Esta variação está muito próxima a variação apresentada pelo solo "B+20" impossibilitando uma definição mais clara da influência da pressão de entrada de ar sobre a função condutividade hidráulica e indiretamente sobre a estabilidade do talude de referência.

Simplificadamente, quanto mais próxima a pressão de entrada de ar estiver da sucção de campo, maior será a taxa de infiltração no solo, o que justifica a existência de correlações entre precipitações acumuladas e a ocorrência de escorregamentos.

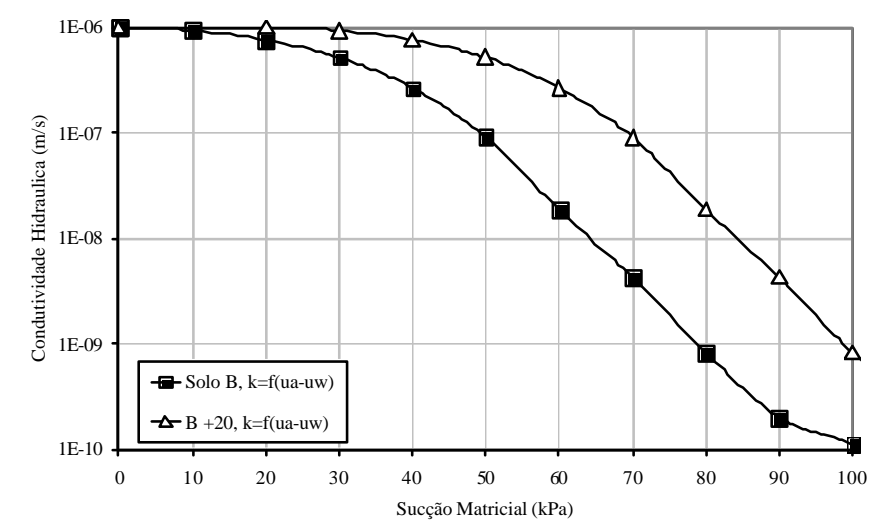

Figura 66. Função condutividade hidráulica fictícia solo $B$ e "B+20”

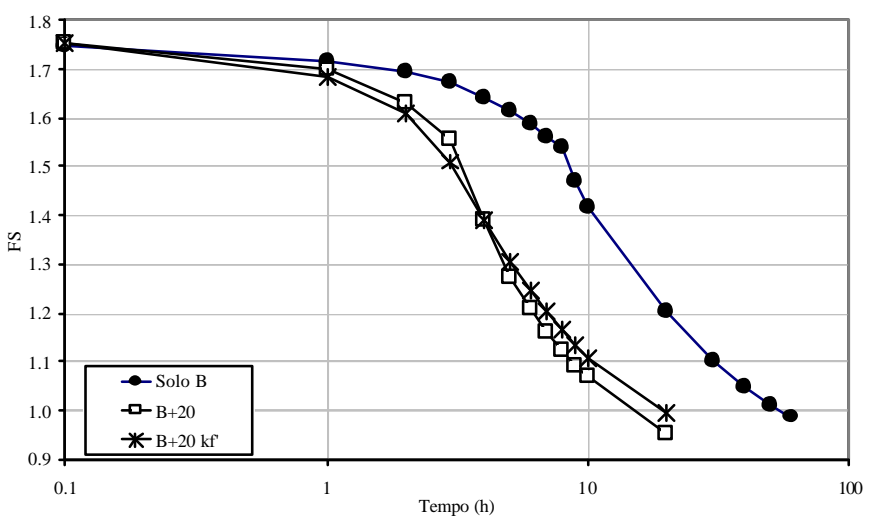

Figura 67. Evolução do Perfil de Segurança com o tempo - Solos B, "B+20" e $" B+20 \mathrm{kf}$ ", $k s=1 E-6 \mathrm{~m} / \mathrm{s}$ e precipitação $=20 \mathrm{~mm} / \mathrm{h}$. 


\subsection{7 - Influência do parâmetro $\phi^{b}$ da envoltória de Resistência ao Cisalhamento}

Além da possibilidade de alteração do perfil de pressão na ruptura, a conseqüência direta do aumento de $\phi^{\mathrm{b}}$ é o aumento do Fator de Segurança inicial, assim como a diminuição deste parâmetro ocasiona a diminuição do Fator de Segurança inicial.

Para avaliar a influência do parâmetro $\phi^{\mathrm{b}}$ (FREDLUND et al.,1978) da envoltória de Resistência ao Cisalhamento do solo na estabilidade do talude de referência, foi utilizado o caso básico do solo A (item 4.2.3) com $\phi^{\mathrm{b}}$ valendo $10^{\circ} \mathrm{e}$ $30^{\circ}$. Nestas condições, o talude de referência foi submetido às precipitações de 1 e 20 $\mathrm{mm} / \mathrm{h}$ e avaliada a variação do Fator de Segurança (Fig.68).

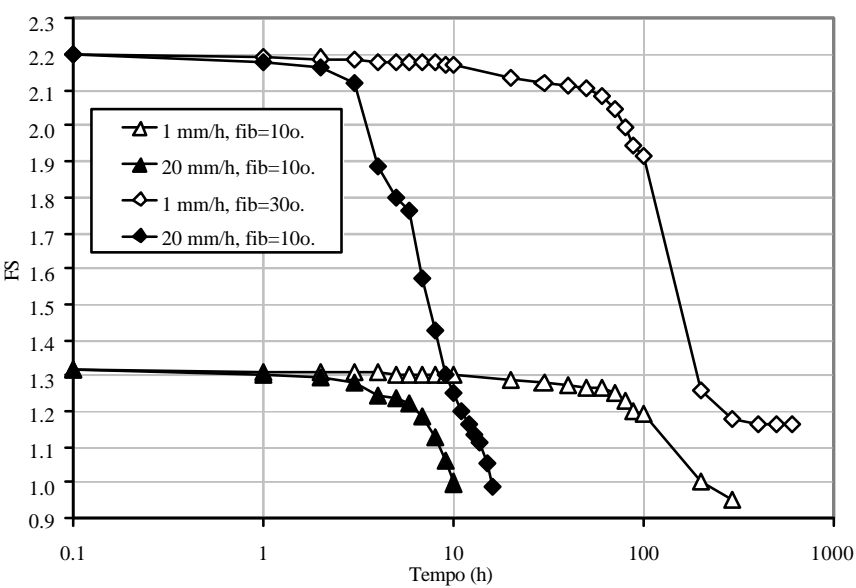

Figura 68. Evolução do Fator de Segurança com o tempo - Solo A, $\phi^{b}=10^{\circ}$ e 30,$k_{s}$ $=5 \mathrm{E}-6 \mathrm{~m} / \mathrm{s}$, e precipitação $=1$ e $20 \mathrm{~mm} / \mathrm{h}$.

As curvas de variação do Fator de Segurança para os diferentes valores de $\phi^{\mathrm{b}}$ são aproximadamente paralelas, ou seja, a redução do Fator de Segurança do talude sujeito a uma dada precipitação inicia-se decorrido sempre o mesmo intervalo de tempo. Isto ocorre pois, para um dado tempo, o perfil de sucção para uma dada precipitação é independente do valor de $\phi^{\mathrm{b}}$.

Para o solo A com condutividade hidráulica igual a 5 E-6m/s, as precipitações de 1 e $20 \mathrm{~mm} / \mathrm{h}$ conduziriam a sucções de 10 e $0 \mathrm{kPa}$ respectivamente.

No item 4.2.1, para que o talude atingisse Fator de Segurança igual a um, o valor de $c$ (coesão total) deveria ser igual $7.5 \mathrm{kPa}$. 
De posse do valor de $c^{\prime}$ (coesão efetiva) adotado $\left(c^{\prime}=5 \mathrm{kPa}\right), \operatorname{com} \phi^{\mathrm{b}}$ igual a $10^{\circ}$ e $30^{\circ}$, a sucção média necessária para a manutenção da estabilidade do talude deve ser igual a 14 e $4 \mathrm{kPa}$ respectivamente.

Assim a precipitação de $1 \mathrm{~mm} / \mathrm{h}$, que conduz a sucções de $10 \mathrm{kPa}$ dentro da frente de umedecimento para o solo A, configura duas situações distintas:

- $\quad$ Para $\phi^{\mathrm{b}}$ igual a $10^{\circ}$ o talude atinge Fator de Segurança igual a 1 devido ao avanço da frente de umedecimento, Perfil Tipo 1 de pressão de água;

- Para $\phi^{\mathrm{b}}$ igual a $30^{\circ}$ o talude estabiliza o Fator de Segurança temporariamente, Perfil Tipo 3 de pressão de água.

Já a precipitação de $20 \mathrm{~mm} / \mathrm{h}$, que configura uma condição de precipitação excedente, satura o solo e conduz o talude a ruptura devido ao avanço da frente de umedecimento.

Assim o parâmetro $\phi^{\mathrm{b}}$ influi indiretamente sobre o perfil de pressão de água, pois uma vez garantida a estabilidade momentânea do talude, com o decorrer da precipitação pode ocorrer a ascensão do nível freático.

\section{3 - Evolução da superfície crítica}

$\mathrm{Na}$ maioria dos casos em que a intensidade da precipitação é maior que $\mathrm{k}_{\mathrm{s}}$ e que a ruptura se dá pelo avanço da frente de umedecimento, a superfície crítica (mínimo Fator de Segurança) inicia-se profunda no talude, torna-se mais rasa com o decorrer da precipitação e novamente aprofunda-se até que seja atingida a ruptura (Fig.69). Esta tendência pode ser explicada da seguinte forma:

Com o avanço da frente de saturação, ocorre a diminuição da contribuição da sucção para a coesão, fazendo com que superfícies mais próximas à face do talude tornem-se críticas;

- $\quad$ Continuando o processo de infiltração a superfície crítica torna-se bem próxima à face do talude, com sucções atuantes quase nulas (superfície 2 na Fig. 69);

Com a continuação do avanço da frente de saturação, a superfície rasa mencionada satura-se e atinge seu fator de segurança na condição em 
que não há contribuição da sucção para a resistência. Este fator de segurança ainda é maior que o de superfícies mais profundas que contam com ainda considerável contribuição da sucção;

Na ruptura, com a perda parcial ou total da contribuição da sucção, a superfície crítica (superfície 3 na Fig. 69) distancia-se da face do talude, mas ainda permanece mais rasa que a superfície inicial.

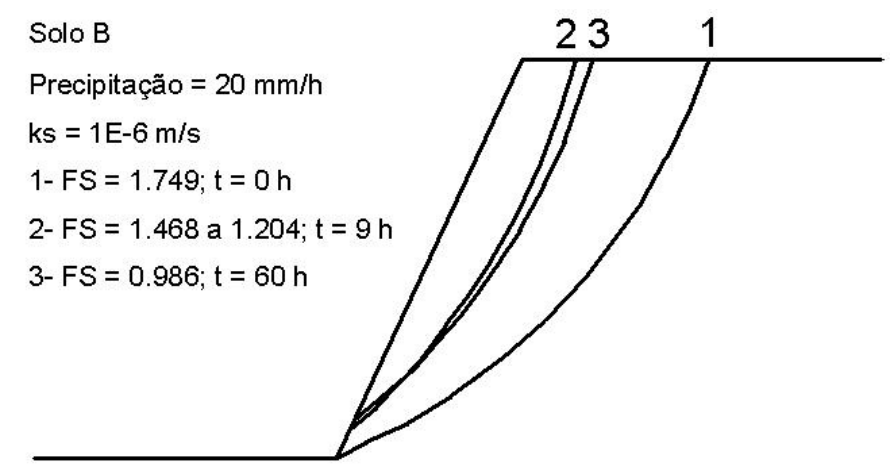

Figura 69. Evolução da Superfície Crítica com o tempo - Solo B, $\phi^{b}=20^{\circ}, k_{s}=1 E-6$ $\mathrm{m} / \mathrm{s}, 20 \mathrm{~mm} / \mathrm{h}$

Nos casos em que a intensidade da precipitação é menor que $\mathrm{k}_{\mathrm{s}}$, não ocorre a evolução descrita, uma vez que nas superfícies mais próximas a face do talude ainda existe a contribuição da sucção para a resistência.

A ocorrência de uma superfície crítica estável próxima à face do talude é mais pronunciada no talude composto pelo solo A, devido a maior definição da frente de saturação e perda completa da contribuição da sucção para a resistência. As Figuras 70 a 72 apresentam as superfícies criticas e os diagramas de pressões de água atuantes para o talude composto pelo solo A. 


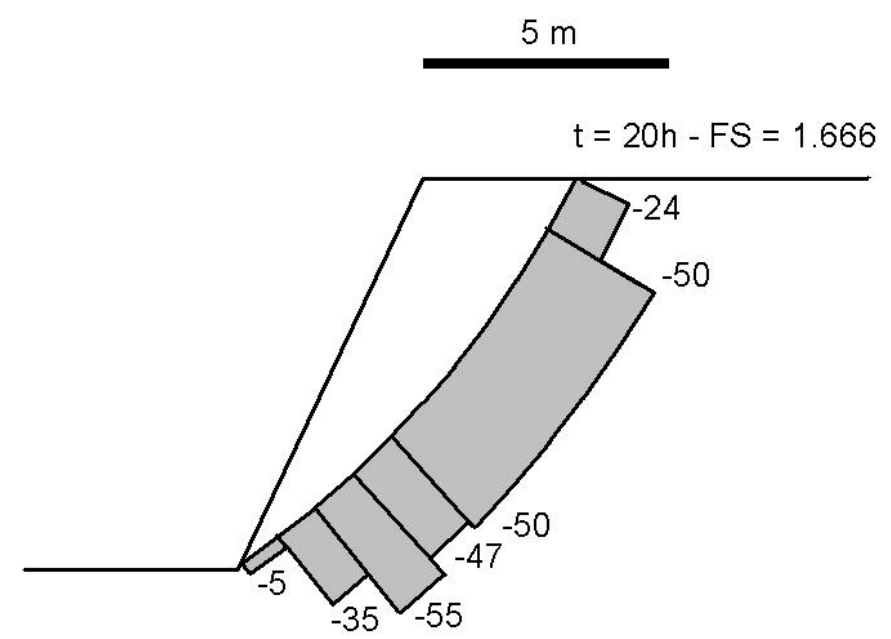

Figura 70. Diagrama de pressões de água atuantes na superfície crítica - Solo A, $\phi^{b}=20^{\circ}, k_{s}=1 E-6 \mathrm{~m} / \mathrm{s}, 20 \mathrm{~mm} / \mathrm{h}, t=20 \mathrm{~h}$
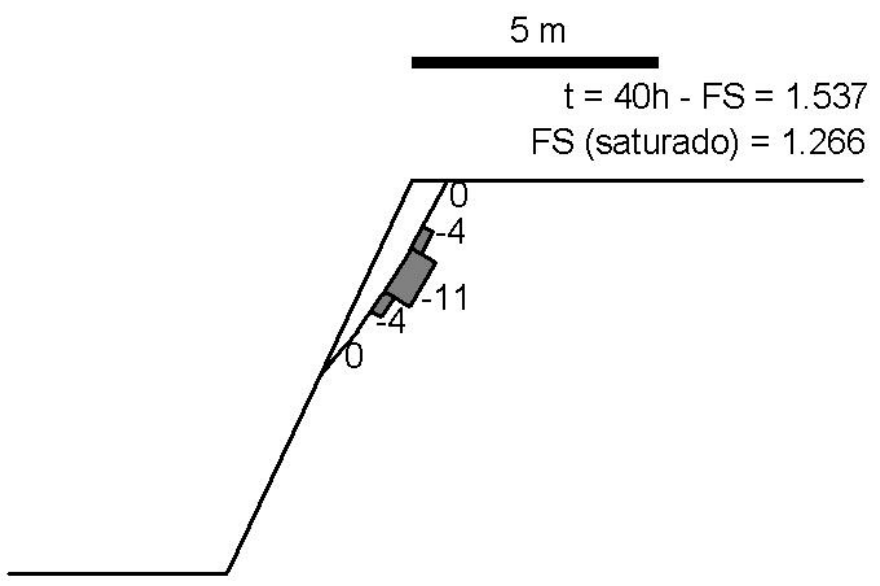

Figura 71. Diagrama de pressões de água atuantes na superfície crítica - Solo A, $\phi^{b}=20^{\circ}, k_{s}=1 E-6 \mathrm{~m} / \mathrm{s}, 20 \mathrm{~mm} / \mathrm{h}, t=40 \mathrm{~h}$

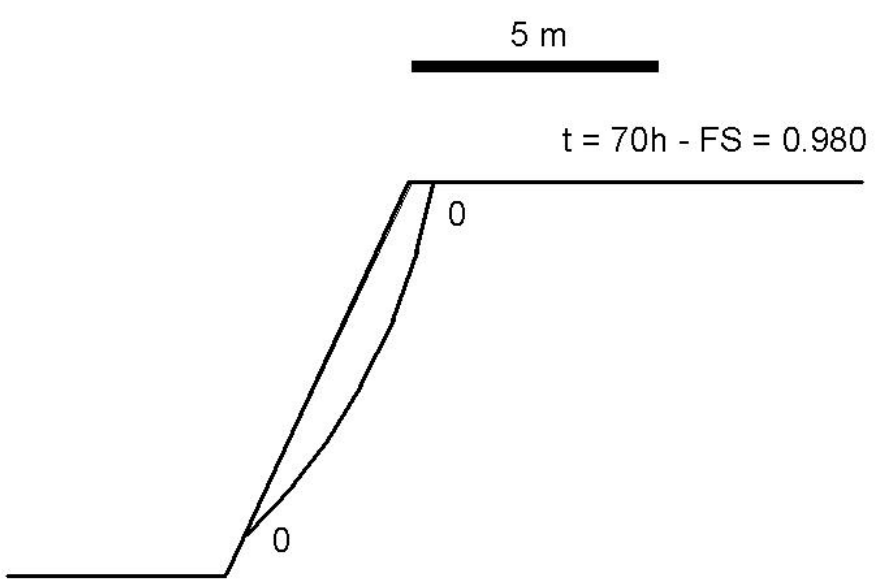

Figura 72. Diagrama de pressões de água atuantes na superfície crítica - Solo A, $\phi^{b}=20^{\circ}, k_{s}=1 \mathrm{E}-6 \mathrm{~m} / \mathrm{s}, 20 \mathrm{~mm} / \mathrm{h}, t=70 \mathrm{~h}$ 
Na Figura 71, onde é apresentada uma superfície crítica próxima à face do talude, a análise de estabilidade na condição saturada permite observar que esta superfície não romperia com o avanço da frente de umedecimento $\left(\mathrm{FS}_{\text {saturado }}=\right.$ 1,266), permitindo assim que superfícies críticas mais profundas atinjam Fator de Segurança igual a um, confirmando o comportamento descrito anteriormente.

Vale a pena ressaltar que esta evolução da superfície crítica pode estar sendo condicionada pelos parâmetros de resistência adotados, pela geometria do talude e pelo avanço da frente de umedecimento, não constituindo efeito unicamente causado por este último fator. 


\section{5 - CONCLUSÕES}

A partir de um talude de referência, com geometria fixada segundo a inclinação típica para taludes em areia argilo siltosa, típica para a região do Centro-Oeste do estado de São Paulo, foi desenvolvida uma análise paramétrica acerca das características do solo e da precipitação a fim de determinar a influência destas na infiltração de água e na estabilidade de taludes em solo não saturado. As hipóteses adotadas para a realização desta análise paramétrica compreendem:

a) O talude de referência foi considerado como sendo composto por um único tipo de solo, homogêneo e isotrópico, e não há variação do peso específico do solo durante o umedecimento, ou seja, o peso específico natural é igual ao peso específico saturado;

b) O talude é composto por um dos seguintes tipos de solo: A (Areia), B (Silte argiloso) e C (Areia argilo siltosa), tendo sido adotados os mesmos índices físicos $(\theta$ e $\gamma)$ para os três tipos de solo;

c) O modelo de resistência adotado para o solo não saturado foi o proposto por FREDLUND et al. (1978);

d) Os taludes compostos por estes solos foram submetidos a precipitações maiores e menores que a condutividade hidráulica saturada do solo, configurando condições de precipitação excedente e não excedente, respectivamente;

e) As análises de fluxo foram realizadas utilizando o programa SEEP/W do pacote GEOSLOPE;

f) $\mathrm{O}$ volume precipitado, que não infiltra, escoa instantaneamente ou seja não há a formação de lâmina de água na superfície, fenômeno que apesar de alterar muito pouco as condições de carga hidráulica, estabelece uma fonte permanente de água 
sobre a superfície e que pode alterar significativamente as condições de infiltração. As intensidades de precipitação foram adotadas como sendo constantes durante todo a duração da precipitação;

g) A análise de estabilidade do talude de referência durante a precipitação foi realizada utilizando o método de BISHOP Simplificado conforme resolvido pelo programa SLOPE/W do pacote GEOSLOPE.

Com base nessas premissas e nas análises efetuadas foi possível concluir:

1) Para a condição de precipitação não excedente, a sucção na região da frente de umedecimento reduz-se a valores correspondentes à taxa de infiltração aplicada na superfície, ou seja, ocorre o avanço da frente de umedecimento sem que ocorra a saturação do solo.

2) Com o prolongamento da precipitação (excedente ou não) ocorre a ascensão do nível freático até a saturação do solo em superfície, permitindo assim o desenvolvimento de diferentes tipos perfis de pressão na água durante a infiltração.

3) A função condutividade hidráulica e a pressão de entrada de ar são os principais determinantes do comportamento da infiltração e consequentemente da estabilidade do talude. Quanto maior a condutividade hidráulica inicial (correspondente à sucção inicial) e a condutividade hidráulica saturada do solo, mais rápido é o avanço da frente de umedecimento e maior é a possibilidade de ocorrência de ascensão do nível freático.

4) Nas análises de estabilidade, para a condição de precipitação não excedente pode ocorrer uma estabilização do Fator de Segurança, em patamar inferior ao inicial. Esta estabilização, justificada pela sucção resultante dentro da frente de umedecimento, é momentânea uma vez que com o prosseguimento da precipitação ocorre a elevação do nível freático e consequentemente a perda da contribuição da sucção para a resistência ao cisalhamento.

5) A redução do Fator de Segurança ocorre mais lentamente no casos de precipitação não excedente que a redução apresentada nos casos de precipitação excedente.

6) Dentre os três tipos de solos analisados, os taludes compostos pela areia (Solo A) apresentam redução mais rápida do Fator de Segurança que as reduções apresentadas pelos taludes compostos pela areia silto argilosa (Solo C) e pelo silte 
argiloso (Solo B), sendo que estes últimos foram os que apresentaram as reduções mais lentas do Fator de Segurança.

7) Quanto menor a diferença entre a pressão de entrada de ar e a condição inicial de sucção, mais rapidamente ocorre a ascensão do nível freático, pois menor é a quantidade de água necessária para a saturação do solo.

8) O desenvolvimento dos perfis de pressão de água tem reflexo direto sobre a estabilidade do talude de referência, onde a taxa de redução do fator de segurança está diretamente ligada às velocidades de avanço da frente de umedecimento e de ascensão do nível freático.

9) A superfície crítica (mínimo FS) do talude de referência, nos casos em que a ruptura se dá pelo avanço da frente de umedecimento, inicia-se profunda no talude, torna-se mais rasa com o decorrer da precipitação e novamente aprofunda-se até que ocorra a ruptura. Esta evolução pode estar sendo condicionada pelos parâmetros de resistência adotados, pela geometria do talude e pelo avanço da frente de umedecimento, não constituindo efeito unicamente deste último fator.

10) As análises de estabilidade do talude sujeito a diversas precipitações permitem constatar que taludes em solos com maior condutividade hidráulica saturada, como o solo A (areia), apresentam maiores taxas de infiltração e consequentemente maiores taxas de redução do Fator de Segurança que as apresentadas por taludes compostos por solos com baixas condutividade hidráulica, como o solo B (Silte Argiloso).

Embora este estudo seja altamente idealizado, algumas aplicações práticas podem ser vislumbradas, como por exemplo a utilização de impermeabilizações superficiais para a manutenção da sucção e de sua contribuição para a estabilidade de taludes em solo não saturado, e a definição do "gatilho" de instabilização a partir da relação pressão de entrada de ar e sucção de campo.

Recomenda-se, finalmente, utilizar o presente trabalho apenas como referência para futuros estudos de infiltração e análise de estabilidade em taludes em solo não saturado, pois as simplificações adotadas podem representar situações extremas e idealizadas distantes das reais condições encontradas em campo. 
ANEXOS 
ANEXO A : ROTINA SIMPLIFICADA DE UTILIZAÇÃO DO PROGRAMA SEEP/W (DEFINE E SOLVE) 


\section{Rotina Simplificada para Utilização do Programa SEEP/W}

ATENÇÃO: sempre salve o arquivo de trabalho após terminar cada passo (File > Save)

1- inicie o programa SEEP/W (DEFINE)

2- ajuste o tamanho do papel ( et $>>$ Page)

3- ajuste a escala do desenho ( set $>>$ Scale)

4- desenhe esquemas do problema a ser analisado (sketch)

5- ajuste o tipo de análise de fluxo (transiente ou estabilizado) (keyIn>>Analysis Control)

\section{Analise de Fluxo estabilizado}

6- Entre com a função condutividade hidráulica (keyIn $>>$ Functions $>>$ Conductivity)

Obs: Para fluxo estabilizado não é necessária a entrada de Curva de Retenção

7- Defina os materiais analisados (keyIn>>Material Properties)

8- Desenhe a malha de elementos finitos (pontos: keyIn>>Nodes; elementos: keyIn>>elements) ou (pontos: draw >>Nodes; elementos: keyIn>>Single Elements ou Multiple Elements)

9- Defina as condições de contorno: (Draw >>Boundary conditions)

- Condição de carga $(\mathrm{H})$

- Seção de fluxo (q)

10- Execute a verificação de erros do SEEP/W (Tools>>Verify/Sort Data)

11- Corrija possíveis erros existentes

12- Processe os cálculos (Tools $>>S O L V E)$

13- Visualize os resultados (Tools $>>$ Contour) 


\section{Analise de Fluxo transiente}

5' - Entre com a curva de retenção (keyIn>>Functions >>Vol. Water Content)

6' - Entre com os intervalos de tempo de análise (keyIn>>Time Increments)

7' - Repita os procedimentos 5 a 12 da Analise de fluxo estabilizado

Obs: Para fluxo transiente, há opção para condições de contorno variáveis com o tempo. (keyIn >>Function>>Boundary Conditions) 
ANEXO B : PARÂMETROS DE CONVERGÊNCIA UTILIZADOS NO PROGRAMA SEEP/W (GEO-SLOPE) 


\begin{tabular}{|c|c|c|c|c|c|}
\hline 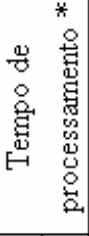 & 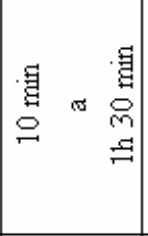 & 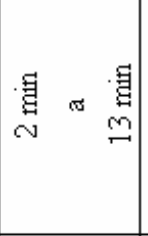 & 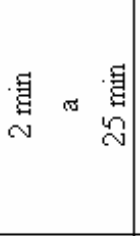 & 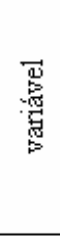 & 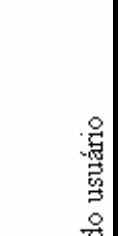 \\
\hline 荵 & 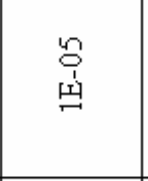 & 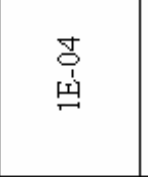 & 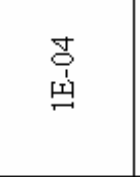 & 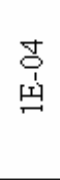 & 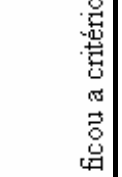 \\
\hline 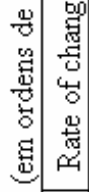 & $\stackrel{\infty}{\stackrel{\circ}{\rightleftharpoons}}$ & $\Rightarrow$ & $\Rightarrow$ & 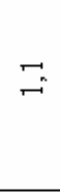 & 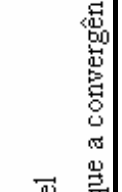 \\
\hline 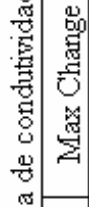 & ? & na. & n. & $\stackrel{n}{0}$ & 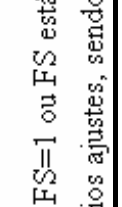 \\
\hline 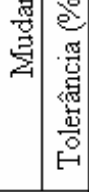 & $\stackrel{\mathrm{g}}{\circ}$ & $\stackrel{\overrightarrow{0}}{\circ}$ & $\vec{\circ}$ & $\overrightarrow{0}$ & 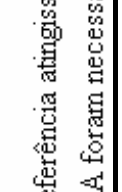 \\
\hline 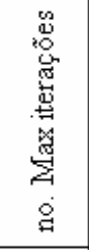 & 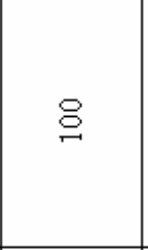 & 怘 & 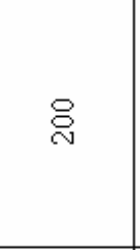 & $\stackrel{8}{\stackrel{8}{\circ}}$ & 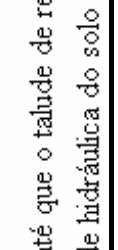 \\
\hline 总莺 & $\Rightarrow$ & Ф & 0 & 唃 & 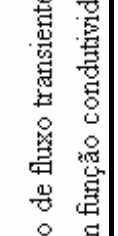 \\
\hline 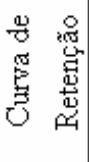 & $\Delta$ & Ф & 0 & 夢 & 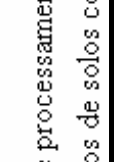 \\
\hline $\begin{array}{l}\stackrel{8}{\circ} \\
\stackrel{2}{2}\end{array}$ & 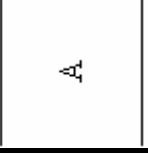 & $\varphi$ & $v$ & 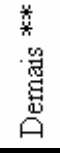 & 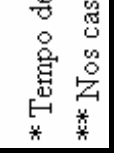 \\
\hline
\end{tabular}




\section{6 - REFERÊNCIAS BIBLIOGRÁFICAS}

ABRAMENTO, M. \& CARVALHO, C. S. (1989). Geotechnical parameters for the study of natural slopes instabilization at "Serra do Mar", Brazil. Proceedings of 12th International Conference on Soil mechanics and Foundation Engineering. Rio de Janeiro. Vol. 3: 1599 - 1602.

ABRAMENTO, M. (1988). Resistência ao cisalhamento de solos não saturados: Considerações teóricas e estudo experimental sobre solo coluvionar das encostas da serra do mar, Dissertação de Mestrado, Escola Politécnica da USP, 1988.

ALONSO, E., GENS, A., LLORET, A. \& DELAHAYE, C. (1995). Effect of rain infiltration on the stability of slopes. Proceedings of 1st International Conference on Unsaturated Soils, Paris. Vol. 1: 241 - 249

BISHOP, A. W., ALPAN, G. E. \& DONALD, B. I. (1960). Factors controlling the shear strength of partly saturated cohesive soils. In: research Conference on Shear strength of cohesive soils, Boulder, 1960. Proceedings. American Society of Civil Engineers, 1960. P: $503-532$.

BISHOP, A.W. (1955). The use of the slip circle in the stability analysis of slopes. Géotechnique, v.5, n.1, p.7-17.

BRUCH, P. G. (1993). A laboratory study of evaporative fluxes in homogeneous and layered soils. MSc Thesis, Deparment of Civil Engineering, University of Saskatchewan, Saskatoon, Canada. 
4CALLE, J. A. C. (2000). Análise de ruptura de talude em solo não saturado. Dissertação de mestrado. EESC-USP.

CAMPOS,L E. P. (1985). Influência da sucção na estabilidade de taludes naturais em solos residuais. 3o. Simpósio Regional de Mecânica dos Solos e Engenharia de Fundações. Vol. 1: 31 - 49.

CHO, S. E. \& LEE, S. R. (2001). Instability of unsaturated soil slopes due to infiltraton. Computers and Geotechnics, Vol 28 : 185 - 208.

DELAGE, P., SURAJ DE SILVA, G. P. R. \& DE LAURE, E. (1987). Un Noveal appareil triaxial pour les sols nonsaturés. Proceedings of $9^{\text {th }}$ European conference on Soil Mechanics and Foundation Engenieering. Dublin, 1987, Rotterdam, A. A. Balkema. Pp 25-28. apud RÖHM (1997).

DONALD, L. B. (1956). Shear Strength Measurements in Unsaturated NonCohesive soils with negative pore-pressure. Proceedings of $2^{\text {nd }}$ Australia- New Zealand Conference on Soil Mechanics and Foundation Engineering, pp.200-204. apud FREDLUND (1995).

ESCARIO, V. \& JUCA, J. F. T. (1989). Strength and deformation of partly saturated soils. Proceedings of 12th International Conference on Soil Mechanics and Foundation Engineering, Rio de Janeiro, Vol. 1: 43 - 46

ESCARIO, V. \& SAEZ, J. (1986). The shear strength of partly saturated soils. Géotechnique, Vol 36 (3): 453 - 456

ESCARIO, V. (1988). Formulaciones para la definición de la resistencia a esfuerzo cortante de los suelos parcialmente saturados. Ingieniera Civil Vol 68, CEDEX.

FREDLUND, D. G. \& MORGENSTERN, N. R. (1977). Stress state variables for unsaturated soils. Journal of Geotechnical engineering Division, American Society of Civil Engineers, Vol. 103 (GT5): 447 - 466.

FREDLUND, D. G. \& RAHARDJO, H. (1993). Soil Mechanics for unsaturated soils. New York, John Wiley \& Sons, Inc. 1993. 
FREDLUND, D. G. \& XING, A. (1994). Equations for the soil water characteristic curve. Canadian Geotechnical Journal, Vol. 31 (4) : 533-546

FREDLUND, D. G. (1995). Prediction of Unsaturated Soil functions using the Soil-water Characteristic Curve. Bengt B. Broms Symposium in Geotechnical Engineering, Singapore.

FREDLUND, D. G., RAHARDJO, H. \& GAN, J. K. M. (1987). Non-linearity of strength envelope for unsaturated soils. Proc. of International Conference on Expansive Soils. New Dehli, 1987.

FREDLUND, D. G.; MORGENSTERN, N. R. \& WIDGER, R. A. (1978). The Shear Strengh of Unsaturated Soils. Canadian Geotechnical Journal, Vol.15(3):313321.

GASMO, J. M., RAHARDJO, H. \& LEONG, E. C. (2000). Infiltration effects on stability of a residual soil slope. Computers and Geotechnics, Vol. 26: 145 - 165.

GEO-SLOPE INTENATIONAL LTD.(1998a). Seep/W for finite element seepage analysis (v.4). Users manual. Calgary, Alberta, Canada.

GEO-SLOPE INTENATIONAL LTD.(1998b). Slope/W for slope stability analysis (v.4). Users manual. Calgary, Alberta, Canada.

GEO-SLOPE INTENATIONAL LTD.(2003a). Infiltration into a Soil With a Deep Water Table. Disponível em<http://www.geo-slope.com/support/articles.asp> .Acesso em: 30 nov. 2003.

GEO-SLOPE INTENATIONAL LTD.(2003b). SEEP/W 5.0 User's Guide. Disponível em<http://www.geo-slope.com/support/webhelp> .Acesso em: 30 nov. 2003.

HILLEL, D. (1971). Soil water - Physical principles and processes. New York, Academic Press, 1971. Cap. 1-5. apud RÖHM (1997). 
HO, P. G. (1979). The Predicition of Hydraulic Conductivity from Soil Moisture Suction Relationship . BSc. Thesis, University of Saskatchewan, Saskatoon, Canada.

IPT (1991). Manual de Geotecnia: taludes de rodovia: orientação para diagnóstico e soluções de seus problemas. Instituto de Pesquisas Tecnológicas, São Paulo.

JENNINGS, J. E. B\& BURLAND, J. B. (1962). Limitations to the use of effective stresses in partly saturated soils. Géotechnique, London, 12(23):125 - 144.

JUCA, J. F. T. (1990). Comportamento de los suelos parcialmente saturados bajo succión controlada. Madrid, 1990, 346p, Doctorado, Universidad Politecnica de Madrid de España. apud CALLE (2000).

KAWAI, T. \& TOI, Y. (1977). A New element in discrete analysis of plane strrain problem. Journal of "Seisan Keyku"Inst. Of Ind. Sci., Univ. of Tokyo, no 29 Vol. 4, pp 204-207. apud SHIMADA (1995)

KHRAN, J., FREDLUND, D. G. \& KLASSEN, M. J. (1989). Effect of soil suction on slope stability at Notch Hill. Canadian Geotechnical Journal, v.26, p.269278.

LEONG, E. C. \& RAHARDJO, H. (1997a). Review of soil-water characteristic curve equations. Journal of Geotechnical and Geoenvironmental Engineering, Vol. 123 (2): $1106-1117$

LEONG, E.C. \& RAHARDJO, H. (1997b). Permeability functions for unsaturated soils. Journal of Geotechnical and Geoenvironmental Engineering.Vol.123: 1118-1126.

LIM T. T., RAHARDJO H., CHANG, M. F. \& FREDLUND, D. G. (1996). Effect of rainfall on matric suctions in a residual soil slope. Canadian Geotechnical Journal. Vol. 22: 618 - 628. 
LUMB, P. (1975). Slope Failures in Hong Kong. Quarterly Journal of Engineering Geology. Vol 8: 31-65.

MACHADO, S. L. (1998) Aplicação de conceitos de elastoplasticidade a solos não saturados. Dissertação de Doutorado. Escola de Engenharia de São Carlos Universidade de São Paulo. 361p.

McKEE, C.R.\& BUMB, A.C. (1987) apud LEONG, E. C. \& RAHARDJO, H. (1997a).

MERIGGI, R. , DI MARCO, C. , PAVONI, R. (2002). A parametric analysis of colluvial slope stability during heavy rainfalls. Proceedings of 3th International Conference on Unsaturated Soils, Recife. Vol. 2: 741 - 747.

MILLER, R. J. \& LOW, P.F. (1963). Threshold gradient for water flow in clay system. Proceeding of Soil Science Society of America, Madison, Vol 27 : 605 609.

MIYAZAKI, T. (1993). Water Flow in soils.New York, Marcell Dekker Inc., 1993.

NG, C. W. W. \& PANG, Y. W. (2000). Influence of Stress State on soil- water characteristics and slope stability. Journal of Geotechnical and Geoenvironmental Engineering. Vol. 126(2): 157 - 166.

NG, C. W. W. \& SHI, Q, (1998). A numerical investigation of the stability of unsaturated soil slopes subjected to transient seepage. Computers and Geotechnics, Vol. 22: $1-28$.

REICHARDT, K. (1985). Processos de Transferência no sistema solo-plantaatmosfera. Fund. Cargill, Campinas. 466p.

RICHARDS, B.G. (1974). Behaviour of unsaturated soils. In: LEE, I. K., ed. Soil Mechanic. New York, American Elsevier Publishing Company Inc., cap.4. 
RIGHETTO, A M. (1998) Hidrologia e Recursos Hídricos. São Carlos, EDUSP, Escola de Engenharia de São Carlos, USP.

RÖHM, S. A. (1992). Resistência ao cisalhamento de um solo arenoso laterizado não saturado da região de São Carlos. Tese de Doutoramento, Escola de Engenharia de São Carlos - Universidade de São Paulo.

RÖHM, S. A. (1997). Solos não Saturados. Monografia Geotécnica No 4, Escola de Engenharia de São Carlos - Universidade de São Paulo.

SHIMADA, K. , FUJII, H. , NISHIMURA, S. \& MORII, T. (1995). Stability analysis of unsaturated slopes considering changes of matric suction. Proceedings of 1st International Conference on Unsaturated Soils, Paris. Vol. 1: 293 - 299

SMITH, P. G. C. , ADDENBROOKE, T. I. \& POTTS, D. M. (2002). Coupled finite analysis of infiltration into unsaturated soils. Proceedings of 3th International Conference on Unsaturated Soils, Recife. Vol. 1: 3 - 7

TEIXEIRA, R. S. (1996). Resistência ao cisalhamento de um solo arenoso compactado não saturado. Dissertação de Mestrado, Escola de Engenharia de São Carlos - Universidade de São Paulo.

VANAPALLI S. K. (1994). Simple Test Procedures and their Interpretation in evaluating the Shear Strength of Unsaturated Soils. Ph. D. thesis, Dept. of Civil Eng. , University of Saskatchewan, Saskatoon, Canada, 350p. apud FREDLUND (1995).

VANAPALLI, S. K., FREDLUND, D. G. \& PUFAHL, D. E. (1999). The influence of soil structure and stress history on the soil-water characteristics of a compacted till. Géotechnique, Vol. 49 (2): 143-159

VANAPALli, S. K., FREDLUND, D. G., PUFAHL, D. E. \& CLIFTON, A. W. (1996). Model for the prediction of shear strength with respect to soil suction. Canadian Geotechnical Journal. 33(3): 379-392..

van GENUCHTEN, M. T (1980). A closed-form equation for predicting the hydraulic conductivity of unsaturated soils. Soil Science Society of America Journal, Vol. 44, pp:892-898 
VILAR, O. M. (2001). Introdução a mecânica dos solos não-saturados. Notas de aula. Escola de Engenharia de São Carlos - Universidade de São Paulo.

WOLLE, C. M. \& HACHICH, W. (1989). Rain-Induced landslides in southeastern Brazil. Proceedings of 12th International Conference on Soils Mechanics and Foundation Engineering. Rio de Janeiro. Vol.3: 1639-1642

WOOD, D. M. (1979). The behaviour of partly saturated soils: A review, CUED/D -Soils/TR 691979. 